Portland State University

PDXScholar

\title{
An Indoor Environmental Quality Assessment: the Study of Naturally Ventilated University Classrooms within a Mixed-Mode Ventilated Building
}

Kyhetica M. Lattin

Portland State University

Follow this and additional works at: https://pdxscholar.library.pdx.edu/honorstheses Let us know how access to this document benefits you.

\section{Recommended Citation}

Lattin, Kyhetica M., "An Indoor Environmental Quality Assessment: the Study of Naturally Ventilated University Classrooms within a Mixed-Mode Ventilated Building" (2018). University Honors Theses. Paper 583.

https://doi.org/10.15760/honors.592

This Thesis is brought to you for free and open access. It has been accepted for inclusion in University Honors Theses by an authorized administrator of PDXScholar. Please contact us if we can make this document more accessible: pdxscholar@pdx.edu. 


\title{
AN INDOOR ENVIRONMENTAL QUALITY ASSESMENT: The Study of Naturally Ventilated University Classrooms Within a Mixed-Mode Ventilated Building
}

\author{
by \\ Kyhetica Lattin \\ An undergraduate honors thesis submitted in partial fulfillment of the requirements for the \\ degree of \\ Bachelor of Science \\ in \\ University Honors \\ and \\ Architecture
}

Thesis Advisor

Corey Griffin

Portland State University 


\section{TABLE OF CONTENTS}

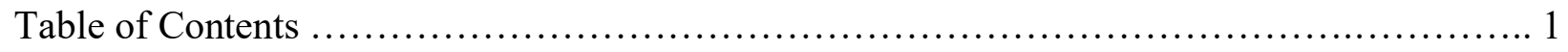

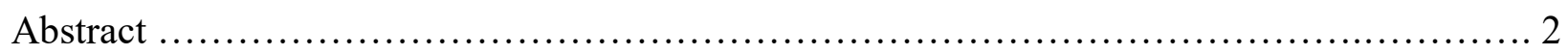

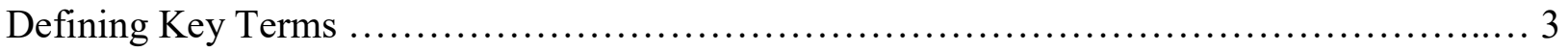

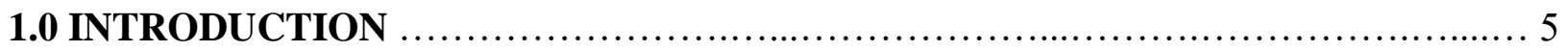

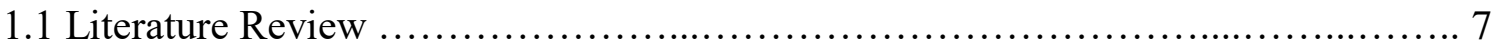

1.2. The KMC Building Design and Systems................................. 11

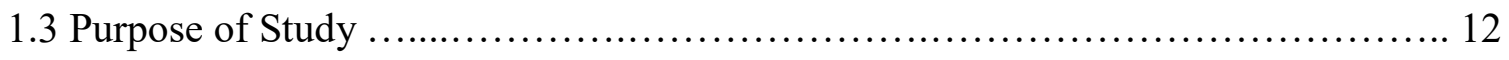

2.0 RESEARCH DESIGN AND METHODS ..................................... 14

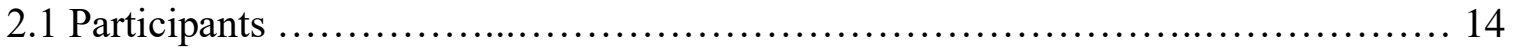

2.2 Materials ................................................................ 14

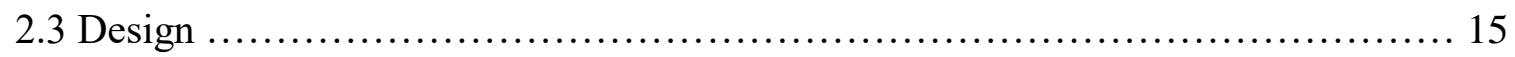

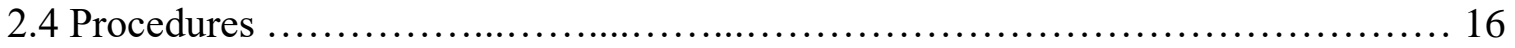

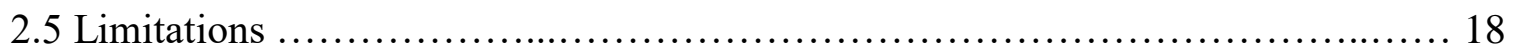

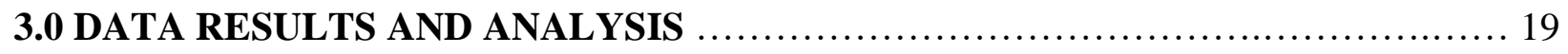

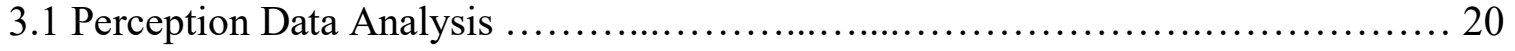

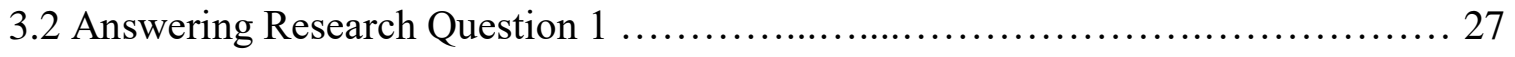

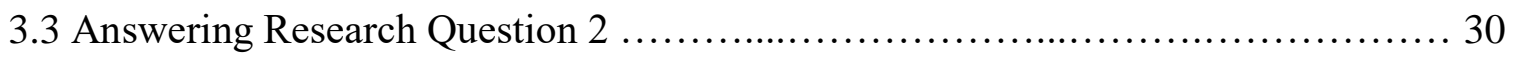

3.4 Answering the Hypothesis ............................................ 31

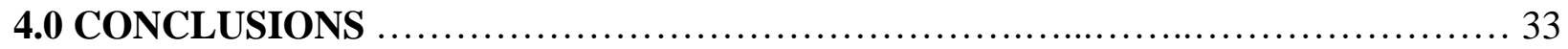

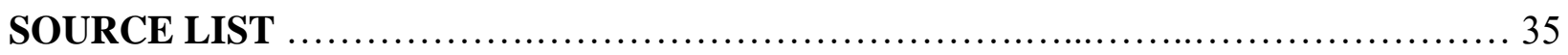

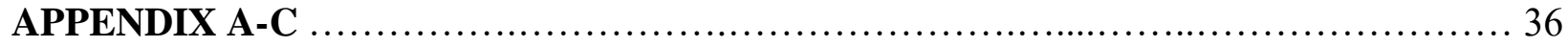




\title{
AN INDOOR ENVIRONMENTAL QUALITY ASSESMENT: The Study of Naturally Ventilated University Classrooms Within a Mixed-Mode Ventilated Building
}

\begin{abstract}
Housing classrooms and office space for a school of business, the recently renovated and expanded the Karl Miller Center at Portland State University utilizes mixed-mode ventilation, a combination of natural and mechanical ventilation. The mixed-mode ventilation system present within the Karl Miller center is classified as a zoned system, where mechanical and natural ventilation are working in some parts of the building individually and in combination in other parts. In the newly constructed north wing, an HVAC system has been omitted and natural ventilation system employed through the use of: operable windows, ceiling fans, interior below-sill heaters, and exhaust vents. The purpose of this study is to examine and evaluate the ability of the classrooms within this zone to provide thermal comfort. Data for this indoor environmental quality (IEQ) study includes post occupancy surveys and interior air temperature, humidity, and $\mathrm{CO}_{2}$ data collected between October and December of 2017.
\end{abstract}

Keywords: Indoor environmental quality, Comfort, Passive design, Mixed-mode ventilation, Natural nentilation, Passive cooling, Post-occupancy survey, Higher education, Portland State University, Karl Miller Center 


\section{DEFINING KEY TERMS}

Climate Data: hourly, site-specific values of representative meteorological data, such as temperature, wind speed, solar rotation, and relative humidity. ${ }^{1}$

Clo: a unit used to express the thermal insulation provided by garments and clothing ensembles, where $1 \mathrm{clo}=0.155 \mathrm{~m}^{2} \cdot{ }^{\circ} \mathrm{C} / \mathrm{W}\left(0.88 \mathrm{ft}^{2} \cdot \mathrm{h} \cdot{ }^{\circ} \mathrm{F} / \mathrm{Btu}\right) .{ }^{1}$

Descriptions for associated clo levels used in perception surveys were created using the Center for the Built Environment's Thermal Comfort Tool: shorts and short sleeves shirt (0.36 clo), pants/long skirt and short sleeve shirt $(0.57 \mathrm{clo})$, pants/long skirt and long sleeve shirt $(0.61 \mathrm{clo})$, pants and long-sleeve sweatshirt (0.74 clo), pants and long sleeve shirt and jacket (0.96 clo), typical indoor winter clothing $(1.0$ clo). 2

Comfort Condition: environmental condition in a space such that the majority of the occupants should, on a statistical basis, be comfortable. ${ }^{3}$

Comfort Zone: those combinations of air temperature, mean radiant temperature, and humidity that are predicted to be an acceptable thermal environment at particular values of air speed, metabolic rate, and clothing insulation. ${ }^{1}$

Cross Ventilation: (1) natural ventilation in which the airflow mainly results from wind pressure effects on the building facades and where stack effects in the building are of less importance. (2) type of ventilating with air supply and exhaust points at opposite sides of ventilated space. ${ }^{2}$

Environment, acceptable thermal: a thermal environment that a substantial majority (more than $80 \%$ ) of the occupants find thermally acceptable. ${ }^{1}$

HVAC (Heating, Ventilation, and Air Conditioning) System: the equipment, distribution systems, and terminals that provide, either collectively or individually, the processes of heating, ventilating, or air conditioning to a building or portion of a building. ${ }^{2}$

Metabolic Rate (met): the rate of transformation of chemical energy into heat and mechanical work by metabolic activities of an individual, per unit of skin surface area (expressed in units of met) equal to $58.2 \mathrm{~W} / \mathrm{m}^{2}\left(18.4 \mathrm{Btu} / \mathrm{h} \cdot \mathrm{ft}^{2}\right)$, which is the energy produced per unit skin surface area of an average person seated at rest. ${ }^{1}$

Mechanical Ventilation: (1) the active process of supplying or removing air to or from an indoor space by powered equipment such as motor-driven fans and blowers but not by devices such as wind-driven turbine ventilators and mechanically operated windows. (2) ventilation provided by mechanically powered equipment, such as motor-driven fans and blowers, but not by devices such as wind-driven turbine ventilators and mechanically operated windows. ${ }^{2}$

\footnotetext{
${ }^{1}$ See ASHRAE, Thermal Environmental Conditions for Human Occupancy (2013) pg. 3-4.

2 See drop down menu titled, Clothing Level (clo), in Hoyt, Tyler et al.'s, CBE's Thermal Comfort Tool, (2017).

${ }^{3}$ See ASHRAE, TERMINOLOGY.
} 
Mixed-Mode Ventilation: a combination of natural ventilation from operable windows (either manually or automatically controlled), and mechanical systems that include air distribution equipment and refrigeration equipment for cooling. ${ }^{1}$

Natural Ventilation: movement of air into and out of a space primarily through intentionally provided openings (such as windows and doors), through non-powered ventilators, or by infiltration. $^{2}$

Perception Based Comfort Data: the attitudes, understanding, and feelings of an occupant associated with the five senses, used to expressed one's level of comfort.

Performance Based Comfort Data: collecting, analyzing, and reviewing data through the use of technology, to identify gaps in how a system, building, or technology works to establish areas of improvement

Stack Effect: (1) movement of air into and out of buildings, chimneys, flue gas stacks, or other containers and is driven by buoyancy. Buoyancy occurs due to a difference in indoor to outdoor air density resulting from temperature and moisture differences. The result is either a positive or negative buoyancy force. The greater the thermal difference and the height of the structure, the greater the buoyancy force, and thus the stack effect. The stack effect is also referred to as the chimney effect, and it helps drive natural ventilation and infiltration. (2) movement of air or other gas in a vertical enclosure (e.g., duct, chimney, building), induced by the density difference between the air or other gas in the enclosure and the ambient atmosphere. Note: stack effect is a significant concern in heating-system design for tall buildings in cold climates. Sometimes referred to as chimney effect. (3) pressure difference caused by the difference in density between indoor and outdoor air due to an indoor/outdoor temperature difference. (4) the vertical airflow within buildings caused by temperature differences between the building's interior and exterior. ${ }^{4}$

Thermal Comfort: that condition of mind which expresses satisfaction with the thermal environment and is assessed by subjective evaluation. ${ }^{3}$

Thermal Sensation: a conscious subjective expression of an occupant's thermal perception of the environment, commonly expressed using the categories "cold", "cool", "slightly cool", "neutral", "slightly warm", "warm", and "hot". 5

Ventilation: (1) the process of supplying air to or removing air from a space for the purpose of controlling air contaminant levels, humidity, or temperature within the space. (2) the process of supplying or removing air by natural or mechanical means to or from any space. Such air is not required to have been conditioned. ${ }^{4}$

\footnotetext{
${ }^{1}$ See the section titled, Introduction, in Brager, Gail and Baker, Lindsay's, "Occupant satisfaction in mixed-mode buildings," (2008).

${ }^{2}$ See ASHRAE, TERMINOLOGY.

${ }^{3}$ See ASHRAE, Thermal Environmental Conditions for Human Occupancy (2013) pg. 3-4
} 


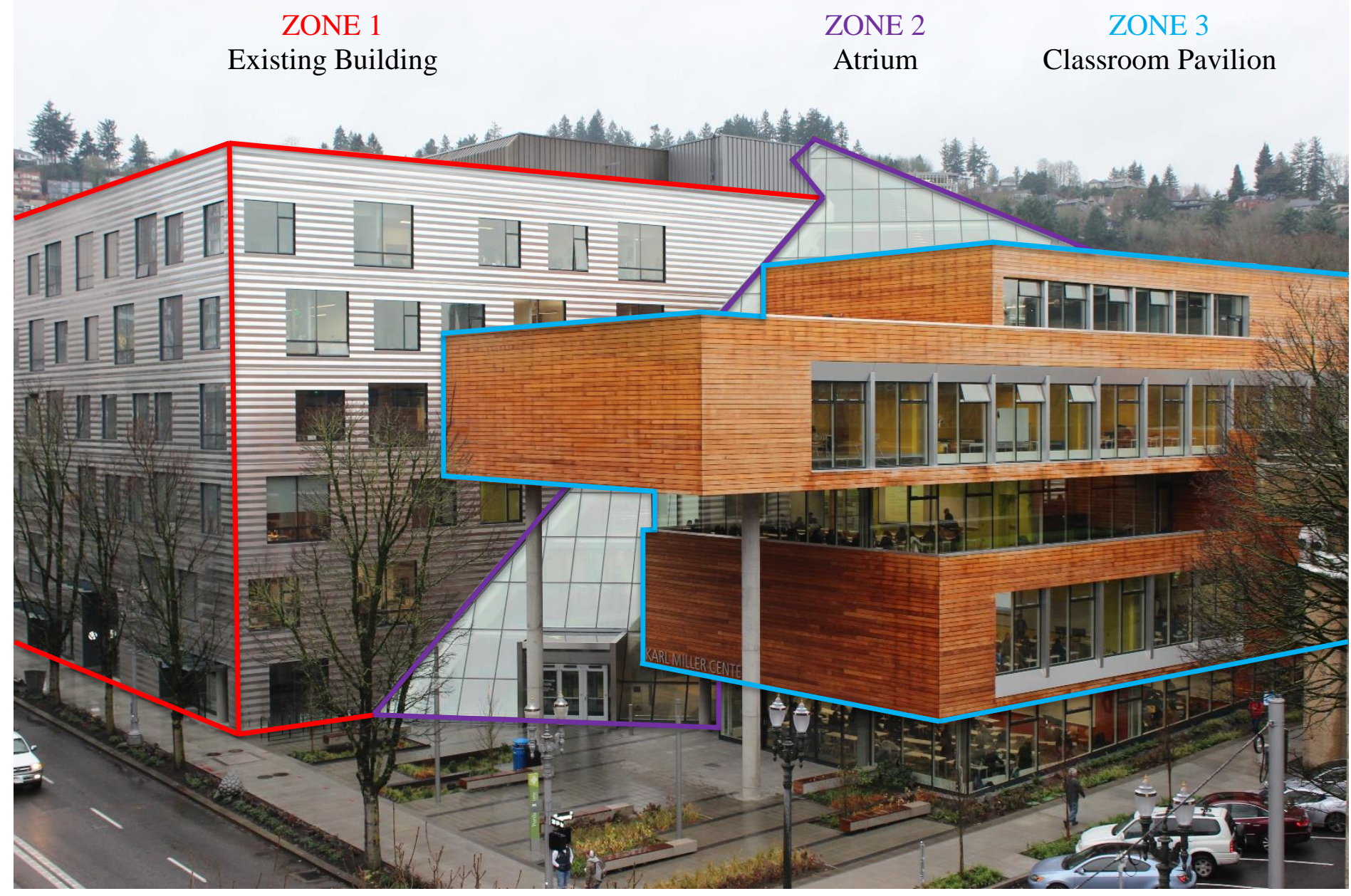

FIGURE 1. Image illustrations the three wings that make up the Karl Miller Center building.

\section{INTRODUCTION}

This paper examines the indoor environmental quality (IEQ) of the recently opened Karl Miller Center (KMC) building at Portland State University. The KMC includes the renovation of an existing Portland State University (PSU) campus building along with the addition of an atrium and new classroom wing to the north of the existing building (see FIGURE 1). The project was a collaboration between PSU, Behnisch Architekten, SRG Partnership, Skanska, and the mechanical engineering firm Transsolar. The KMC's atrium and new classroom pavilion are the location of the biggest sustainability design moves within the building. Standard HVAC system have been omitted from the northern wing of the building, replaced by automated natural ventilation systems to cool and provide fresh air. 
Mixed-mode ventilation (MMV) utilizes the climate, orientation, and location of a building to optimize the use of heat naturally given off by the sun, decrease necessary cooling loads, and harnesses natural air movement through a space. This reduces the need for and energy consumption of conventional HVAC systems. MMV is, "a combination of natural ventilation (NV) from operable windows (either manually or automatically controlled), and mechanical systems that provide air distribution and some form of cooling." ${ }^{1}$ The whole of the Karl Miller Center acts as a zoned mixed-mode building because the southern renovated half, utilizes the existing HVAC system whereas the newly constructed north wing utilizes operable windows and vents, ceiling fans, perimeter heaters, and the stack effect to ventilate and cool spaces.

As buildings account for more than $40 \%$ of all energy consumed within the U.S. ${ }^{2}$, it's $^{\prime}$ crucial that all building typologies make strides towards lowering energy demand. Although, HVAC systems are the standard method used to cool, heat, and pull clean fresh air into buildings in the U.S., other systems that have the ability of being more efficient in areas of energy usage, thermal comfort for occupants, and indoor environmental quality. Methods of improving the efficiency of one of the least efficient systems of the buildings, "cooling and mechanical ventilation account for over $30 \%$ of total energy use, approximately $20 \%$ of electricity use, and approximately $40 \%$ of peak demand," 3 can be seen through the, "simulations using EnergyPlus [which] demonstrated that energy savings associated with various forms of mixed-mode operation ranged from $13 \%$ (medium-sized office building with a $\mathrm{VAV}^{4}$ system in Miami) to $29 \%$ (small office building with a $\mathrm{CAV}^{5}$ system in Atlanta) to $79 \%$ (similar building in Los Angeles)." 6 As these statistics have been derived from simulations, they lack the perceptions of occupant comfort. Thus, a combination of perception (qualitative) and performance-based (quantitative) comfort data found in this paper aims to explore the advantages and disadvantages of the natural ventilation zone with a mixed-mode system provides.

\footnotetext{
1 See the section titled, Introduction, in Brager, Gail and Baker, Lindsay's, "Occupant satisfaction in mixed-mode buildings," (2008).

${ }^{2}$ See U.S. Energy Information Administration (2017)

${ }^{3}$ See the section titled "1.2 Justification" in Brager, Gail et al. "Summary Report: Control Strategies for MixedMode Buildings" (2007).

${ }^{4}$ The EPA defines VAV (Variable Air Volume) System by, "variation in the thermal requirements of a space are satisfied by varying the volume of air that is delivered to the space at a constant temperature." (2017).

${ }^{5}$ The EPA defines CAV (Constant Air Volume) Systems by, "variations in the thermal requirements of a space are satisfied by varying the temperature of a constant volume of air delivered to the space." (2017).

${ }^{6}$ See the section titled,1.4 Benefits of Mixed-Mode, in Brager Gail et al, "Summary Report: Control Strategies for Mixed-Mode Buildings," (2007).
} 


\subsection{LITERATURE REVIEW}

Due to the complex nature of $\mathrm{KMC}$, this paper reviews multiple topics with respect to ventilation, cooling and occupant comfort, including: mixed-mode ventilation, natural ventilation, HVAC systems, human thermal comfort, and research focused on combining performance and perception-based data. While the KMC as a whole is an example of a zoned MMV system, the new classroom pavilion (north wing), the focus of the research documented in this paper, is solely a naturally ventilated system equipped with operable windows and fans. The body of literature on these topics is extensive in: definitions, detailed methods of design, and only recently consists of research on the performance of combined natural and mechanical ventilation..

The reason the literature is relatively new, and this type of ventilation technique is not more widespread in the U.S., is likely due to several factors. First, because of the standard and integrated practice of HVAC systems especially of the scale of buildings currently being built in our larger cities. There are not enough examples of MMV buildings that can meet U.S. fire codes, therefore the incentive to employ and explore these design techniques has not caught on whilst HVAC systems continue to be successful. Due to these fire code standards it is hard to employ certain natural and MMV methods in the U.S., whereas in other countries such Europe, New Zealand, and Australia they have the ability to utilize and explore mixed-mode systems on a greater scale. Consequently, in the U.S. we see a lack of MMV dominated buildings, and instead more HVAC dominated buildings with the ability to supplement with natural ventilation, yet not depend on it. Another factor is due to the issue that both MMV and natural ventilation, "may not be suitable for all situations, perhaps least so far climates with very high humidity, or sites with excessive levels of outside noise or pollution," ${ }^{1}$ whereas HVAC systems are nearly universal.

Most of the existing literature on mixed-mode ventilation is directed towards the ownerbuilders and those interested in finding sustainable ways to retrofit a building in certain climate and areas free of air pollutants. An abundance of information on MMV can be found online, with a focus on differentiating types of MMV, identifying where they work best, and providing advantages and disadvantages. Online you can look at articles regarding MMV and natural ventilation from sites such as Whole Building Design Guide's "Natural Ventilation" (2016) or Better Buildings Partnership "Natural Ventilation and Mixed Mode Systems" (2015).

\footnotetext{
${ }^{1}$ See the section titled, What is a Mixed-Mode Building?, in Brager Gail's, "Mixed-Mode Cooling" (2006).
} 
The literature related to mixed-mode ventilation also acts to provide standards for design and construction of spaces that prove a certain level of indoor environmental quality (IEQ) and occupant comfort like ANSI/ASHRAE's Standard 55-2013 “Thermal Environmental Conditions for Human occupancy" (2013). These standards provide definitions to important related terminology and clearly differentiate how the parts of MMV work together in standards of HVAC and natural ventilation design. However, this standard does not actually reference or relate to mixed-mode ventilation but instead natural ventilation, therefore it acts as a guideline that alongside HVAC standards, MMV can try end up somewhere in between. The literature presents the possibility of MMV design to those looking for sustainable and efficient ways of conditioning buildings. The academic literature is geared towards design, engineering, and construction professionals by providing standards, definitions, and design guidelines to demonstrate the efficiency of MMV and natural ventilation.

Strong arguments in favor of mixed-mode ventilation are found in scholarly journals over the use of just natural ventilation or just conventional HVAC systems. One example of an online database of MMV literature, is The University of Berkeley's "Center for the Built Environment" (2013). This database of papers and studies, contextualizes mixed-mode ventilation alongside related indoor environmental quality (IEQ) characteristics. The CBR also, provides sources for more information on MMV the related topics, and provides tools for testing IEQ.

The CBE is a culmination of research done by the students and professors at the University of California Berkeley who are interested in understanding and exploring the possibilities of building systems. In the research published through the CBE, there is a plethora of information related to MMV. Several articles address how the advantages outweigh the disadvantages of MMVs. Although MMV has the potential to be less user friendly than the conventional HVAC systems, potentially resulting in higher energy consumptions and costs, there is a greater chance the system will achieve the following:

1. reduce energy consumption, have higher associated occupant satisfaction because of improved thermal comfort, health and productivity; ${ }^{1}$

2. "fewer sick building syndrome symptoms"; ${ }^{2}$ and

3. create "highly 'tuneable' buildings". 1

\footnotetext{
${ }^{1}$ See the section titled, Benefits of Mixed-Mode?, in Brager, Gail et al. "Summary Report: Control Strategies for Mixed-Mode Buildings." (October 2007).

${ }^{2}$ See Brager, Gail's, "Mixed-Mode Cooling," (2006).
} 
Although, the benefits may outweigh the disadvantages, the research presents reasons why there are so few MMV buildings in the US including: the convenience and conventionality of HVAC systems, the lack of knowledge and case studies regarding MMVs successes, a lack of knowledge regarding automatic and manual controls that are necessary for MMV which in turn affects the confidence that a building will meet energy codes, and finally fire and safety codes in the U.S. that inhibit our exploration of this type of design. ${ }^{2}$ Their research clearly differentiates three typologies of MMV that can be used in a building to optimize occupant comfort based on design factors, the KMC falling into the zoned-system, where different spaces are being conditioned differently at the same time of day. ${ }^{3}$

As stated above, to successfully contextualize this research not only is it necessary to review the literature on mixed-mode ventilation but also on the elements that make up that system, that's where a review of literature on natural ventilation becomes crucial.. One example of case-study based research, is David Ogoli's paper titled "Thermal Comfort in a NaturallyVentilated Educational Building" which provides two separate case studies in separate locations, further identifying the advantages of natural ventilation.

Ogoli reviews the adaptive model and why operable systems are suited for the occupant's comfort and not the ease of the system, He states:

"The adaptive model allows people to make adjustments to their clothing, activity, posture, eating and drinking, shifting position in a room, operating a window or shading device, or other adaptive opportunities in order to achieve or maintain thermal comfort. It appears that when people are allowed greater adjustment and control over their own indoor environment, it extends the comfort zone. The adaptive model acknowledges the occupant is not just a passive recipient of the environment but an active member." 4

This extension of the comfort zone known as the adaptive model is further explained as, "recent ASHRAE-sponsored research conducted by co-author Dr. Gail Brager demonstrated that occupants of naturally ventilated buildings are comfortable over a much wider range of temperatures compared to occupants of air-conditioned building, primary because the higher

\footnotetext{
${ }^{1}$ See the section titled, Potential Benefits, in Brager, Gail et al. "Mixed-Mode Ventilation: HVAC meets Mother Nature." (2000).

${ }^{2}$ See the section titled, Barriers to the Approach, in Brager, Gail et al. "Mixed-Mode Ventilation: Hvac meets Mother Nature." (2000).

${ }^{3}$ See the section titled, What is Mixed-Mode?, in Brager, Gail et al. "Summary Report: Control Strategies for Mixed-Mode Buildings." (2007).

${ }^{4}$ See Ogoli, David. "Thermal Comfort in a Naturally-Ventilated Educational Building." page 21, section 1.3. "Adaptive 'errors' in thermal comfort."
} 
degree of personal control shifts their expectations and preferences." ${ }^{1}$ The importance of occupant perception of thermal and overall comfort within the buildings, provides more justification for other avenues of cooling and ventilation buildings, and away from the heavy use of inefficient HVAC systems employed today. This idea is further developed again by Gail Brager, and with the help of and Lindsey Baker, as they contextualize the importance of occupant comfort:

"Without question, it is absolutely crucial to reduce energy consumption in buildings, and help avoid the potentially devastating impacts of climate change. But in terms of the building owners' pocketbook, energy costs are still relatively small compared to worker salaries, which represent over $90 \%$ of the total operating costs of a commercial building. In addition, the cost of worker recruitment and retention is significant. From the building or company owner's point of view, perhaps the most persuasive argument for sustainable design in general --- and operable windows in particular --- is one that makes the connection between a higher quality indoor environment, and increased comfort, health and productivity of the workers. If we can demonstrate that occupant satisfaction is higher in buildings with operable windows, a powerful part argument builds in support of avoiding or minimizing the use of air-conditioning." 2

Further exploration in the possibilities, successes, and failures of natural and mixed-mode ventilation is in the collection of twenty-one case studies on mixed-mode buildings the University of California, Berkeley's Center for the Built Environment's report titled "Summary Report: Control Strategies for Mixed-Mode Buildings" (October 2017). This helps to compare, and contrast issues seen across the board in mixed-mode buildings to help improve and identify the best practices, such as a lack of knowledge regarding both the automatic and manual controls necessary for successful MMV design. This helps create an easier avenue for future designers and developers to employ MMV systems as is done in this report.

Another related topic within the literature, is using simulations to compare and contrast either natural ventilation and MMV, the effects of various facade designs on thermal data, and those manual and automatic controls discussed above, to identify the effects and relationships to improved occupant thermal comfort. In the academic literature there are numerous examples of reports and research using these types of simulations: Wright and Levermor's "Natural

\footnotetext{
${ }^{1}$ See Brager, Gail et al.'s, "Mixed-Mode Ventilation: HVAC meets mother nature," (2000).

${ }^{2}$ See the section titled, introduction, in Brager, Gail and Baker, Lindsay's, "Occupant satisfaction in mixed-mode buildings." (2008).
} 
Ventilation or Mixed Mode? An investigation using Simulation", Hu and Karava's "Model predictive control strategies for buildings with mixed-mode cooling" (2013), Spindler and Norford's "Naturally ventilated and mixed-mode buildings --- Part I: Thermal modeling" (2008). Each one of these studies pushes beyond the definitions and literature reviews that other academic literature, to provide simulated data in defense of MMVs.

\subsection{THE KMC BUILDING DESIGN AND SYSTEMS}

The three separate but integrated parts that make up the Karl Miller Center (KMC) building qualify as mixed-mode ventilation design, because of the criteria discussed above. The KMC building's mixed-mode system can be categorized as a zoned-system. This categorization holds through three entities that make up the whole, each differentiated in the strategy of which they condition their spaces. ${ }^{1}$

First, the existing and renovated southern wing of the building, identifiable by its paneled metal enclosure system, utilizes a combination of natural ventilation with the use of operable windows, and it is equipped with an existing but updated HVAC system. The second zone within the $\mathrm{KMC}$, is the central atrium which has an array of functions: central circulation, gathering and study space, and acts as a full building height lightwell, is the bridge between both the existing building and the new classroom pavilion. The atrium links the north and south classroom wings cooling and ventilation systems together at the highest point, through an exhaust vent drop down from the ceiling. Air that is pulled through the northern classrooms vents into the atrium through a variation of natural ventilation known as the stack effect. The third zone is the new north classroom wing is what makes the KMC building break away from the conventional standard of HVAC dependency in buildings, by being supplemented with a natural ventilation system. Where other buildings on Portland State University's campus utilize natural ventilation but depend on HVAC systems, the KMC provides the opportunity to study at least one set of classrooms with only natural ventilation.

The stack effect process previously mentioned, is the driving mechanism behind the larger ventilation process occurring concurrently in the new classroom pavilion and the atrium. For the purpose of this study a combination of definitions explain the stack effect, "stack effect

\footnotetext{
${ }^{1}$ See the section titled, What is Mixed-Mode?, in Brager Gail's, "Mixed-Mode Cooling," (2006).
} 
takes place in buildings due to buoyancy of heated air moving upward" ${ }^{1}$ and "the vertical airflow within buildings caused by temperature differences between the building's interior and exterior." 2 The stack effect occurs in the KMC as fresh cool air from outside enters into the classrooms from exterior windows, to cool occupants in the classrooms. This process is augmented by operable ceiling fans located within each classroom. The warm, less dense, more buoyant air is vented and recycled up and out of the exhaust vents located near the interior walls of the classrooms into the atrium. This exhausted air moves up through the atrium to the final set of vents. This processed air is vented out of the atrium, meets up with the air from the southern wing of the building, and is finally vented out the building through the roof.

\subsection{PURPOSE OF STUDY}

To summarize, mixed-mode ventilation is used within KMC through a use of small operable ceiling fans found within each classroom (see FIGURE 4), operable windows (see FIGURE 2 and FIGURE 3), soffit and duct work that pulls air in from the classroom and pulls it out into the atrium (see FIGURE 5), an open floor plan outside of the classrooms, the exposed concrete floor works as a thermal battery, operable ground floor east facing glass walls, dampeners and vents over east entrance, vented and radiantly heated concrete stairs on ground floor of atrium, and finally a mechanical system in the older building is connected to the atrium of the new addition which acts to pull air up and out of the building. The passive ventilation system present in the new classroom wing, and the implications of low energy cooling and ventilation design for higher education buildings is the focus of this research project. Efficient buildings need equally efficient building systems and occupant thermal comfort, because when one is neglected, it affects the overall energy efficiency of the building. When a building solely focuses on occupant comfort with little regard to system efficiency and sustainability, you have a design that contributes to excessive energy consumption. In the case of a systems focused building with not the same thought given to occupancy comfort, it leads to occupants taking control of their own comfort which in turn could be even less efficient than a conventional HVAC building system.

\footnotetext{
${ }^{1}$ See the section titled, Introduction, in Jung-yeon, Yu et al.'s, "Resolving Stack Effect Problems in a High-Rise Office Building by Mechanical Pressurization," (2017).

${ }^{2}$ See ASHRAE, TERMINOLOGY.
} 


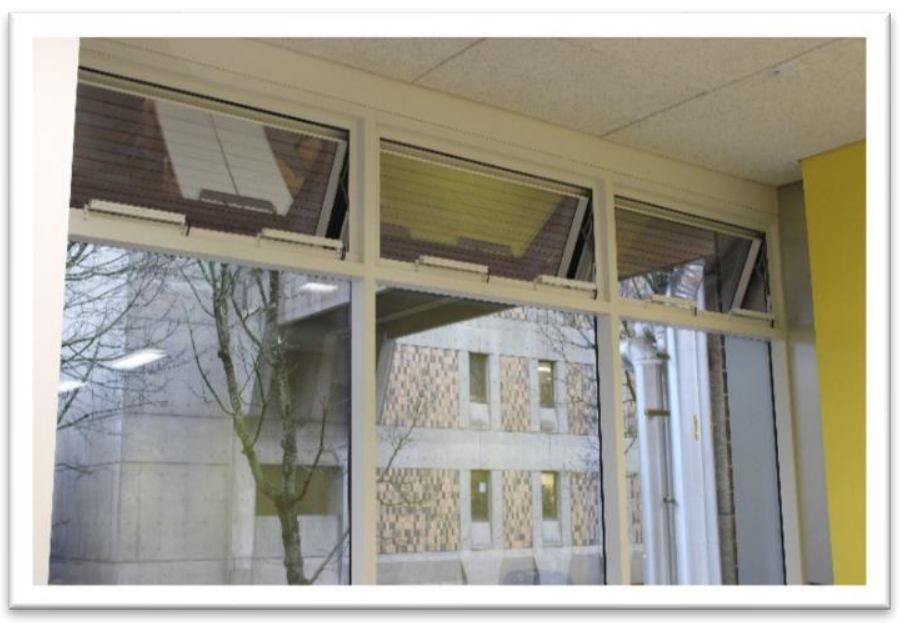

FIGURE 2. Interior view of opened operable windows

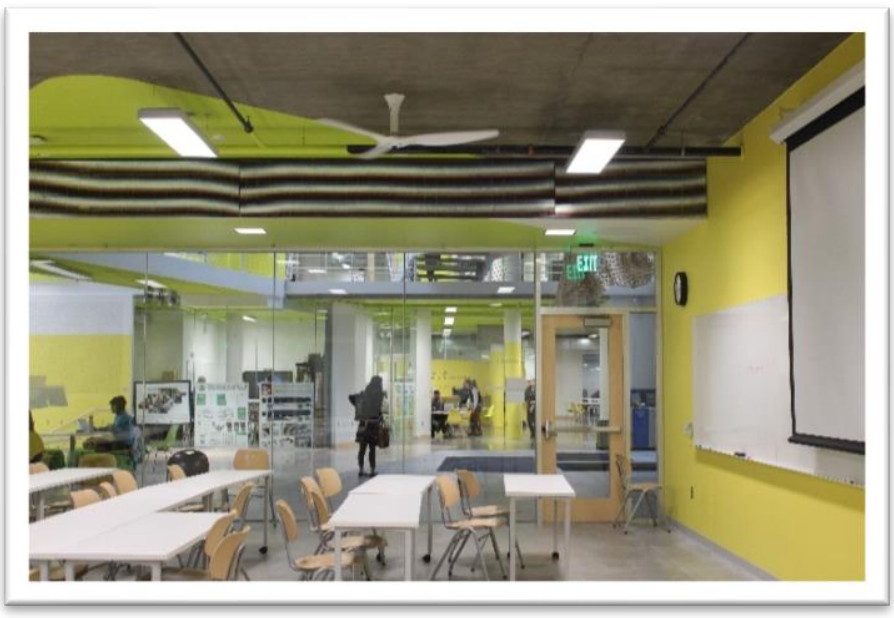

FIGURE 4. Interior view of classroom exhaust vents

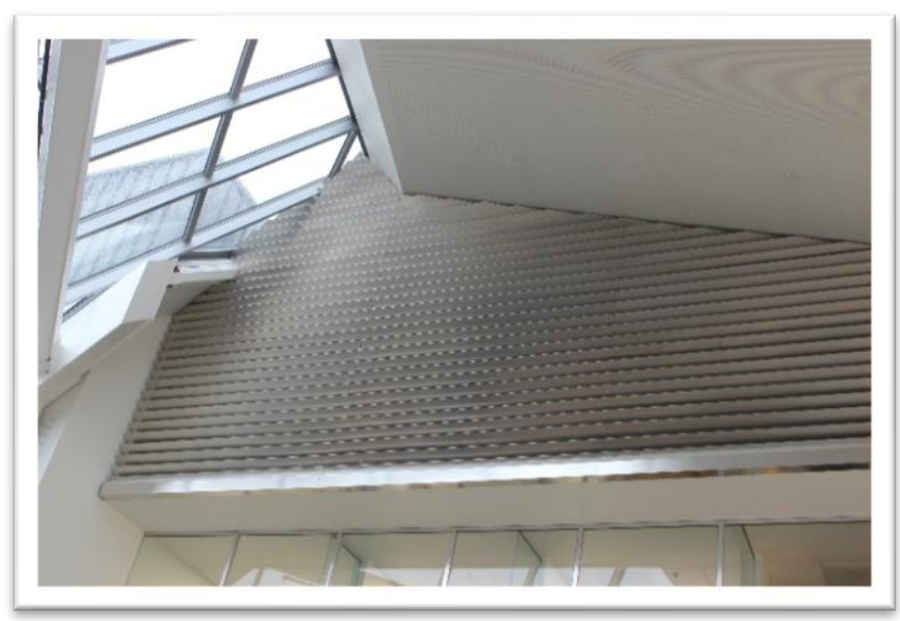

FIGURE 6. Interior view of atrium exhaust vents

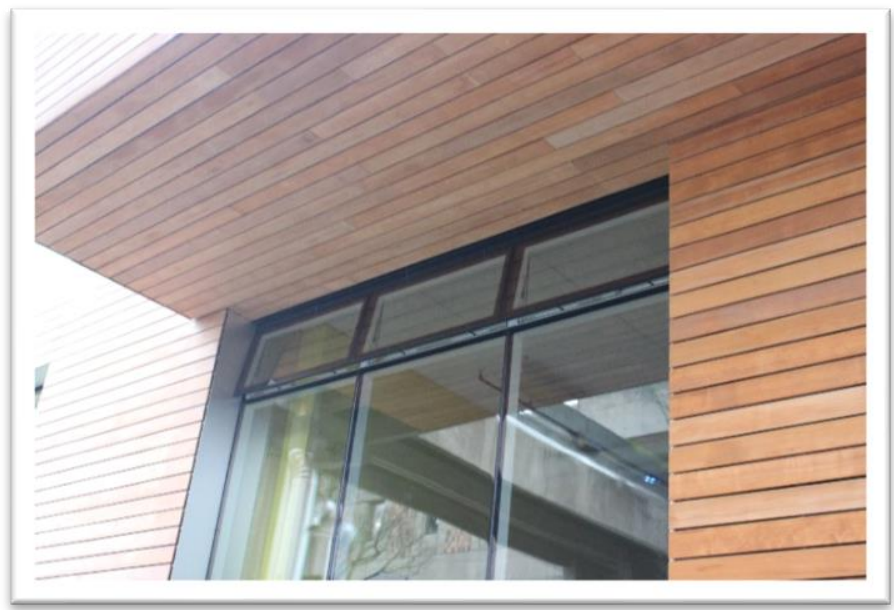

FIGURE 3. Exterior view of opened operable windows

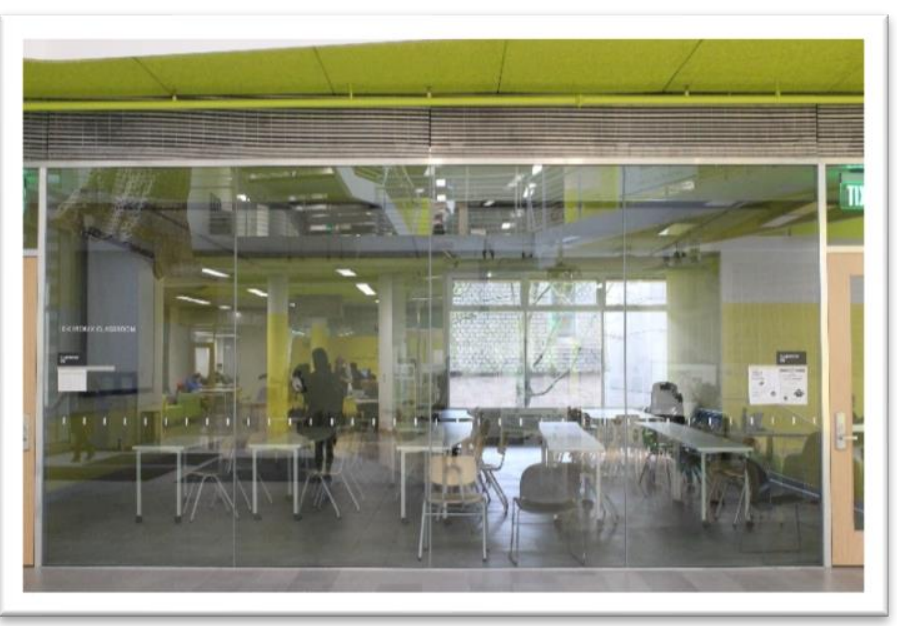

FIGURE 5. View from atrium of classroom exhaust

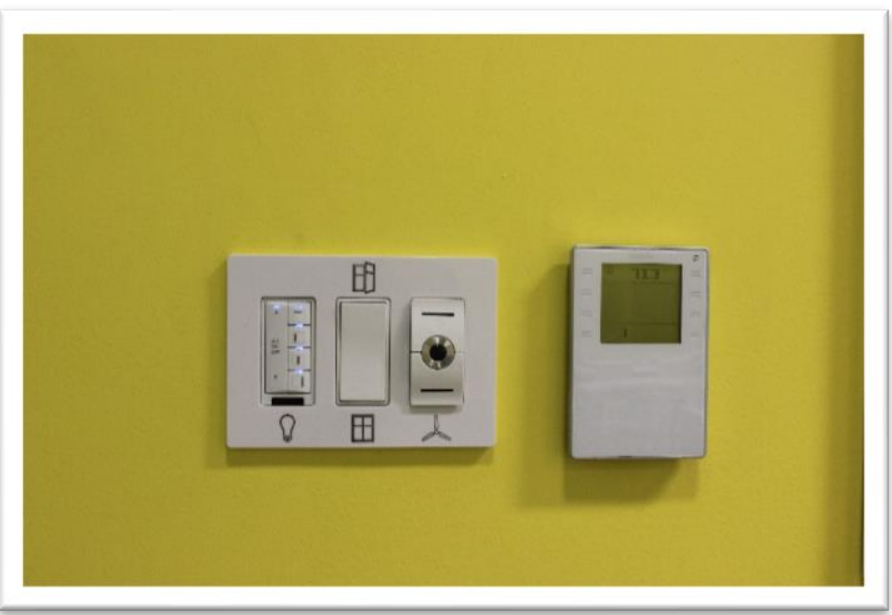

FIGURE 7. Classroom occupant controls 
This led to a need for the two types of data collected and evaluated for this case study: the perception of comfort by the actual occupants and the performance-based data that may explain why these occupants are feeling a certain way. This combination of two different types of data helps to more accurately answer whether or not a higher education building in a climate like Portland, Oregon can successfully create a series of comfortable spaces through passive natural ventilation that is proven not just through simulations or data but also is matched by real life perception comfort data.

Research Question 1: How effective is the Karl Miller Center's new classroom pavilion's natural ventilation dominated system in creating thermally comfortable spaces to occupy?

Research Question 2: What type of picture does a combination of perception and performancebased comfort data portray, and is that enough to identify if the Karl Miller Center's addition is successful in creating comfortable spaces to occupy?

Hypothesis 1: Participant responses will generally correlate a perception of thermal comfort in the areas above neutral (i.e. slightly warm, warm, and hot).

a) Both the performance and perception above the thermal comfort range will increase on average in correlation with the higher floors within the building.

b) Both the performance and perception above the thermal comfort range will increase on average in correlation with classes held in the early afternoon, when the sun is at its highest point, and in the evenings, when the heat trapped inside the concrete is released.

c) Both the performance and perception above the thermal comfort range will decrease in classrooms with multiple elevations of glazing. The thinking behind this hypothesis is due to: these classrooms having less concrete available to hold heat, a high glass ratio correlating with increased thermal bridging for the outside air, and because although there is more opportunity for direct sunlight and therefore heat through radiation, the classrooms with multiple elevations of glazing are set back allowing the floor above to act as it's sunshade. 


\subsection{RESEARCH DESIGN AND METHODS}

\subsection{PARTICIPANTS}

An initial participant email list was created by using the master class list for the KMC during the Fall 2017 academic term, and then isolating the classes that would be held in the new classroom wing. From there, classes were sorted by time, cardinal location, floor, and number of walls with windows to help create a hierarchy of classroom variation in relation to participating professor response. This helped to identifying which classrooms

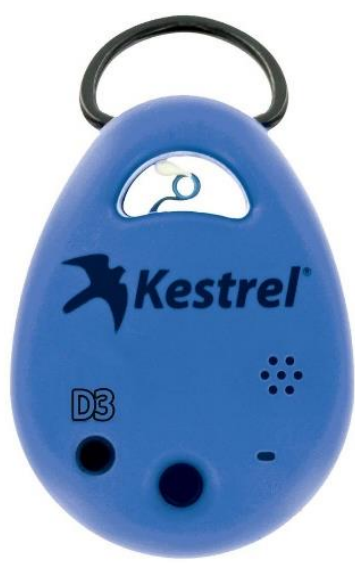

FIGURE 8. added more variation to the overall data, and therefore were chosen above another classroom in instances of willingness to participate from multiple professors of classes held at the same time. In total, 863 surveys across eight classrooms were collected, although due to a building system flush the first week of the term, only 741 responses are used for analysis in this paper. The surveys were distributed across four out of the five floors within the KMC new classroom pavilion: six were held from 5:30/5:40 pm to 9:00/9:30 pm, one was held at 10:15-11:15 am, and finally one held from $12: 00 \mathrm{pm}$ to $15: 50 \mathrm{pm}$. In the end, the final criteria that helped to identify the pool of participants was the willing professors who responded to the initial recruitment email. Distribution of surveys was completely confidential, and data was only used when consent was given on survey.

\subsection{MATERIALS}

Two primary groups of materials were used in this study: the Kestrel data loggers (see FIGURE 8) that were located within each classroom and the comfort surveys distributed to participants. Forty-four loggers were installed

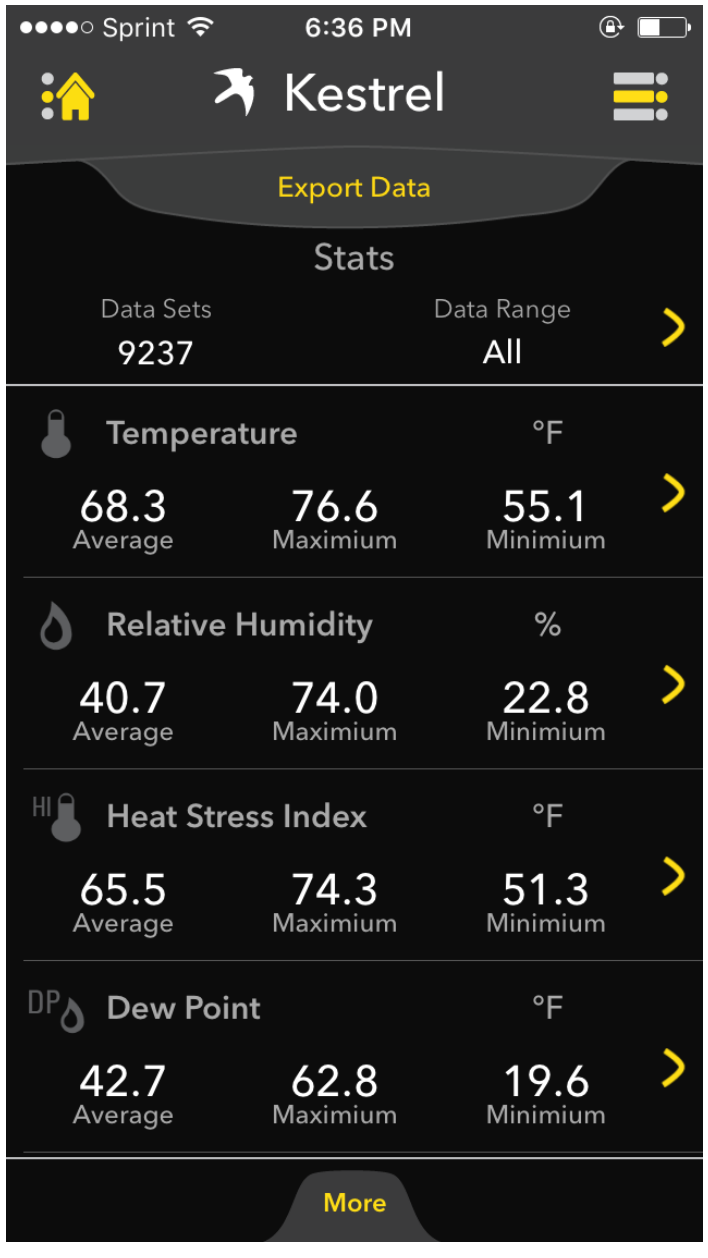

FIGURE 9.

Kestrel Data Logger Interface 
in a total of eleven classrooms, across the five floors in the new classroom pavilion. Although only eight classrooms were surveyed, Kestrel data loggers were installed inside three extra classrooms to obtain at least two sets of performance-based data per floor. Of the four loggers located within each classroom, two were attached to the ceiling using zip ties and carabiners, and the remaining two were located underneath tables using tape, accompanied by a courtesy note asking anyone who came into contact with the loggers to leave them be and explaining in the research they were being used for. Data loggers were suspended from the ceiling, away from fire sprinkler pipes and surfaces that could affect the temperatures logged, as well as proximity to other factors that may have an effect on data (i.e. windows, fans, and occupant's legs underneath the tables). Alongside the Kestrel loggers, an iPhone was used to download the Kestrel App, where the interface (see FIGURE 9) allowed monitoring and collection of air temperature and relative humidity data.

The materials used to collect the perception based data included: a lab notebook used to make notes during survey distribution in terms of window position (open or close), fan operation (on or off), and to keep a record of Kestrel location in correlation with serial number (i.e. floor or ceiling; north or south) to make downloading of data go more smoothly; eight different surveys that correlate to the specific classrooms that were surveyed (see APPENDIX $C$ for example survey); and a master classroom survey distribution list was made for organization, to act as a calendar and record for how many surveys were needed based on $x$ number of students registered for a class obtained through PSU's registration database/

\subsection{DESIGN}

During this research process, the biggest influencers of the methodology were the definition of human comfort and the factors that affect one's perception of thermal comfort. ${ }^{1}$ For the purpose of this research, ASHRAE standard 55-2013's definition of thermal comfort, "that condition of mind which expresses satisfaction with the thermal environment and is assessed by subjective evaluation," was used to define human comfort. The factors that affect human comfort are what the same standard defines as comfort zone, "those combinations of air temperature, mean radiant temperature, and humidity that are predicted to be an acceptable thermal environment at particular values of air speed, metabolic rate, and clothing insulation." 2 Since

\footnotetext{
${ }^{1}$ See ASHRAE, Thermal Environmental Conditions for Human Occupancy (2013) pg. 's 3-4; CBE comfort tool.

${ }^{2}$ See ASHRAE, Thermal Environmental Conditions for Human Occupancy (2013).
} 
this definition of thermal comfort clearly combines quantitative and qualitative data, that changes from person to person based on location, sensation, physiology, and state of mind, it was evident that both performance and perception-based data needed to be collected.

Using these initial definitions, the comfort data aimed to answer thermal insulation levels (clo) and a subjective evaluation of thermal satisfaction within the occupied classrooms, whereas the Kestrel data loggers combined with the data provided by building management, intended to answer the other half: air temperature, $\mathrm{CO}_{2}$ levels, and humidity. Regarding the questions of metabolic rate and air velocity, some assumptions were made: the metabolic rate for the participants of the surveys would be a constant variable of 1.2 met, correlating with slightly above the 1.1 rate associated with typing. ${ }^{1}$ This assumption was partially due to a presumption that there would be more of a desire to participation from professors and their students if the survey was simple, clear and short. Therefore, to keep the surveys short and simple, some questions were removed. However, the questions omitted from this research provide a gap for future versions of research on this building to fill: gender, windows open/closed, fans on/off, preference of new classroom pavilion versus the existing renovated building

The survey questions utilized the ASHRAE 7-point thermal sensation scale/CLO point scale as a reference. Most of the data was taken right before class when some of the participants have just done a bit of "exercise" (i.e. walking to class) and haven't had a chance to really perceive their comfort in the space. This is where having a range of ways the surveys were distributed and collected, such as with rooms 380 and 190 (surveys were distributed by professors midway through the allotted class time), could inform the design of future studies.

\subsection{PROCEDURES}

The performance-based half of the data was collected in two separate ways, to check the validity and margin of error of each. The primary data was collected by installing four Kestrel DROP data loggers in two to three classrooms per floor within the KMC's north classroom wing, totaling to forty-four loggers installed in eleven classrooms. Four Kestrels were located within each chosen classroom. Two were located underneath tables to collect data at the occupant level, and the other two were located directly above at the ceiling height. Again, although surveys were collected from only eight classrooms, Kestrel data loggers were installed inside three extra

\footnotetext{
${ }^{1}$ See drop down menu titled, Metabolic Rate, in Hoyt, Tyler et al.'s, CBE's Thermal Comfort Tool, (2017).
} 
classrooms to obtain at least two sets of performance-based data per floor. These extra Kestrels were located on floors where: only perception-based data was being collected in one classroom, and therefore provided secondary data on that floor; to get data on rooms with more than one wall of glazing; or to obtain data on the fifth floor again in regard to the stack effect, although no perception-based data would be collected in those classrooms.

Once the loggers were installed and batteries were checked, the loggers were only periodically tested for battery life. Downloading of the data did not occur until the loggers were removed from the building at the end of the term, which is why the detailed catalogue of logger number and location (north or south, table or ceiling) was crucial for organization. Although leaving the download until the end of the term presented the possibility of not obtaining data from all the loggers, and therefore an incomplete picture, there simply was not enough time to download the data weekly.

The perception-based data was collected in person during the 2017 fall term, October $2^{\text {nd }}$ through to November $26^{\text {th }}$ (eight total weeks). The process of distribution and collection of the surveys was nearly consistent across the board. It consisted of arriving ten minutes before the start of a participating professor's class and distributing the surveys five minutes prior to the start of class. In most cases, nearly half of the students were already in the class either studying, socializing, or waiting for the class to begin. Then, at five minutes prior to the start of a class, the surveys were distributed based on the classroom number, since each survey's final question was specific to the room itself. Students were asked to pass the completed surveys towards the hallway, where they were picked up as class began.

Three classes however took a different approach in which surveys were dropped off at the beginning of class and distributed during the middle of the class before a break. These surveys were then picked up after the break, at the end of class, or the following week, depending on the professor's preference. Each survey consisted of the previously stated four-question survey: clothing level, comfort level in building, current time occupying one's classroom, and finally one's location within the room itself, followed by space left empty for comments. All survey answers were collected anonymously, and data was only used where consent was given in the survey. 


\subsection{LIMITATIONS}

Although some of the limitations have been mentioned above, this section aims to directly state, list and summarize the limits of this research. The goal is to identify gaps for future research to fill both on the $\mathrm{KMC}$, other natural ventilated building systems, and other mixed-mode ventilation buildings. While methods, tools of survey distribution, and data analysis was discussed with the research advisor, data collection and analysis occurred solely by the author. Therefore, though observations and methods were informed by the research and coursework in relation to the related disciplines, there is a lack of professional experience. One of the more obvious limitations of this study, is the quality and quantity of data that was collected due to various issues including:

1. only one survey distributor,

2. the small number of professors who responded with a willingness to participate,

3. the perception-based data collected mostly in the evening in part due to the limit number of professor participation,

4. both types of data were only collected on the new classroom wing and therefore no comparisons can be made to the existing HVAC system,

5. data was collected right after opening of building and the building systems were still being flushed and tested, and

6. the presumptions made that the ease and simplicity of the survey would correlate to more participation.

This data pool could have also benefited from more variance in the data by placing loggers within the atrium to test air temperature and to locate personally locate carbon dioxide sensors alongside the Kestrels, although this was provided by building management, two sets had carbon levels could help check the validity of the data. Secondly, leaving the downloading of data until the end of the term provided the possibility of not obtaining data from all the loggers, and therefore an incomplete picture. With more than one survey distributor and researcher, there is the possibility that more data could be collected and more often. Thirdly, another limitation and therefore opportunity for a future researcher to improve their own study by developing and being able to employ a more prescribed distribution technique with the possibility of having posters (using spannable codes and links to a digital platform) or an electronic survey could be done, although the electronic version might mean less data. 


\subsection{DATA RESULTS AND ANALYSIS}

Research Question 1: How effective is the Karl Miller Center's new classroom pavilion's natural ventilation dominated system in creating thermally comfortable spaces to occupy?

Research Question 2: What type of picture does a combination of perception and performancebased comfort data portray, and is that enough to identify if the Karl Miller Center's addition is successful in creating comfortable spaces to occupy?

Hypothesis 1: Participant responses will generally correlate a perception of thermal comfort in the areas above neutral (i.e. slightly warm, warm, and hot).

a) Both the performance and perception above the thermal comfort range will increase on average in correlation with the higher floors within the building.

b) Both the performance and perception above the thermal comfort range will increase on average in correlation with classes held in the early afternoon, when the sun is at its highest point, and in the evenings, when the heat trapped inside the concrete is released.

c) Both the performance and perception above the thermal comfort range will decrease in classrooms with multiple elevations of glazing. The thinking behind this hypothesis is due to: these classrooms having less concrete available to hold heat, a high glass ratio correlating with increased thermal bridging for the outside air, and because although there is more opportunity for direct sunlight and therefore heat through radiation, the classrooms with multiple elevations of glazing are set back allowing the floor above to act as it's sunshade.

The main goal of this section of the paper is to summarize the perception-based data by comparing data collected from classrooms 180, 290, 295, 385, and 480 to create a series of graphs to summarize participants clothing level (clo) and their perception of thermal comfort (7point scale; a range from cold-hot) ${ }^{1}$. After that initial analysis of solely perception-based data, this section will act as a comparative analysis of perception-based data alongside performance-

\footnotetext{
${ }^{1}$ See APPENDIX A.
} 
based. The method of assembling the performance-based data consisted of identifying days with outdoor temperature highs or lows and logging the hourly temperature and humidity data, as well as viewing at the indoor $\mathrm{CO}_{2}$ data alongside healthy indoor standards set by the ASHRAE Standard 62.1-2016 (2017); charts for the temperature and $\mathrm{CO}_{2}$ data were also constructed. ${ }^{1}$

For this section, $\mathrm{CO}_{2}$ data is looked at during the second half of the data collected (October $30^{\text {th }}-$ November $22^{\text {nd }}$ ). This time period is used because as days were getting colder, an assumption was made that there would be a decrease in use of the operable windows to cool and ventilate the spaces. Less fresh air being ventilated into the classrooms coupled with a concentration of people, correlated to an increase in $\mathrm{CO}_{2}$ levels. Regarding healthy and comfortable indoor $\mathrm{CO}_{2}$ levels, the ASHRAE Standard 62.1-2016 calculates that, "an activity level at 1.2 met units $\left(1.0 \mathrm{met}=18.4 \mathrm{Btu} / \mathrm{h} \cdot \mathrm{ft}^{2}\right)$, corresponding to a sedentary persons," therefore if the "ventilation rate is to be held to $15 \mathrm{cfm}(7.5 \mathrm{~L} / \mathrm{s})$ per person, the resulting steadystate $\mathrm{CO}_{2}$ concentration relative to that in the outdoor air is equal to 700 ppm." After identifying that outdoor $\mathrm{CO}_{2}$ levels generally range from "300 to 500 ppm," the standard sets an indoor $\mathrm{CO}_{2}$ maximum concentration of 1000 to $1200 \mathrm{ppm}$ to correlate with indoor air that is perceived as breathable fresh air and an atmosphere disassociated with headaches or discomfort. ${ }^{2}$

\subsection{PERCEPTION DATA ANAL YSIS}

This section focuses exclusively on analysis of the surveys distributed in the 2017 fall academic term within eight classrooms, across four days of the week, for eight weeks. The pool of data for examination consists of 37 survey sets consisting of 741 total responses. An initial isolation of the surveys is done to identify trends within the data, which the section that follow, uses other forms of data to further explain the trends and recognize additional trends. TABLE 1 presents a summary of the diversity of the data pool in relation to the classes surveyed, in terms of: classroom number (i.e. floor), times of the classes surveyed, number of walls of glazing, and the overall percentage of data from each classroom out of the total of surveys collected. Using a complete catalog of thermal responses relayed in two different formats (see FIGURE 10 and TABLE 2), some initial conclusions and trends are identified:

\footnotetext{
${ }^{1}$ See, Figures $1-10$, in APPENDIX B.

${ }^{2}$ See the section titled, Informative Appendix D: RATIONALE FOR MINIMUM PHYSIOLOGICAL REQUIREMENTS FOR RESPIRATION AIR BASED ON CO2 CONCENTRATION, in the ASHRAE Standard 62.12016. "Ventilation for Acceptable Indoor Air Quality." ANSI/ASHRAE. 2016, pg. 40.
} 
FIGURE 10.

Floor Plans for the eight classrooms used within study

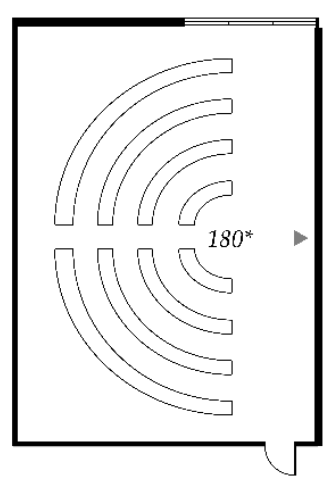

N

$\triangleleft$ points towards front of room (i.e. whiteboard)

"Classroom 180 is the only classroom within this study that has built in seating, shown here within the plans
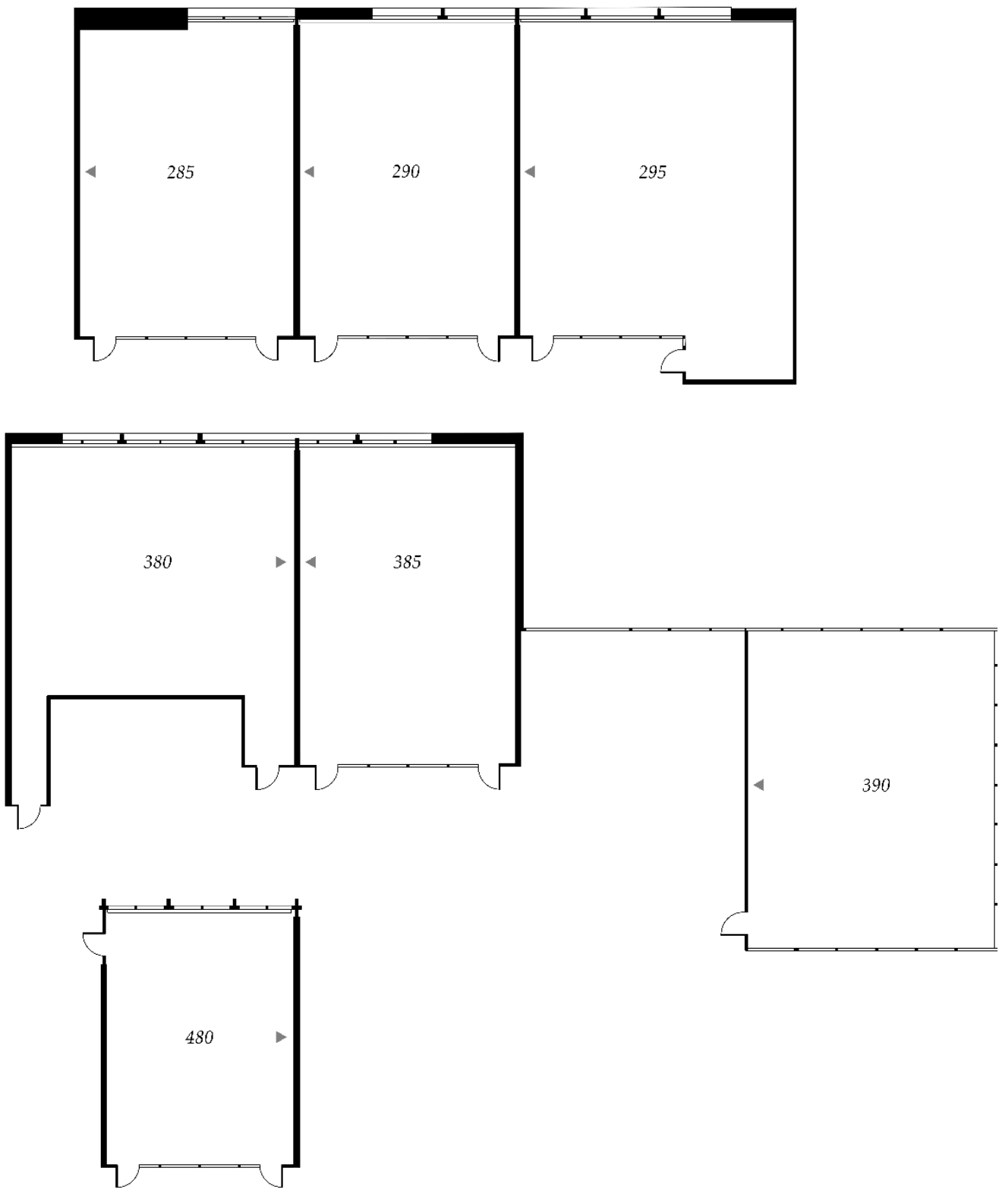
1. A neutral perception of thermal comfort dominates the overall data. Within the survey sets a neutral perception is either the leading response or is equal to slightly warm or slightly cool perceptions within the data, with few exceptions. ${ }^{1}$

2. Another overarching trend in the data that cold and hot are never leading answers, nor is eithers percentage out of the overall data set ever more than $20 \%$

3. For classroom 480, neutral responses are always greater than those above neutral (i.e. slightly warm + warm + hot responses), with at least an $18 \%$ difference.

Classroom 180 has the same relationship between neutral and above natural, with one exception of data collected on October $23^{\text {rd }}$ : Classroom 285 also has a similar relationship between those two response groups within the data, with one exception on October $4^{\text {th }}$.

4. The trend spreading across classrooms 390, 385, 380, 295, and 290, is that these classrooms on average were relatively warm, with (1) at least half of each classroom's set of data either having the responses of slightly warm, warm, and hot combined being greater than the neutral responses, and/or (2) the gap between these above neutral responses (i.e. slightly warm + warm + hot) and neutral, being less than 10 percent difference. ${ }^{2}$

5. Using two sets of classroom comparisons, 385 versus 180 and 295 versus $480^{3}$, two different conclusions are identified within the data regarding stack effect. The comparison between 385 and 180 is in line with hypothesis 1 (a) and concerns regarding a naturally ventilated building, where the classroom held on a higher floor with be warmer on average. Whereas when comparing classrooms 295 and 480, although classroom 480 is on a higher floor, a contradiction of the hypothesis is presented, since room 295 is warmer than 480, although it is located on a lower floor.

6. The trend found within the data from classroom 285 starts after the second survey, where the gap between above natural and neutral gets smaller and smaller, although with the neutral response percentage always dominating.

\footnotetext{
${ }^{1}$ See CHART 2 for exceptions: 385 - 10/2, 285- 10/4, 385 -10/16, 295 - 10/18, and 290 - 11/22.

${ }^{2}$ See the red highlights and red superscript 1 in CHART 2.

${ }^{3}$ See Classroom 285 for similar data as seen with classroom 480, and therefore acts to support the responses presented by classroom 480 . The reason classroom 285 is not used for primary analysis, is because classroom 285 is an example of a professor distributed survey and therefore different methods.
} 
Analysis of the other data sets provided by the surveys, such as: clo levels, location, and comments, provides little correlation related to thermal comfort. Graphics were created, and initial analysis done, but as seen in APPENDIX A for example, little relationship can be found between clo levels and thermal comfort, whereas knowledge of gender in correlation with both perception of thermal comfort and clo level could have been more insightful. When looking at the comments left by participants on the surveys (see TABLE 3), qualities of classrooms are presented: warm, comfortable, and/or unformattable in regard to the quality of the air. However, the issue with the comments is that few were given, and those that were given seem to have been elicited mostly by discomfort, especially by the operable fans. Finally, little relationship between location within the classroom and thermal comfort was found, but instead more relationship between negative comments were found with the proximity to the operable windows and fans. Therefore, the analysis that follows focuses on the trends and insightful data found within the actual perception of thermal comfort responses.

TABLE 1.

Break Down of Overall Classroom Data Pool

\begin{tabular}{|c|c|c|}
\hline $\begin{array}{c}\text { CLASSROOM \# } \\
(\text { TIME })\end{array}$ & $\begin{array}{c}\text { NUMBER OF WALLS OF GLAZING } \\
\text { (ORIENTATION) }\end{array}$ & $\begin{array}{c}\text { \% OF PARTICIPANTS OUT OF } \\
\text { OVERALL SAMPLE SIZE OF 741 } \\
\text { RESPONSES }\end{array}$ \\
\hline $\mathbf{4 8 0}(17: 30-19: 30)$ & Single Wall $(N)$ & $14 \%$ \\
\hline $\mathbf{3 9 0}(17: 40-21: 20)$ & Three Walls $(N, S, E)$ & $19 \%$ \\
\hline $\mathbf{3 8 5}(17: 40-21: 10)$ & Single Wall $(N)$ & $9 \%$ \\
\hline $\mathbf{3 8 0}(12: 00-13: 50)$ & Single Wall $(N)$ & $8 \%$ \\
\hline $\mathbf{2 9 5}(17: 30-21: 20)$ & Half Wall $(N)$ & $8 \%$ \\
\hline $\mathbf{2 9 0}(17: 30-21: 20)$ & Single Wall $(N)$ & $18 \%$ \\
\hline $\mathbf{2 8 5}(10: 15-11: 20)$ & Single Wall $(N)$ & $8 \%$ \\
\hline $\mathbf{1 8 0}(17: 40-21: 10)$ & Single Wall $(N)$ & $16 \%$ \\
\hline
\end{tabular}




\section{FIGURE 11.}

Complete Catalog of all Thermal Comfort Responses on the 7-Point Scale. ${ }^{1}$

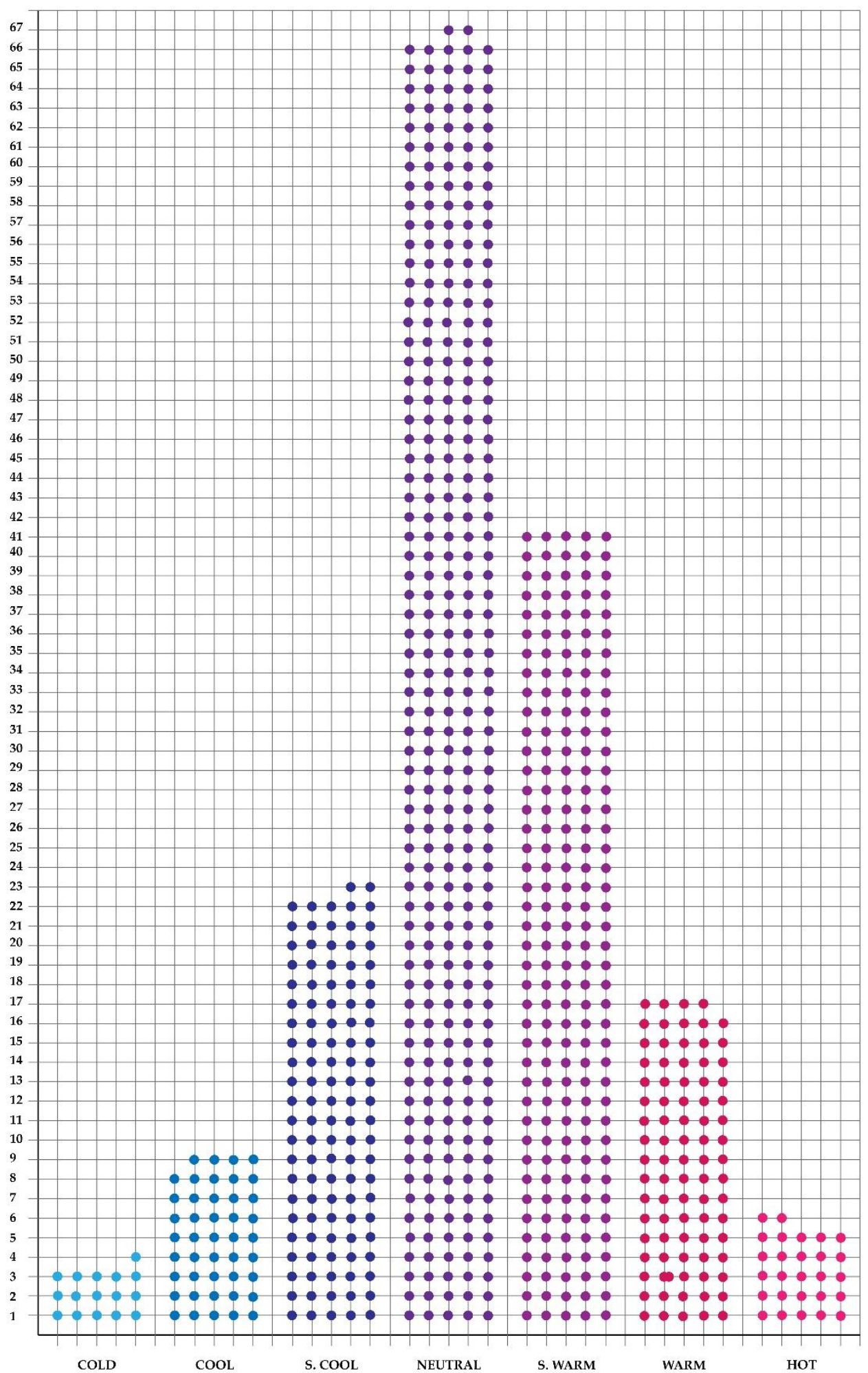

${ }^{1}$ Data beak down: cold - 16, cool - 44, s. cool-112, neutral - 332, s. warm - 205, warm - 84, and hot - 27. 
TABLE 2.

A Catalog of Thermal Comfort Response Pie Charts Based on Classroom Number, Including Related Notes.

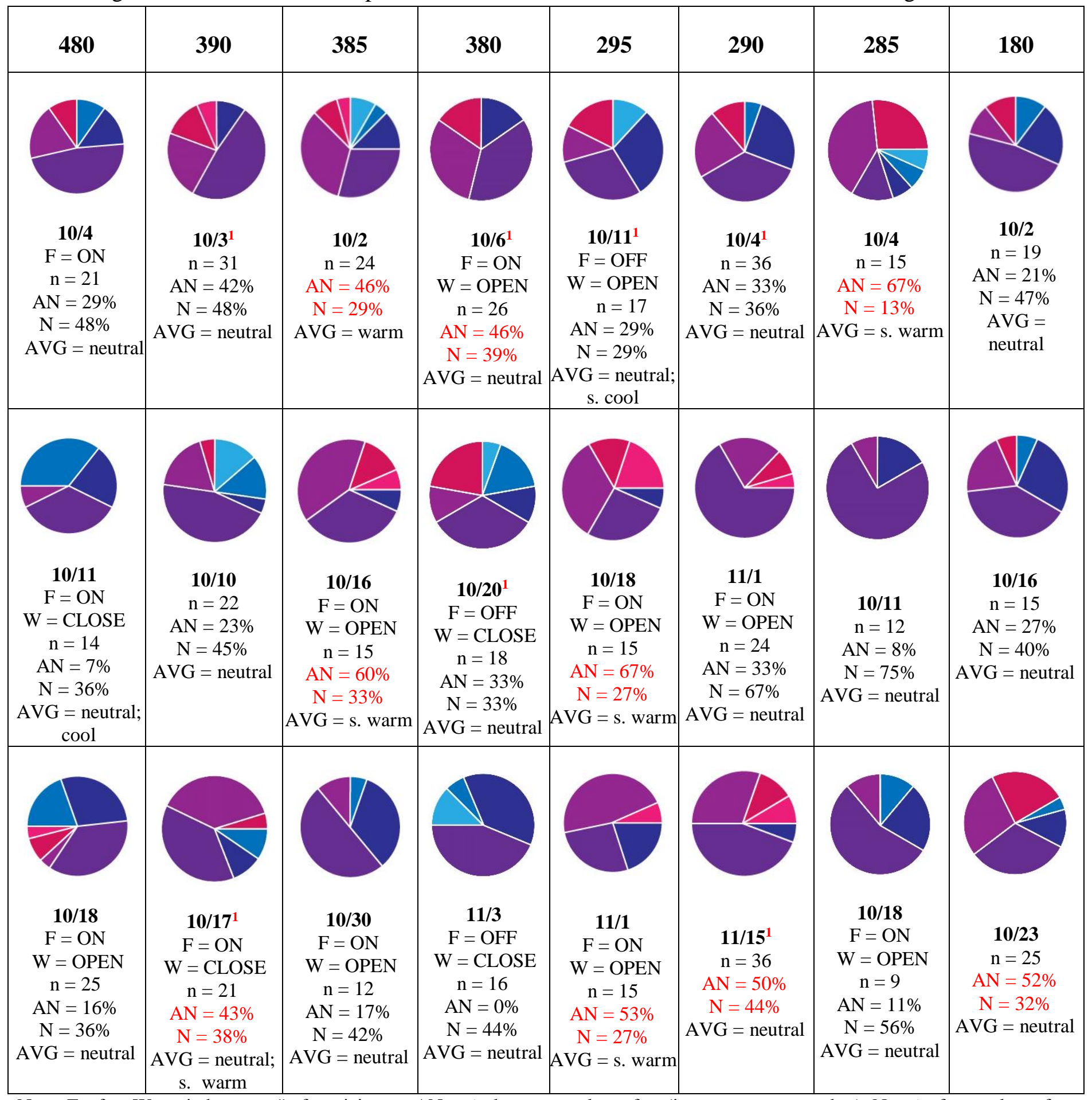

Note: $\mathrm{F}$ - fan, $\mathrm{W}-$ window, $\mathrm{n}$ - \# of participants, $\mathrm{AN}-\%$ above neutral comfort (i.e. s. warm, warm, hot), $\mathrm{N}-\%$ of neutral comfort, AVG - average comfort (leading response(s)), s. warm/s. cool - slightly cool/warm, red highlight - above neutral > neutral.

KEY
cold
cool
o slightly cool
- neutral
slightly warm
warm hot

${ }^{1}$ Indicates a difference of less than $10 \%$, between percentage of neutral and above natural thermal comfort responses. 
TABLE 2. CONTINUED ...

A Catalog of Thermal Comfort Response Pie Charts Based on Classroom Number, Including Related Notes.

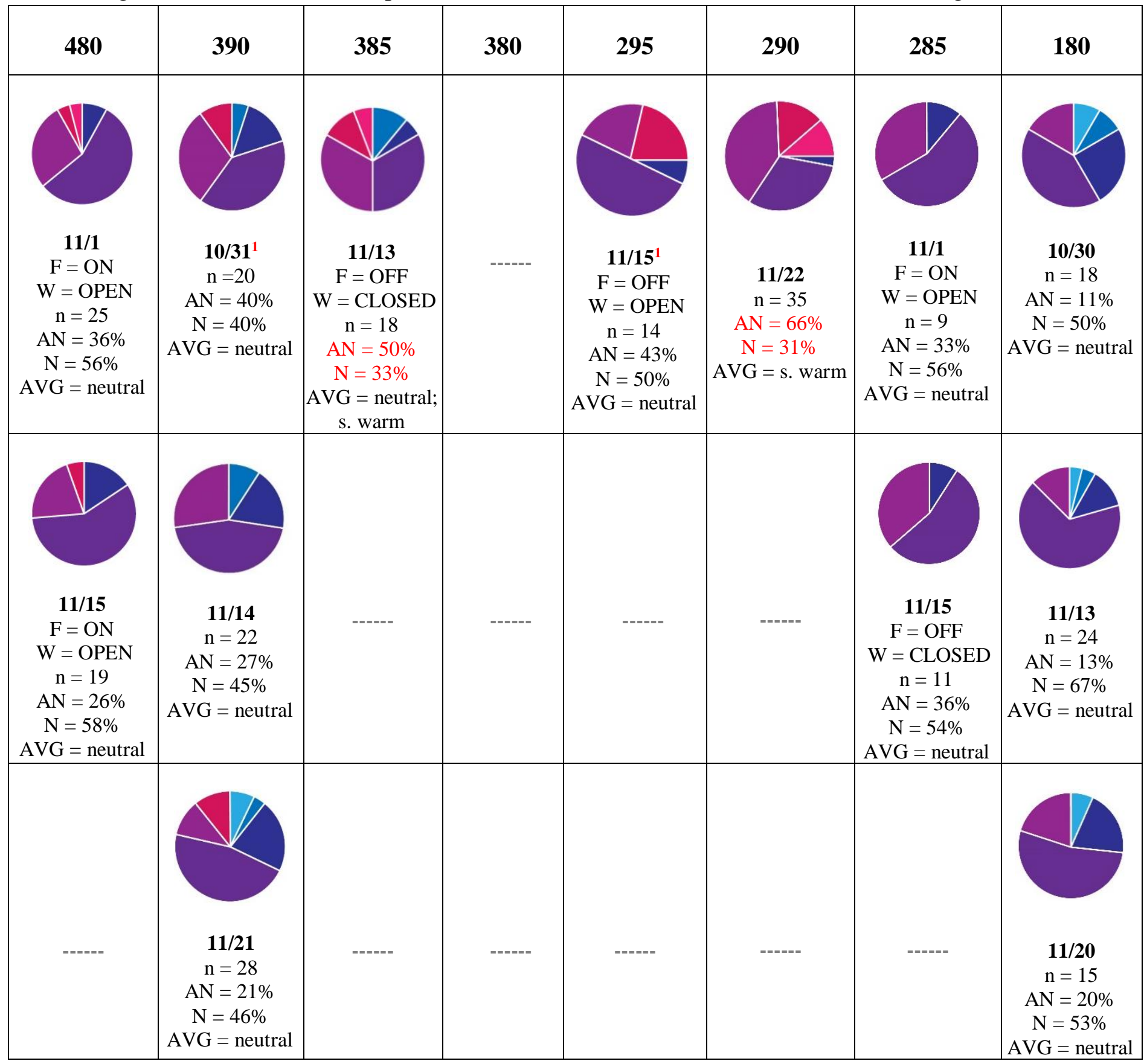

Note: $\mathrm{F}-$ fan, $\mathrm{W}$ - window, $\mathrm{n}$ - \# of participants, $\mathrm{AN}-\%$ above neutral comfort (i.e. s. warm, warm, hot), $\mathrm{N}-\%$ of neutral comfort, AVG - average comfort (leading response(s)), s. warm/s. cool - slightly cool/warm, red highlight - above neutral > neutral.

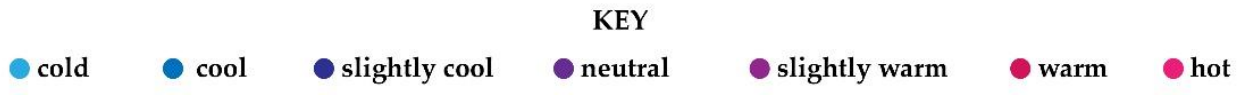

\footnotetext{
${ }^{1}$ Indicates a difference of less than $10 \%$, between percentage of neutral and above natural thermal comfort responses.
} 
TABLE 3.

A Catalog of Relevant Comments Left on Surveys.

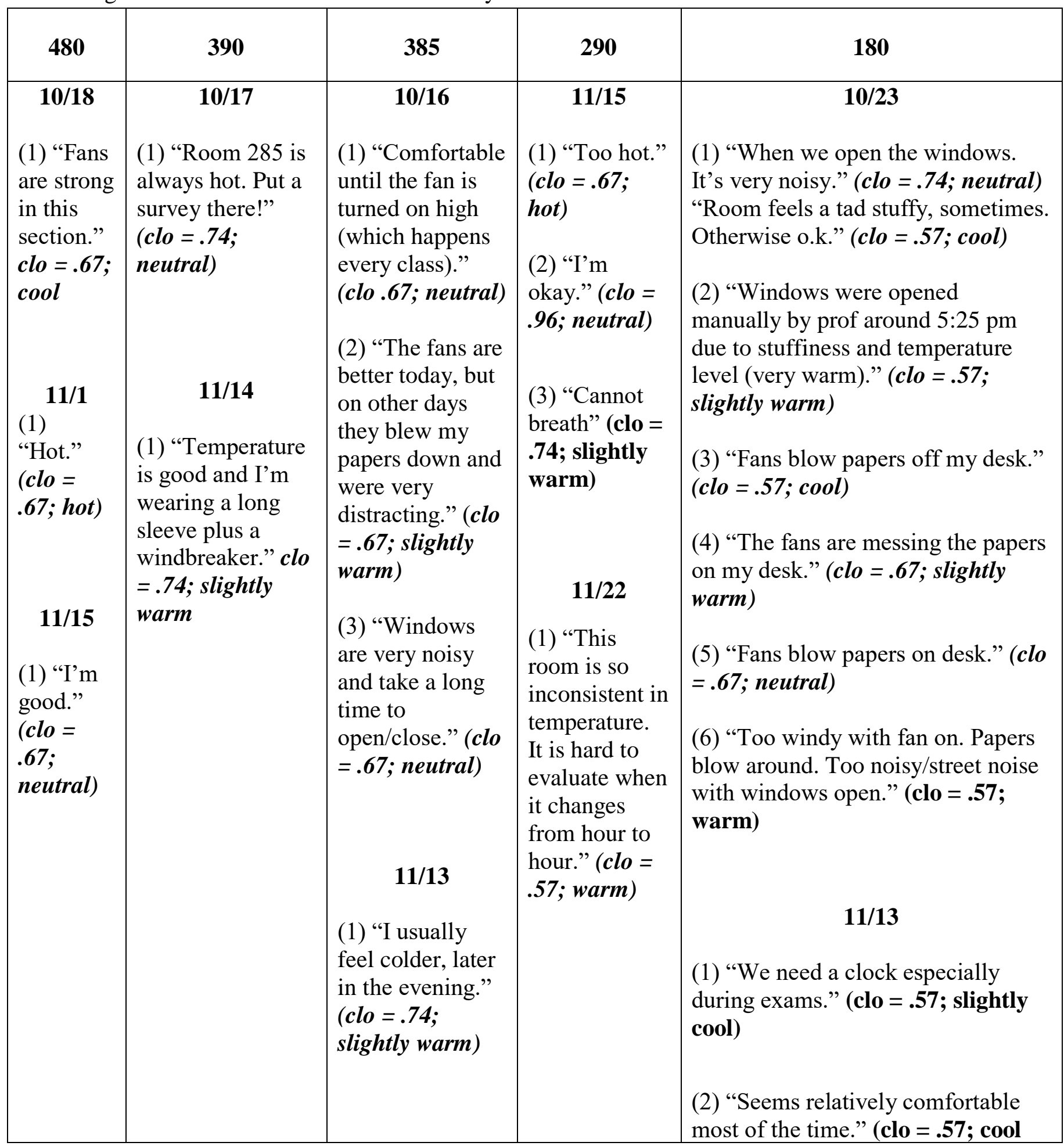




\subsection{ANSWERING RESEARCH QUESTION 1}

Through analysis of the occupant thermal comfort survey data, the overall conclusion is that on average the KMC's new classroom pavilion's naturally ventilated system provides thermally comfortable spaces. Synthesis of the perception data included in Appendix A, shows that out of the thirty-seven surveys included, a feeling of neutral comfort was perceived and dominated the results in more than half of those surveys, twenty-seven to be exact. Although on average the classrooms are perceived by occupants as thermally comfortable, the perception of slightly warm and/or slightly cool are close contenders. The remaining ten surveys not categorized by a neutral perception of comfort, can be categorized as the following: slightlywarm dominates seven, one shows a tie between neutral and slightly warm, one with a tie between neutral and slightly cool, and one with a tie between neutral and cool. ${ }^{1}$ Again, although most of the data sets are dominated by a neutral perception of thermal comfort, in half of those cases either slightly cool and/or slightly warm was a close contender. Therefore, the perceptionbased data of this study exemplifies that the KMC's new classroom pavilion falls within the thermal comfort range of slightly warm to slightly cool, dominated by a neutral and slightly warm perception.

Comparing the exterior climate data, alongside the comfort survey data, identifies and highlights patterns within the data. One pattern previously discussed, is within classrooms 480 and 295 held at the same time, the data shows a contradiction to hypothesis 1 (a), in correlation with warm climate data. This phenomenon is visible in both the performance and perception data, as exterior temperatures drop (see TABLE 4) during October

TABLE 4. $11^{\text {th }}$ and November $15^{\text {th }}$, there is a closer relationship between the perceived comfort of occupants related to a neutral or cooler perception compared to a warmer perception for the dates of October $11^{\text {th }}$ and November $15^{\text {th }}$ (see GRAPH

\begin{tabular}{|c|c|}
\hline Date & $\begin{array}{c}\text { Outdoor Temp. at Time } \\
\text { of Survey Distribution }\end{array}$ \\
\hline${\text { October } 11^{\text {th }}}^{\text {th }}$ & $46.9^{\circ} \mathrm{F}-48.9^{\circ} \mathrm{F}$ \\
\hline October $18^{\text {th }}$ & $64.0^{\circ} \mathrm{F}-63.0^{\circ} \mathrm{F}$ \\
\hline November $1^{\text {st }}$ & $55.0^{\circ} \mathrm{F}-53.1^{\circ} \mathrm{F}$ \\
\hline November 15 th & $45.0^{\circ} \mathrm{F}-43.0^{\circ} \mathrm{F}$ \\
\hline
\end{tabular}

\footnotetext{
${ }^{1}$ See, Figures 1-23, in APPENDIX A.

${ }^{2}$ Data taken from weatherunderground.com, where climate data is collected hourly; data relates to the time range of 4:53pm to $5: 53 \mathrm{pm}$.
} 
1-8). In each set of surveys,

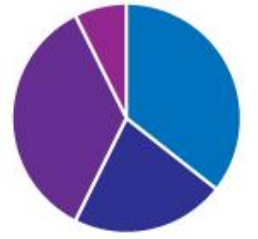

GRAPH 1.

Classroom 480

October $11^{\text {th }}$

fans on \& windows closed

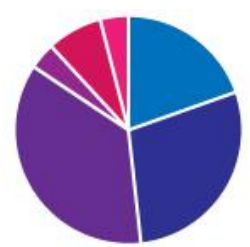

GRAPH 5.

Classroom 480 October $18^{\text {th }}$

fans on \& windows open

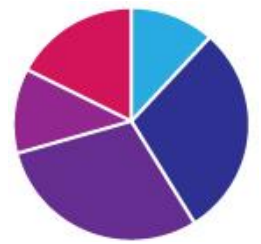

GRAPH 2.

Classroom 295

October $11^{\text {th }}$ fans off \& windows open

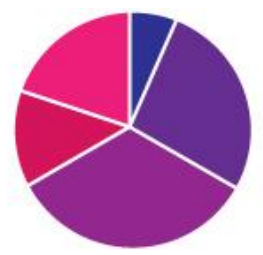

GRAPH 6.

Classroom 295

October $18^{\text {th }}$

fans on \& windows open

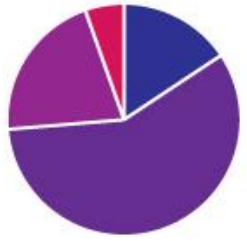

GRAPH 3.

Classroom 480

November $15^{\text {th }}$

fans off \& windows open

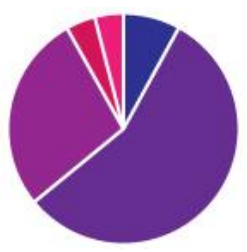

GRAPH 7.

Classroom 480

November $1^{\text {st }}$

fans off \& windows open

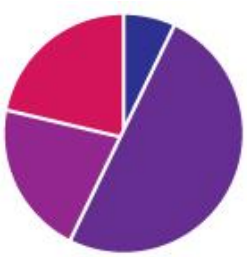

GRAPH 4.

Classroom 295

November $15^{\text {th }}$

fans off \& windows open

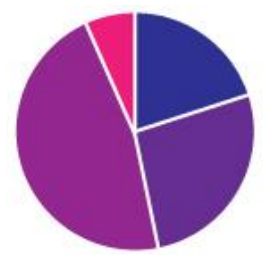

GRAPH 8.

Classroom 295

November $1^{\text {st }}$

fans on \& windows open

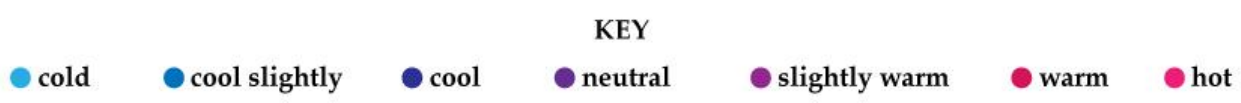

regardless of eternal temperatures, classroom 295 feels warmer to occupants than classroom 480, though it is on a higher floor. For the second two dates (see CHART 2), interior temperature data supports the perception felt by the occupants and the reoccurring contradiction of hypothesis 1 (a). However, the survey data collected from classroom 290 (see APPENDIX A), falls closely in line with the survey data collected from classroom 480. Therefore, classroom 295 classifies as a classroom with difficulties staying within a neutral thermal comfort zone compared to other classrooms in the KMC, such as classroom 480, which when taking other factors in to account, does a good job on average providing a neutral thermal comfort. The factors that might explain classroom 480's cooler perception of thermal comfort is due to the fans being on October $11^{\text {th }}$ and $18^{\text {th }}$ (see GRAPH 1 and GRAPH 5). 
TABLE 5.

Interior Temperature Data Between Two Classrooms Held on Different Floors at the Same Time. ${ }^{1}$

\begin{tabular}{|c|c|c|c|c|}
\hline Room \# & $\begin{array}{c}\text { Temperature }\left(\mathbf{F}^{\circ}\right) \\
(\mathbf{1 1} / \mathbf{1} / \mathbf{2 0 1 7})\end{array}$ & $\begin{array}{c}\text { Temperature }\left(\mathbf{F}^{\circ}\right) \\
(\mathbf{1 1} / \mathbf{1 5} / \mathbf{2 0 1 7})\end{array}$ & $\begin{array}{c}\mathbf{C O}_{2}(\mathbf{P P M}) \\
(\mathbf{1 1} / \mathbf{1} / \mathbf{2 0 1 7})\end{array}$ & $\begin{array}{c}\mathbf{C O}_{2}(\mathbf{P P M}) \\
(\mathbf{1 1} / \mathbf{1 5} / \mathbf{2 0 1 7})\end{array}$ \\
\hline 480 & 71.1 & 70.7 & 512.5 & 449.5 \\
\hline 295 & 74 & 72.9 & 622.5 & 796 \\
\hline
\end{tabular}

Another moment of interest in the data relating to the first research question, is the evidence of the stack effect trend between classrooms 385 and 180 held at the same time as well. Although his trend mostly lends itself to the perception data for support, the interior temperature data acts to provide secondary data backing up the occupant's perception of comfort and therefore the stack effect trend. Through analysis of both sets of data (see GRAPH 9-16 and CHART 3), classroom 385 is perceived and performing on a slightly warmer thermal comfort scale than the lower classroom 180. Therefore, although more data is necessary to completely and confidently answer whether the stack effect is contributing to the thermal comfort of these classrooms, this data presents strong evidence in support, where classroom 295 is an anomaly that should be further researched to identify other factors to explain these results.

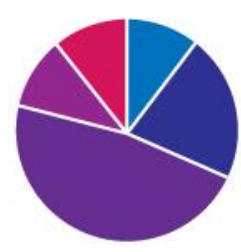

GRAPH 9.

Classroom 180 October $2^{\text {nd }}$

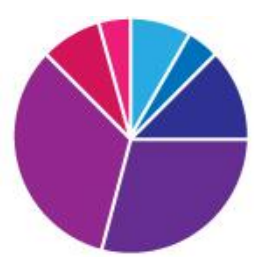

GRAPH 10.

Classroom 385 October $2^{\text {nd }}$

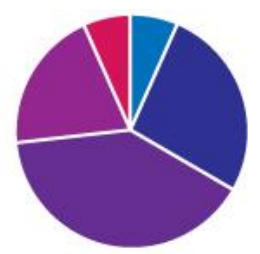

GRAPH 11.

Classroom 180 October $16^{\text {th }}$

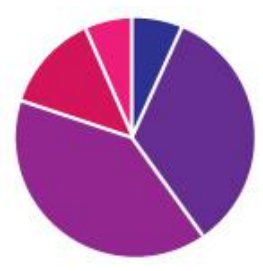

GRAPH 12.

Classroom 385 October $16^{\text {th }}$

\footnotetext{
${ }^{1}$ Shows interior classroom performance data collected 15 minutes before class as surveys were distributed up until the start of class. Classroom 480 data averaged from 17:15 - 17:30 and classroom 295 data averaged from 17:30 17:45.
} 


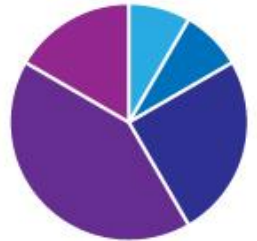

GRAPH 13.

Classroom 180

October $30^{\text {th }}$

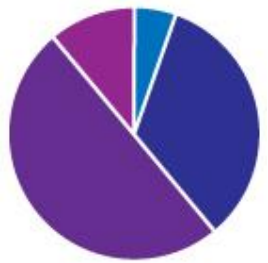

GRAPH 14.

Classroom 385

October $30^{\text {th }}$

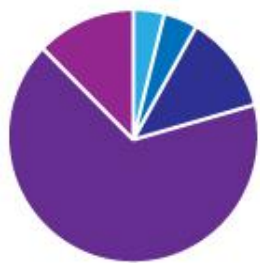

GRAPH 15.

Classroom 180

November $13^{\text {th }}$

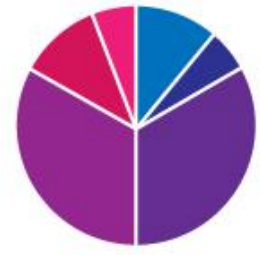

GRAPH 16.

Classroom 385

November $13^{\text {th }}$

KEY

cold cool slightly cool o neutral o warm

TABLE 6.

Interior Temperature Data Between Two Classrooms Held on Different Floors at the Same Time. ${ }^{1}$

\begin{tabular}{|c|c|c|c|c|}
\hline Room \# & $\begin{array}{c}\text { Temperature }\left(\mathrm{F}^{\circ}\right) \\
(\mathbf{1 0 / 3 0 / 2 0 1 7 )}\end{array}$ & $\begin{array}{c}\text { Temperature }\left(F^{\circ}\right) \\
(11 / 13 / 2017)\end{array}$ & $\begin{array}{l}\mathrm{CO}_{2} \text { (PPM) } \\
(11 / 1 / 2017)\end{array}$ & $\begin{array}{c}\mathrm{CO}_{2} \text { (PPM) } \\
(11 / 15 / 2017)\end{array}$ \\
\hline 385 & 75 & 71.5 & 547 & 508 \\
\hline 180 & 72.05 & 70.45 & 583.5 & 506.5 \\
\hline
\end{tabular}

\subsection{ANSWERING RESEARCH QUESTION 2}

The combination of perception-based data and perception-based data collected, presents a solid foundation to answer the simple questions related to indoor air quality and thermal comfort, as well as being to tackle some of the more complex data. However, the addition of a full set of relative humidity data, and indoor temperature data and more data, would be the means of fully answering the research questions with total confidence. The data still justifies that a combination of performance and perception-based data is enough to answer whether the Karl Miller Center's addition is successful in creating comfortable spaces to occupy. This combination of qualitative and quantitative data also begins to address why this is so and what range of thermal comfort these classrooms provide.

\footnotetext{
${ }^{1}$ Shows interior classroom performance data collected 15 minutes before class as surveys were distributed up until the start of class. Classroom 480 data averaged from 17:15 - 17:30 and classroom 295 data averaged from 17:30 $17: 45$.
} 


\subsection{ANSWERING THE HYPOTHESIS}

The overarching hypothesis is close to accurate, in that of the thirty-seven surveys used as the focus for this data analysis: seventeen are dominated by a neutral thermal comfort, three by a slightly warm comfort, four with a tie between neutral and slightly warm, one with a tie between neutral and slightly cool, and one where a cool thermal comfort dominated. ${ }^{1}$ Again, although the data set is dominated by a neutral perception of thermal comfort, in half of these cases either slightly cool and/or slightly warm is a close contender. Therefore, the perceptionbased data of this study exemplifies that the KMC's new classroom pavilion falls within the thermal comfort range of slightly warm to slightly cool.

Regarding Hypothesis (a), which deals with the stack effect, the data discussion for the Research Question 1, begins to answer this hypothesis as well. However, this is where the implication of limited data and data diversity hinders the ability to fully answer the questions initially posed for this research. The data shows that there is an example of the stack effect in two classrooms on different floors as well as a contradiction to hypothesis 1 (a), across two different classrooms and floors, during the term when data was collected. With only these two sets of perception data to compare, the hypothesis deserves further research and analysis to identify the stack effect trend, identify the reason classroom 295 isn't working as effectively as other classrooms, and if there are other anomalies like classroom 295 to detect areas of improvement in the building.

Regarding Hypothesis (b), with the data collected there doesn't seem to be a consistent discrepancy between the two data sets collected outside of the evening classes compared to the evening classes average perception of thermal comfort. Time doesn't seem to be as much as a factor on the perception of comfort as the outdoor temperature, operation of fans/windows, and location has on the overall classrooms perception data. This could be due to the use of concrete as a thermal battery throughout the building and classrooms, which consistently collects heat and releases it as the temperature outside of the concrete decreases helping to maintain the internal temperature of the classrooms.

Thirdly in answering the hypothesis (c), which further discusses how the concrete used through the KMC comes into play into thermal comfort, as it assumes that both the perception and performance of classrooms with multiple elevations of glazing will have a cooler perception

\footnotetext{
${ }^{1}$ See, Figures $1-28$, in APPENDIX A.
} 
of thermal comfort. The thinking behind this, is due to less concrete available to hold heat coupled with the fact that glass is more of a thermal bridge for the outside air than concrete. Although there is more opportunity for direct sunlight and therefore heat through radiation, the classrooms with multiple elevations of glazing are set back allowing the floor above to act as it's sunshade, and in turn present a design that will on average be colder than the other classrooms. The only classroom with data collected that also is categorizes with multiple walls of glazing, and therefore can be used to analysis its overall thermal comfort data, is classroom 390. Looking at the data provided from classroom 390 (see GRAPH 17-22), this third hypothesis appears wrong. The data provided shows that in fact the average perception of human comfort is comfortable, and not slightly warm has hypothesized. However, the performance of this classroom on the days with warmer temperature such as October $3^{\text {rd }}$ and October $31^{\text {st }}$, appears to lean towards providing a warmer space compared to other classrooms. It also is interesting to point out how as the outdoor climate gets cooler (see CHART 3), so does the interior perception of comfort, therefore not completely contradicting the hypothesis. It appears that this classroom, because of the lack of concrete does a poor job at insulating the space, as discussed in the hypothesis. What the hypothesis failed to address is how the lack of insulation and increased opportunity of thermal bridging not only provides increasingly cool spaces, but also in turn increasingly warmer spaces.
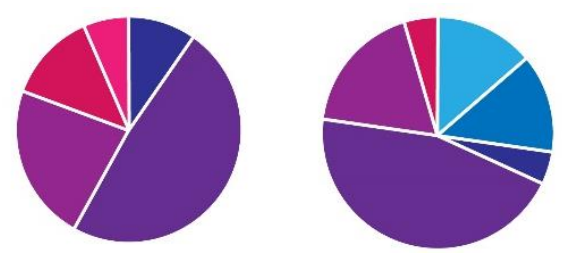

\section{GRAPH 17.}

Classroom 390 October $3^{\text {rd }}$

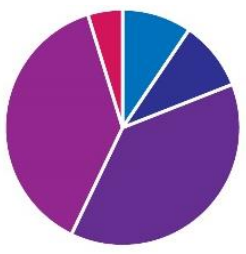

GRAPH 19.

Classroom 390 October $17^{\text {th }}$

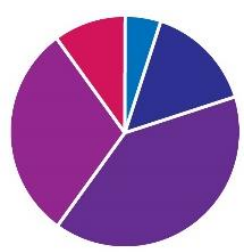

GRAPH 20.

Classroom 390 October $31^{\text {st }}$
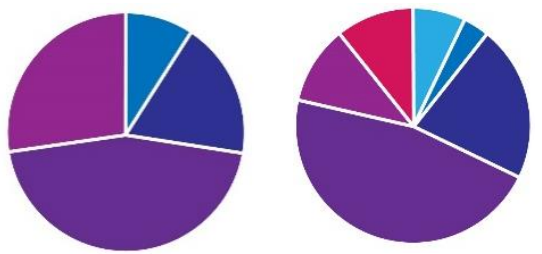

GRAPH 21. GRAPH 22. Classroom 390 November $14^{\text {th }}$
Classroom 390 November 21st 


\section{Table 7.}

Exterior Temperature Data. ${ }^{1}$

\begin{tabular}{|c|c|c|c|}
\hline Date & $\begin{array}{c}\text { Average Outdoor Temperature at } \\
\text { Time of Survey Distribution }\end{array}$ & $\begin{array}{c}\text { Max. } \\
\text { Temperature }\end{array}$ & $\begin{array}{c}\text { Min. } \\
\text { Temperature }\end{array}$ \\
\hline $\begin{array}{c}\text { October } \\
3^{\text {rd }}\end{array}$ & $68.55^{\circ} \mathrm{F}$ & $71^{\circ} \mathrm{F}$ & $44^{\circ} \mathrm{F}$ \\
\hline $\begin{array}{c}\text { October } \\
10^{\text {th }}\end{array}$ & $53.55^{\circ} \mathrm{F}$ & $57^{\circ} \mathrm{F}$ & $43^{\circ} \mathrm{F}$ \\
\hline $\begin{array}{c}\text { October } \\
17^{\text {th }}\end{array}$ & $54.5^{\circ} \mathrm{F}$ & $58^{\circ} \mathrm{F}$ & $42^{\circ} \mathrm{F}$ \\
\hline $\begin{array}{c}\text { October } \\
31^{\text {st }}\end{array}$ & $60^{\circ} \mathrm{F}$ & $62^{\circ} \mathrm{F}$ & $35^{\circ} \mathrm{F}$ \\
\hline $\begin{array}{c}\text { November } \\
14^{\text {th }}\end{array}$ & $54.5^{\circ} \mathrm{F}$ & $58^{\circ} \mathrm{F}$ & $45^{\circ} \mathrm{F}$ \\
\hline $\begin{array}{c}\text { November } \\
21^{\mathrm{st}}\end{array}$ & $48.9^{\circ} \mathrm{F}$ & $51^{\circ} \mathrm{F}$ & $45^{\circ} \mathrm{F}$ \\
\hline
\end{tabular}

\subsection{CONCLUSIONS}

The analysis above provides a solid foundation for the future exploration of the success and concerns of using mixed-mode ventilation and natural ventilation systems. Limitations of classroom diversity and participants data sets aside, this research provides some insights into some of the problematic classrooms and therefore provides avenues for improvement of the overall cooling and ventilation system. Some of these issues include: classroom 295's perception of comfort is an average warmer than comfortable even compared to classrooms above held at the same time, when one would assume the stack affect would correlate to the opposite; although the stack effect was not prominent in the comparison of classrooms 295 and 480, it was in comparing the classrooms 390 and 180, therefore another set of classrooms to compare would have better addresses the hypothesis; and with less concrete within classroom 390 there is less insulation and therefore, the outdoor climate affect this classroom on average more than the there's used in this research.

${ }^{1}$ Data taken from weatherunderground.com, where climate data is collected hourly; data relates to the time range of 4:53pm to $5: 53 \mathrm{pm}$. 
The overall conclusion from this analysis is that the KMC's new classroom pavilion, with its naturally ventilation and cooling system, on average provided comfortable spaces, but nearly equally provides spaces that are slightly outside of a neutrally perceived thermal comfort (i.e. slightly warm or slightly cool). Although participants did relay perceptions of comfort outside of neutral, it is important to note that some individuals prefer to occupy space that are slightly cool or slightly warm, and therefore the data does not portray that occupants of the KMC are necessarily uncomfortable. Therefore, future studies on this building, ill be able to have deeper understanding of how comfortable the natural ventilation system in the KMC's new addition provides by including questions on surveys that ask occupants to rate their comfort as their thermal comfort. As this was the pilot study for future studies on this building's system, another take away from the research is the importance of developing better ways to collect a more diverse set of data by recruiting more professors, assembling a more diverse collection of classrooms held at different times and on different floors, and improving the methods of collecting both performance and perception-based data. Although each data provides thorough insight into how a building or system works, the other half of the data illuminates upon and questions of how and why the system is performing the way it is. 


\section{SOURCE LIST}

Ackerly, Katie et al. "Data Collections Methods for Assessing Adaptive Comfort in Mixed-Mode Buildings and Personal Comfort Systems." Indoor Environment Quality (IEQ), UC Berkeley. Center for the Built Environment, University of California, Berkeley. Escholarship.org. OCTOBER 2012.

ASHRAE. “ASHRAE TERMINOLOGY.” 2018. Ashrae.org. https://www.ashrae.org/technical-resources/authoringtools/terminology

ASHRAE. "Thermal Environmental Conditions for Human Occupancy.” ANSI/ASHRAE Standard 55-2013. www.ashrae.org. ASHRAE. "Ventilation for Acceptable Indoor Air Quality.” ANSI/ASHRAE Standard 62.1-2016. www.ashrae.org.

Better Buildings Partnership. "Natural Ventilation and Mixed Mode Systems." JUNE 2015. Sydney, Australia. www.betterbuildingspartnership.com.au/information/natural-ventilation-mixed-mode-systems/

Brager, Gail. "Mixed-Mode Cooling.” Envelope Systems, UC Berkeley. AUGUST 2006. ASHRAE Journal. ashrae.org.

Brager, Gail and Baker, Lindsay. "Occupant satisfaction in mixed-mode buildings." Envelope Systems, UC Berkeley. JULY 2008. From Proceedings, Air Conditioning and the Low Carbon Cooling Challenge, Windsor, UK.

Brager, Gail et al. "Mixed-Mode Ventilation: Hvac meets Mother Nature." HVAC Systems, UC Berkeley. MAY 2000. ASHRAE Journal. Ashrae.org.

Brager, Gail et al. "Summary Report: Control Strategies for Mixed-Mode Buildings." Center for the Built environment (CBE), University of California, Berkeley. OCTOBER 2007.

Center for the Built Environment (CBE). "About Mixed-Mode.” University of California Berkeley. 2013. https://www.cbe.berkeley.edu/mixedmode/aboutmm.html

Hoyt, Tyler et al. CBE Thermal Comfort Tool. Center for the Built Environment (CBE), University of California Berkeley. 2017. comfort.cbe.berkeley.edu/.

EPA. "Heating, Ventilation and Air-conditioning Text Modules for the Indoor Air Quality Building Education and Assessment Model.” United States Government. Indoor Air Quality (IAQ). JANUARY 2017.

https://www.epa.gov/indoor-air-quality-iaq/heating-ventilation-and-air-conditioning-text-modules-indoorair-quality.

Hu, Jianjun and Karava, Panagiota. "Model predictive control strategies for buildings with mixed-mode cooling." School of Civil Engineering, Purdue University. West Lafayette, IN. ELSEVIER. Building and Environment 71 (2014) 233-244. SEPTEMBER 2013.

Jung-yeon, Yu et. al. "Resolving Stack Effect Problems in a High-Rise Office Building by Mechanical Pressurization." MDPI Journal. Sustainability. 2017.

N.C. Cooperation Extension. "Stack Effect - Defined." NC State University and N.C. A\&T State University. https://energy.ces.ncsu.edu/stack-effect-defined/

Ogoli, David M. "Thermal Comfort in a Naturally-Ventilated Educational Building." Judson College, Elgin, IL. 2007. ARCC Journal, Volume 4 Issue 2.

Spindler, Henry C. and Norford,Leslie K. "Naturally ventilated and mixed-mode buildings --- Part I: Thermal modeling." Massachusetts Institute of Technology. Optimal Energy Solutions LLC. Cambridge, MA and Keene, NH. ELSEVIER. Building and Environment 44(2009) 736-749. MAY 2008.

U.S. Energy Information Administration. "How much energy is consumed in U.S. residential and commercial buildings?." 2017. https://www.eia.gov/tools/faqs/faq.php?id=86\&t=1

Wright, Andre and Geoff Levermore, "Natural Ventilation or Mixed Mode? An investigation using Simulation." EA Technology Ltd, Chester CH1 6ES, UK, Virginia Cooper. UMIST, Manchester, Dept. Building Engineering, M60 1D, U 


\section{APPENDIX A.}

Figure 1.

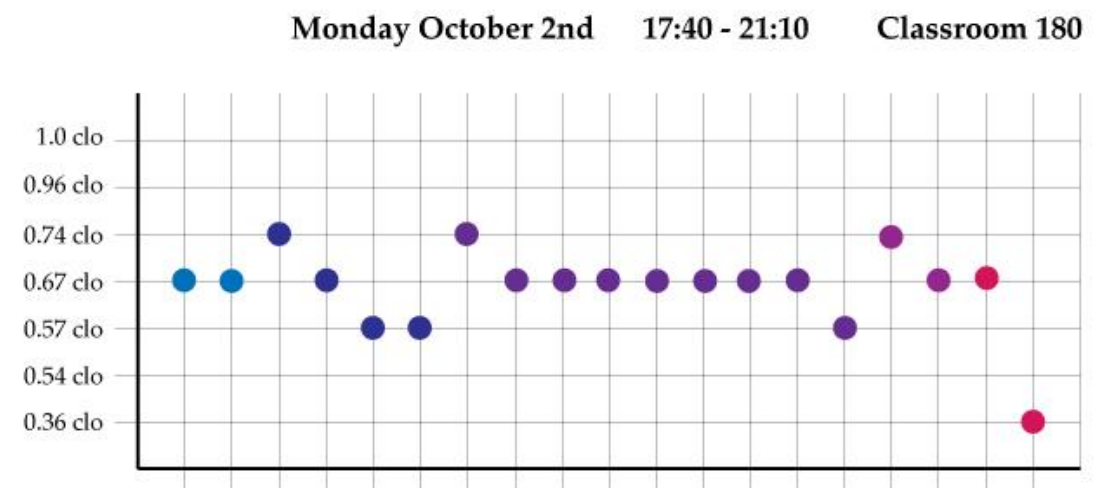

$\begin{array}{lllllllllllllllllllll}\text { P1 } & \text { P2 } & \text { P3 } & \text { P4 } & \text { P5 } & \text { P6 } & \text { P7 } & \text { P8 } & \text { P9 } & \text { P10 } & \text { P11 } & \text { P12 } & \text { P13 } & \text { P14 } & \text { P15 } & \text { P16 } & \text { P17 } & \text { P18 } & \text { P19 }\end{array}$

\section{Figure 2.}
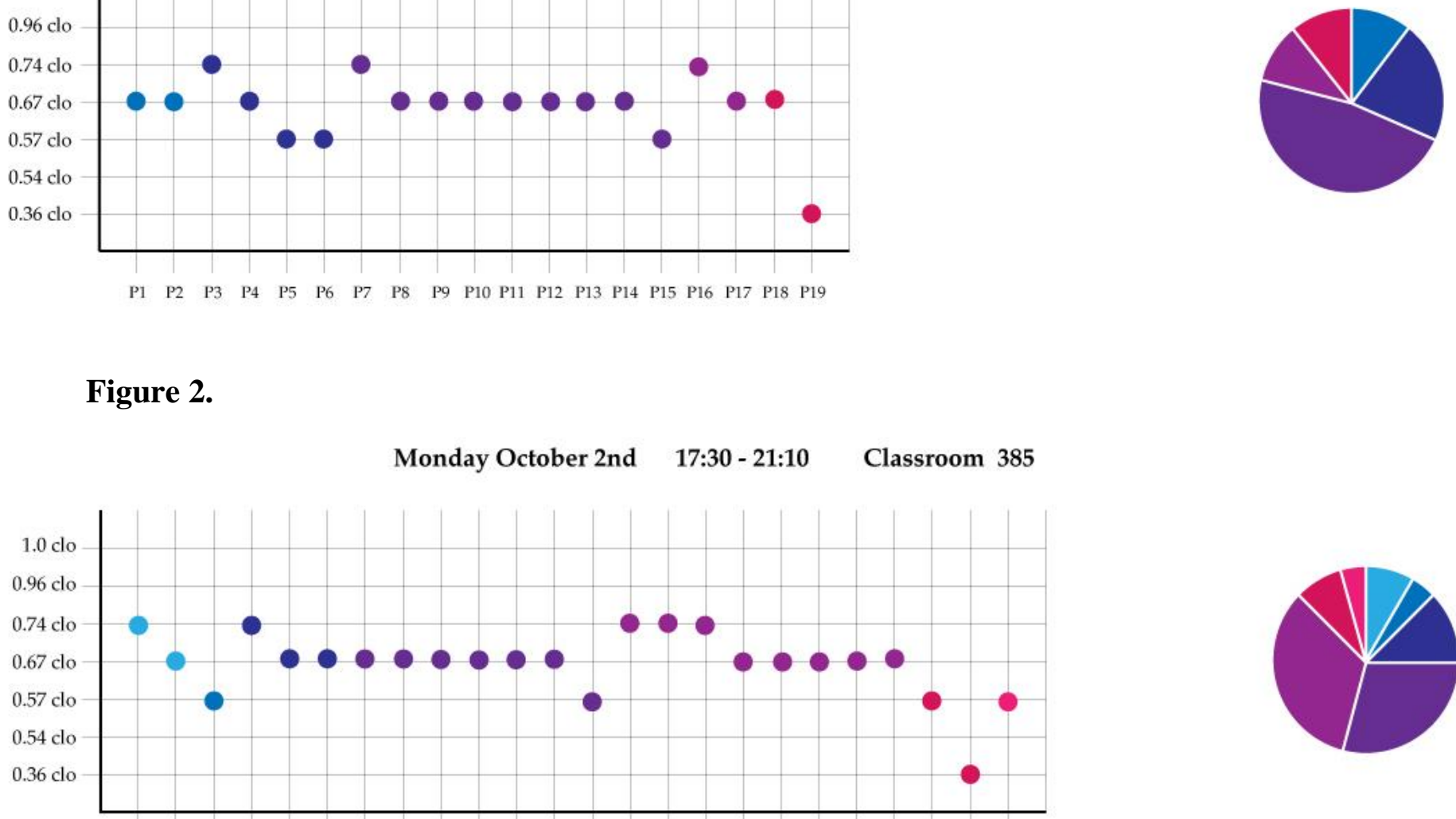

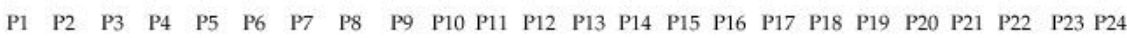

OUTDOOR CLIMATE DATA: MONDAY OCTOBER 2 $2^{\mathrm{ND}}, 2017$

\begin{tabular}{|c|c|c|c|c|}
\hline $\begin{array}{c}\text { Temp. at Time of } \\
\text { Survey Distribution }\end{array}$ & $\begin{array}{c}\text { Max. Temperature } \\
\text { (Entire Day) }\end{array}$ & $\begin{array}{c}\text { Min. Temperature } \\
\text { (Entire Day) }\end{array}$ & $\begin{array}{c}\text { Max. Humidity } \\
\text { (Entire Day) }\end{array}$ & $\begin{array}{c}\text { Min. Humidity } \\
\text { (Entire Day) }\end{array}$ \\
\hline $\mathbf{6 1 . 6}^{\circ} \mathbf{F}$ & $\mathbf{6 5}^{\circ} \mathbf{F}$ & $\mathbf{4 9}^{\circ} \mathbf{F}$ & $\mathbf{9 3 \%}$ & $\mathbf{5 2 \%}$ \\
\hline
\end{tabular}

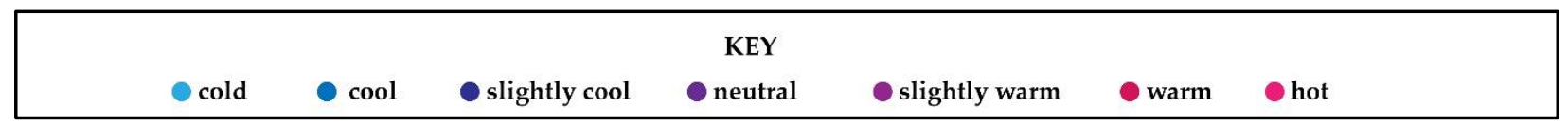

${ }^{1}$ Data taken from weatherunderground.com, where climate data is collected hourly; data range relates to 4:53pm to 5:53pm.. 
Figure 3.

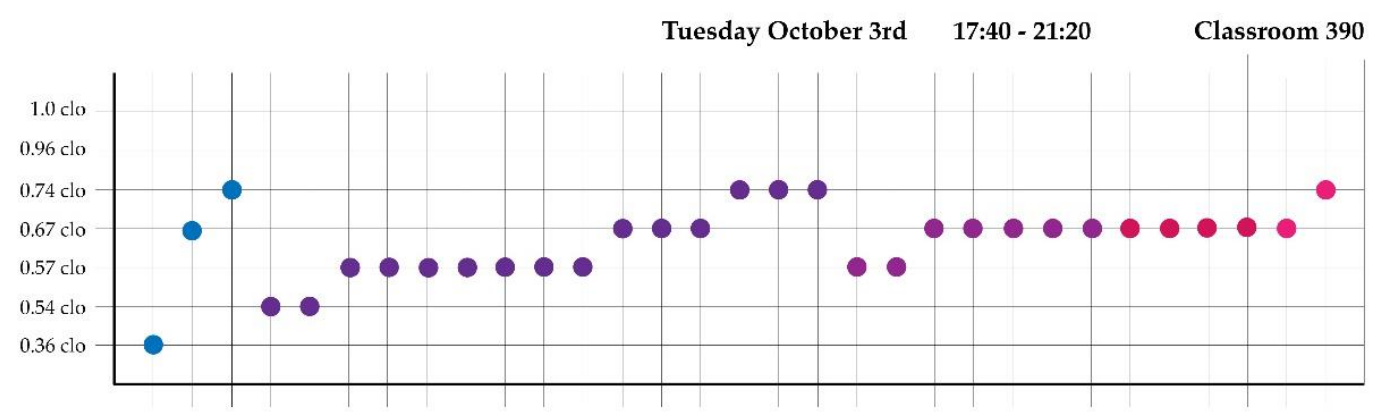

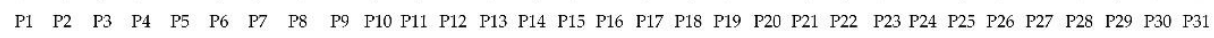

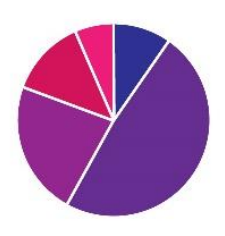

OUTDOOR CLIMATE DATA: TUESDAY OCTOBER $3^{\mathrm{RD}}, 2017$

\begin{tabular}{|c|c|c|c|c|}
\hline $\begin{array}{c}\text { Temp. at Time of } \\
\text { Survey Distribution }\end{array}$ & $\begin{array}{c}\text { Max. Temperature } \\
\text { (Entire Day) }\end{array}$ & $\begin{array}{c}\text { Min. Temperature } \\
\text { (Entire Day) }\end{array}$ & $\begin{array}{c}\text { Max. Humidity } \\
\text { (Entire Day) }\end{array}$ & $\begin{array}{c}\text { Min. Humidity } \\
\text { (Entire Day) }\end{array}$ \\
\hline $\mathbf{6 8 . 6}^{\circ} \mathbf{F}$ & $\mathbf{7 1}^{\circ} \mathbf{F}$ & $\mathbf{4 4}^{\circ} \mathbf{F}$ & $\mathbf{9 3 \%}$ & $\mathbf{3 1 \%}$ \\
\hline
\end{tabular}

Figure 4.

Wednesday October 4th 10:15 - 11:20 Classroom 285

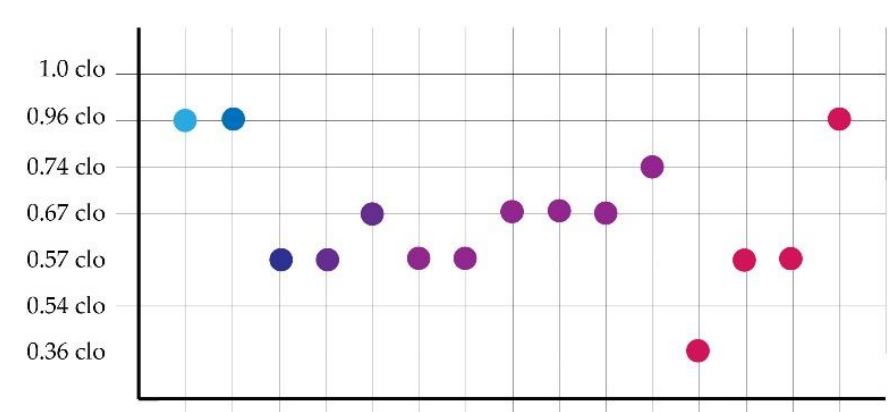

$\begin{array}{llllllllllllllllll}\text { P1 } & \text { P2 } & \text { P3 } & \text { P4 } & \text { P5 } & \text { P6 } & \text { P7 } & \text { P8 } & \text { P9 } & \text { P10 } & \text { P11 } & \text { P12 } & \text { P13 } & \text { P14 } & \text { P15 }\end{array}$

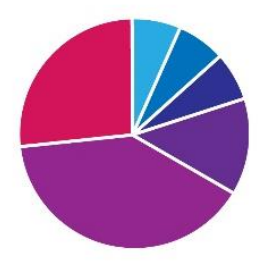

OUTDOOR CLIMATE DATA: WEDNESDAY OCTOBER $4^{\mathrm{TH}}, 2017$

\begin{tabular}{|c|c|c|c|c|}
\hline $\begin{array}{c}\text { Temp. at Time of } \\
\text { Survey Distribution }\end{array}$ & $\begin{array}{c}\text { Max. Temperature } \\
\text { (Entire Day) }\end{array}$ & $\begin{array}{c}\text { Min. Temperature } \\
\text { (Entire Day) }\end{array}$ & $\begin{array}{c}\text { Max. Humidity } \\
\text { (Entire Day) }\end{array}$ & $\begin{array}{c}\text { Min. Humidity } \\
\text { (Entire Day) }\end{array}$ \\
\hline $\mathbf{5 4 . 5}^{\circ} \mathbf{F}$ & $\mathbf{7 1}^{\circ} \mathbf{F}$ & $\mathbf{4 2}^{\circ} \mathbf{F}$ & $\mathbf{9 6 \%}$ & $\mathbf{3 3 \%}$ \\
\hline
\end{tabular}

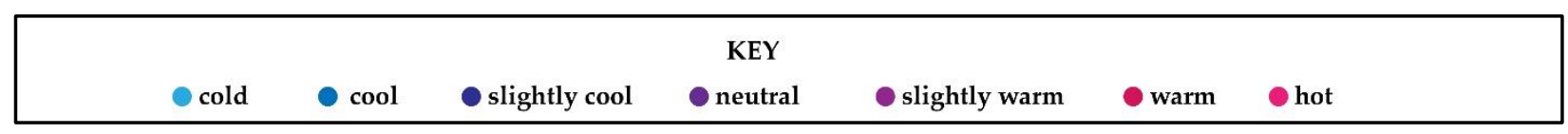

\footnotetext{
${ }^{1}$ Data taken from weatherunderground.com, where climate data is collected hourly; data range relates to the start time of 9:53am.

${ }^{2}$ Data taken from weatherunderground.com, where climate data is collected hourly; data range relates to the start time of 9:53am.
} 


\section{Figure 5.}

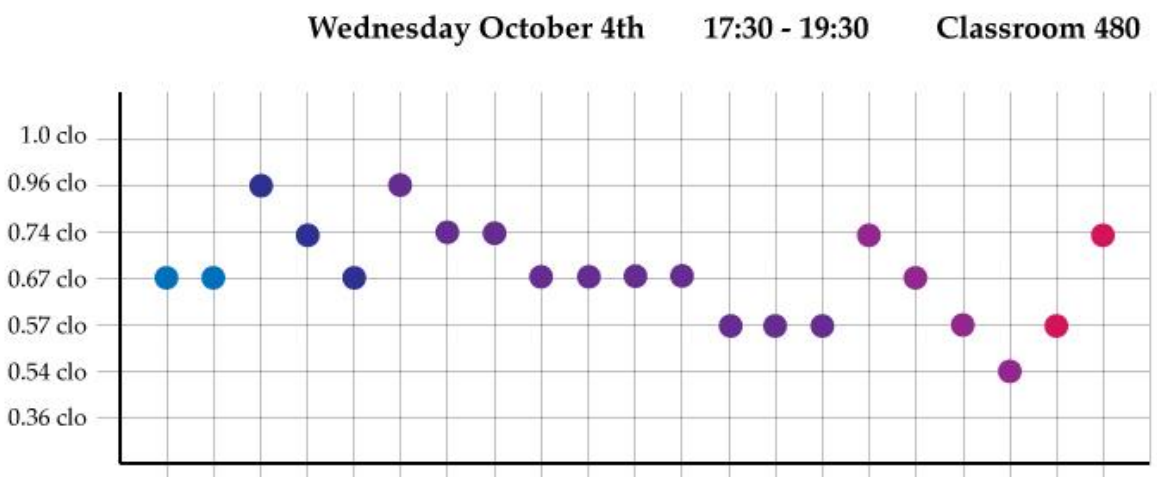

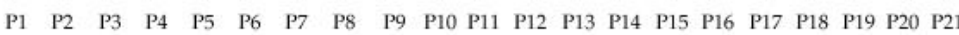

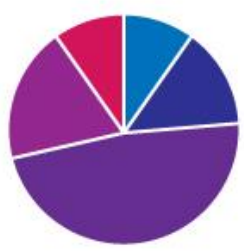

Figure 6.

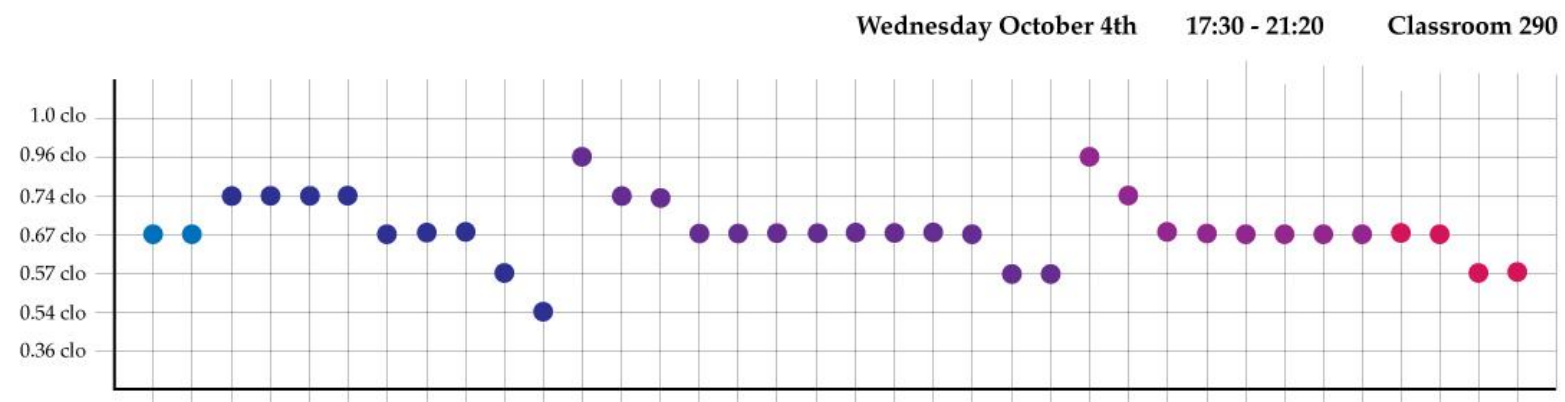

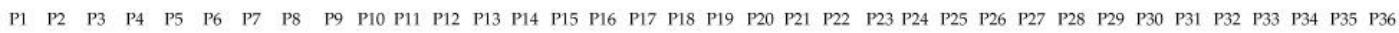

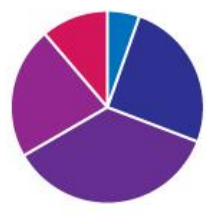

\section{OUTDOOR CLIMATE DATA: WEDNESDAY OCTOBER $4^{\mathrm{TH}}, 2017$}

\begin{tabular}{|c|c|c|c|c|}
\hline $\begin{array}{c}\text { Temp. at Time of } \\
\text { Survey Distribution }\end{array}$ & $\begin{array}{c}\text { Max. Temperature } \\
\text { (Entire Day) }\end{array}$ & $\begin{array}{c}\text { Min. Temperature } \\
\text { (Entire Day) }\end{array}$ & $\begin{array}{c}\text { Max. Humidity } \\
\text { (Entire Day) }\end{array}$ & $\begin{array}{c}\text { Min. Humidity } \\
\text { (Entire Day) }\end{array}$ \\
\hline $\mathbf{6 8}^{\circ} \mathbf{F}$ & $\mathbf{7 1}^{\circ} \mathbf{F}$ & $\mathbf{4 2}^{\circ} \mathbf{F}$ & $\mathbf{9 6 \%}$ & $\mathbf{3 3 \%}$ \\
\hline
\end{tabular}

\begin{tabular}{|c|c|c|c|c|c|c|}
\hline & & & KEY & & & \\
\hline cold & cool & slightly cool & neutral & slightly warm & warm & hot \\
\hline
\end{tabular}

${ }^{1}$ Data taken from weatherunderground.com, where climate data is collected hourly; data range relates to 4:53pm to 5:53pm. 


\section{Figure 7.}

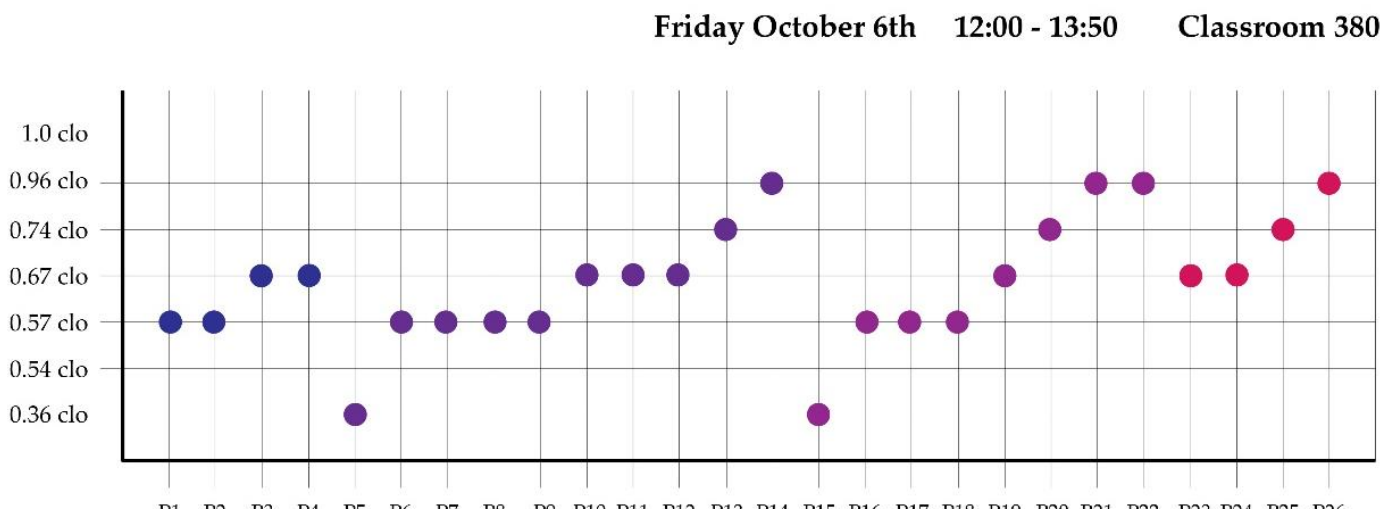

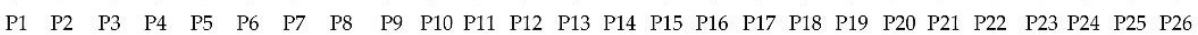

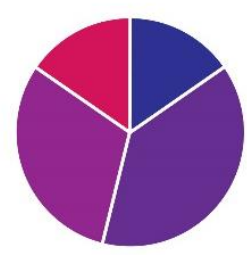

\section{OUTDOOR CLIMATE DATA: FRIDAY OCTOBER $6^{\mathrm{TH}}, 2017$}

\begin{tabular}{|c|c|c|c|c|}
\hline $\begin{array}{c}\text { Temp. at Time of } \\
\text { Survey Distribution }\end{array}$ & $\begin{array}{c}\text { Max. Temperature } \\
\text { (Entire Day) }\end{array}$ & $\begin{array}{c}\text { Min. Temperature } \\
\text { (Entire Day) }\end{array}$ & $\begin{array}{c}\text { Max. Humidity } \\
\text { (Entire Day) }\end{array}$ & $\begin{array}{c}\text { Min. Humidity } \\
\text { (Entire Day) }\end{array}$ \\
\hline $\mathbf{5 9 . 0}^{\circ} \mathbf{F}$ & $\mathbf{7 3}^{\circ} \mathbf{F}$ & $\mathbf{4 3}^{\circ} \mathbf{F}$ & $\mathbf{9 3 \%}$ & $\mathbf{2 3 \%}$ \\
\hline
\end{tabular}

\section{Figure 8.}

Tuesday October 10th $\quad 17: 40-21: 20$

Classroom 390
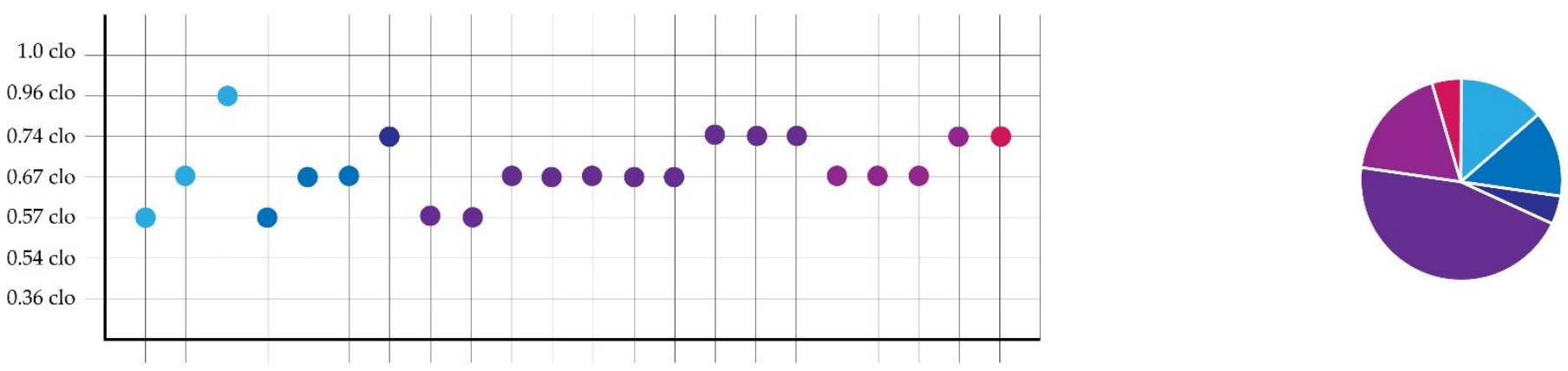

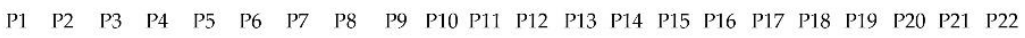

OUTDOOR CLIMATE DATA: TUEDAY OCTOBER 10 ${ }^{\mathrm{TH}}, 2017$

\begin{tabular}{|c|c|c|c|c|}
\hline $\begin{array}{c}\text { Temp. at Time of } \\
\text { Survey Distribution }\end{array}$ & $\begin{array}{c}\text { Max. Temperature } \\
\text { (Entire Day) }\end{array}$ & $\begin{array}{c}\text { Min. Temperature } \\
\text { (Entire Day) }\end{array}$ & $\begin{array}{c}\text { Max. Humidity } \\
\text { (Entire Day) }\end{array}$ & $\begin{array}{c}\text { Min. Humidity } \\
\text { (Entire Day) }\end{array}$ \\
\hline $\mathbf{5 3 . 6}^{\circ} \mathbf{F}$ & $\mathbf{5 7}^{\circ} \mathbf{F}$ & $\mathbf{4 3}^{\circ} \mathbf{F}$ & $\mathbf{1 0 0 \%}$ & $\mathbf{6 6 \%}$ \\
\hline
\end{tabular}

\begin{tabular}{|lccc|}
\hline & KEY & \\
\hline & cold $\quad$ cool $\quad$ slightly cool & ○ neutral $\quad$ slightly warm $\quad$ warm $\quad$ hot \\
\hline
\end{tabular}

1 *Data taken from weatherunderground.com, where climate data is collected hourly; data relates to 11:53am.

${ }^{2}$ Data taken from weatherunderground.com, where climate data is collected hourly; data range relates to the start time of 9:53am. 


\section{Figure 9.}

Wednesday October 11th 10:15 - 11:20 Classroom 285
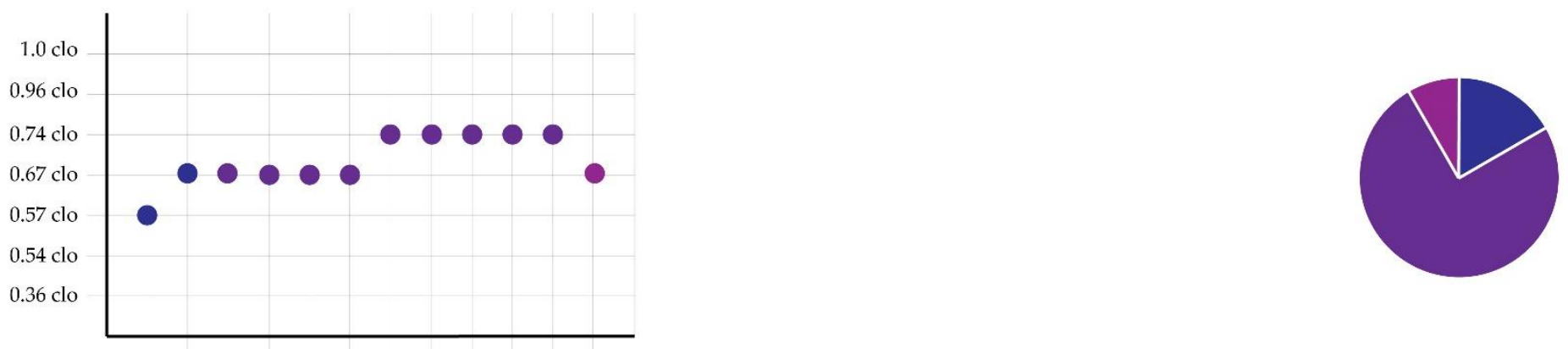

$\begin{array}{llllllllllll}\text { P1 } & \text { P2 } & \text { P3 } & \text { P4 } & \text { P5 } & \text { P6 } & \text { P7 } & \text { P8 } & \text { P9 } & \text { P10 } & \text { P11 } & \text { P12 }\end{array}$

\section{Figure 10.}

Wednesday October 11th 17:30-19:30 Classroom 480

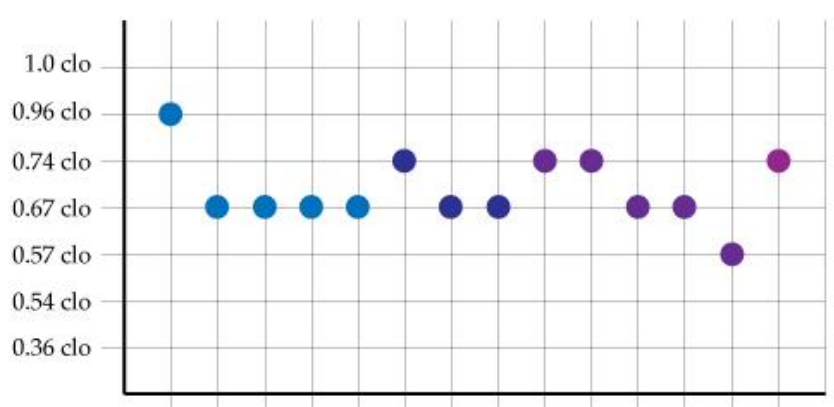

$\begin{array}{llllllllllllll}\text { P1 } & \text { P2 } & \text { P3 } & \text { P4 } & \text { P5 } & \text { P6 } & \text { P7 } & \text { P8 } & \text { P9 } & \text { P10 } & \text { P11 } & \text { P12 } & \text { P13 } & \text { P14 }\end{array}$

\section{Figure 11.}

Wednesday October 11th 17:40 - 21:20 Classroom 295

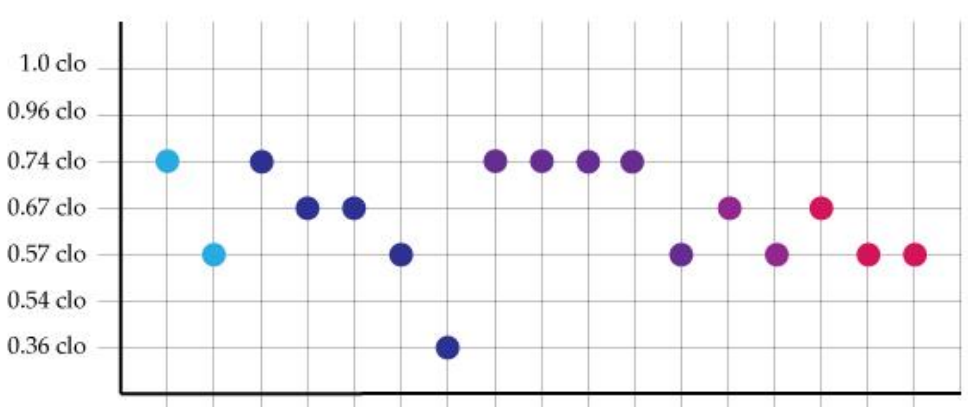

$\begin{array}{llllllllllllllllllllllllllll}\text { P1 } & \text { P2 } & \text { P3 } & \text { P4 } & \text { P5 } & \text { P6 } & \text { P7 } & \text { P8 } & \text { P9 } & \text { P10 } & \text { P11 } & \text { P12 } & \text { P13 } & \text { P14 } & \text { P15 } & \text { P16 } & \text { P17 }\end{array}$

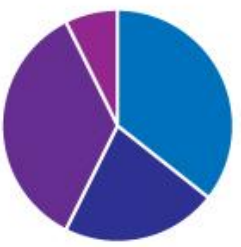

\section{OUTDOOR CLIMATE DATA: WEDNESDAY OCTOBER $1^{\mathrm{TH}}, 2017$}

\begin{tabular}{|c|c|c|c|c|}
\hline $\begin{array}{c}\text { Temp. at Time of } \\
\text { Survey Distribution }\end{array}$ & $\begin{array}{c}\text { Max. Temperature } \\
\text { (Entire Day) }\end{array}$ & $\begin{array}{c}\text { Min. Temperature } \\
\text { (Entire Day) }\end{array}$ & $\begin{array}{c}\text { Max. Humidity } \\
\text { (Entire Day) }\end{array}$ & $\begin{array}{c}\text { Min. Humidity } \\
\text { (Entire Day) }\end{array}$ \\
\hline $\mathbf{4 7 . 9}^{\circ} \mathbf{F}$ & $\mathbf{5 7}^{\circ} \mathbf{F}$ & $\mathbf{4 7}^{\circ} \mathbf{F}$ & $\mathbf{1 0 0 \%}$ & $\mathbf{6 1 \%}$ \\
\hline
\end{tabular}

${ }^{1}$ Data taken from weatherunderground.com, where climate data is collected hourly; data range relates to 4:53pm to 5:53pm. 


\section{Figure 12.}

Monday October 16th 17:30 - 21:10 Classroom 385

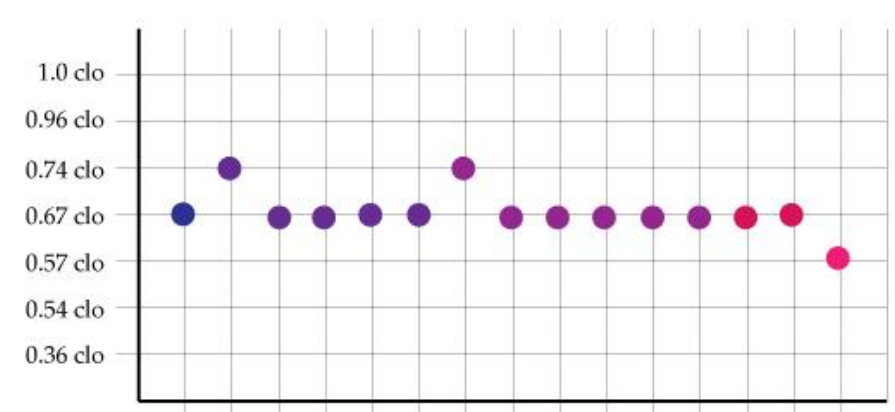

$\begin{array}{llllllllllllllllll}\text { P1 } & \text { P2 } & \text { P3 } & \text { P4 } & \text { P5 } & \text { P6 } & \text { P7 } & \text { P8 } & \text { P9 } & \text { P10 } & \text { P11 } & \text { P12 } & \text { P13 } & \text { P14 } & \text { P15 }\end{array}$

\section{Figure 13.}

\section{Monday October 16th $\quad 17: 40-21: 10 \quad$ Classroom 180}

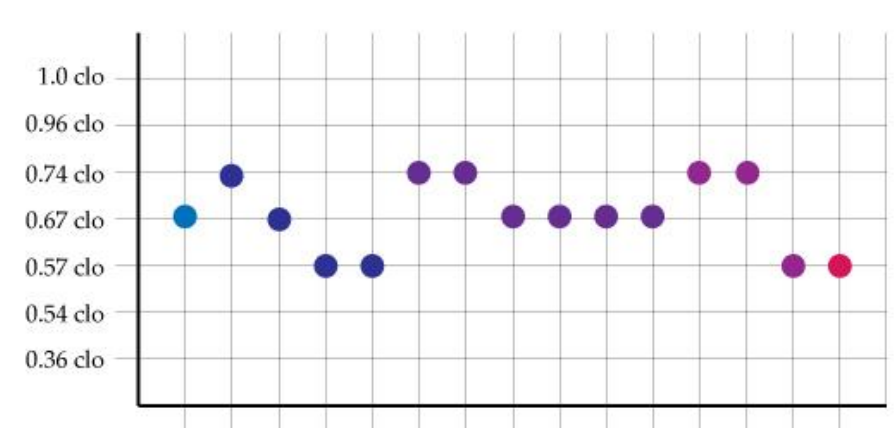

$\begin{array}{lllllllllllllllllllllll}\text { P1 } & \text { P2 } & \text { P3 } & \text { P4 } & \text { P5 } & \text { P6 } & \text { P7 } & \text { P8 } & \text { P9 } & \text { P10 } & \text { P11 } & \text { P12 } & \text { P13 } & \text { P14 } & \text { P15 }\end{array}$

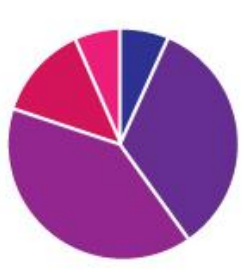

OUTDOOR CLIMATE DATA: MONDAY OCTOBER $16^{\mathrm{TH}}, 2017$

\begin{tabular}{|c|c|c|c|c|}
\hline $\begin{array}{c}\text { Temp. at Time of } \\
\text { Survey Distribution }\end{array}$ & $\begin{array}{c}\text { Max. Temperature } \\
\text { (Entire Day) }\end{array}$ & $\begin{array}{c}\text { Min. Temperature } \\
\text { (Entire Day) }\end{array}$ & $\begin{array}{c}\text { Max. Humidity } \\
\text { (Entire Day) }\end{array}$ & $\begin{array}{c}\text { Min. Humidity } \\
\text { (Entire Day) }\end{array}$ \\
\hline $\mathbf{6 5 . 4 5}^{\circ} \mathbf{F}$ & $\mathbf{6 7}^{\circ} \mathbf{F}$ & $\mathbf{3 9}^{\circ} \mathbf{F}$ & $\mathbf{1 0 0 \%}$ & $\mathbf{4 8 \%}$ \\
\hline
\end{tabular}

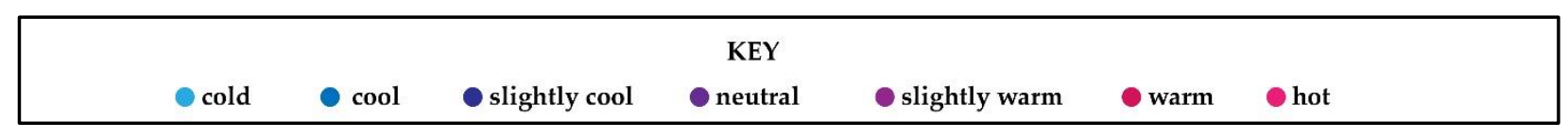

\footnotetext{
${ }^{1}$ Data taken from weatherunderground.com, where climate data is collected hourly; data range relates to 4:53pm to 5:53pm.
} 
Figure 14.

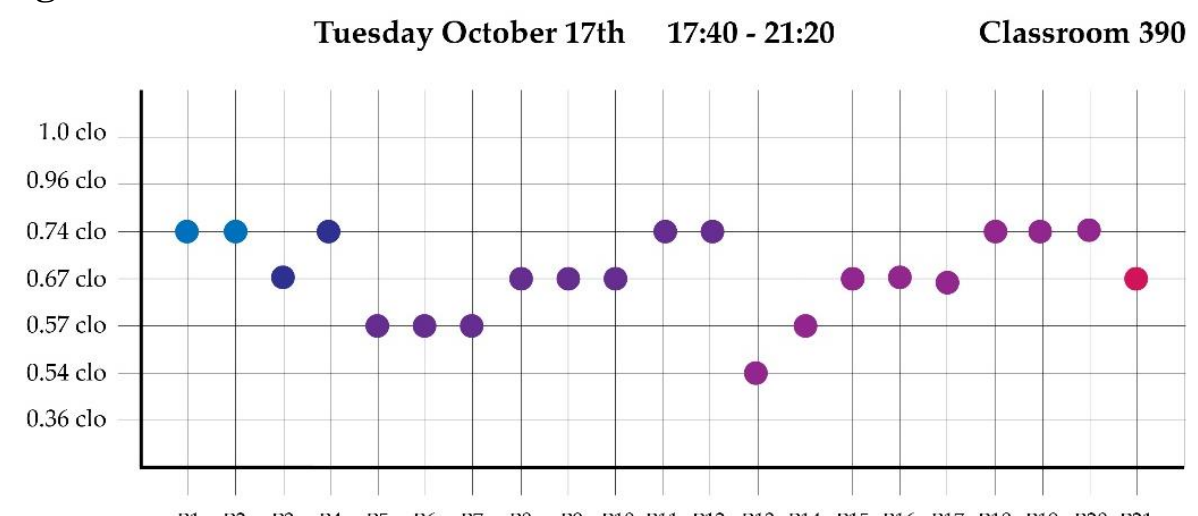

Classroom 390

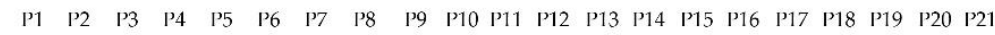

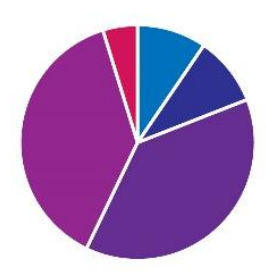

OUTDOOR CLIMATE DATA: TUESDAY OCTOBER $17^{\mathrm{TH}}, 2017$

\begin{tabular}{|c|c|c|c|c|}
\hline $\begin{array}{c}\text { Temp. at Time of } \\
\text { Survey Distribution }\end{array}$ & $\begin{array}{c}\text { Max. Temperature } \\
\text { (Entire Day) }\end{array}$ & $\begin{array}{c}\text { Min. Temperature } \\
\text { (Entire Day) }\end{array}$ & $\begin{array}{c}\text { Max. Humidity } \\
\text { (Entire Day) }\end{array}$ & $\begin{array}{c}\text { Min. Humidity } \\
\text { (Entire Day) }\end{array}$ \\
\hline $\mathbf{5 4 . 5}^{\circ} \mathbf{F}$ & $\mathbf{5 8}^{\circ} \mathbf{F}$ & $\mathbf{4 2}^{\circ} \mathbf{F}$ & $\mathbf{1 0 0 \%}$ & $\mathbf{7 2 \%}$ \\
\hline
\end{tabular}

Figure 15.

Wednesday October 18th $\quad$ 10:15 - 11:20 Classroom 285
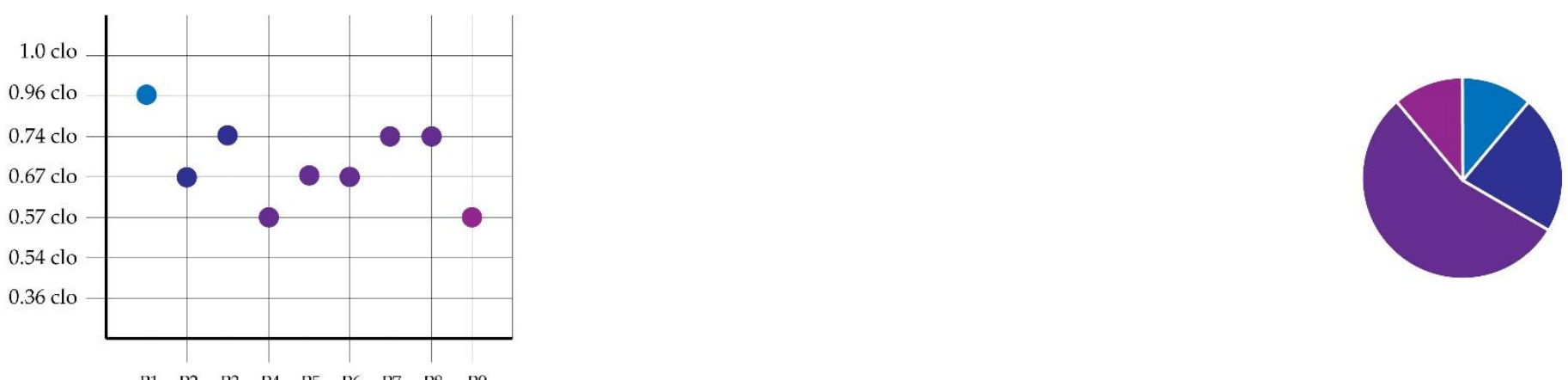

$\begin{array}{lllllllll}\text { P1 } & \text { P2 } & \text { P3 } & \text { P4 } & \text { P5 } & \text { P6 } & \text { P7 } & \text { P8 } & \text { P9 }\end{array}$

OUTDOOR CLIMATE DATA: WEDNESDAY OCTOBER $18^{\mathrm{TH}}, 2017$

\begin{tabular}{|c|c|c|c|c|}
\hline $\begin{array}{c}\text { Temp. at Time of } \\
\text { Survey Distribution }\end{array}$ & $\begin{array}{c}\text { Max. Temperature } \\
\text { (Entire Day) }\end{array}$ & $\begin{array}{c}\text { Min. Temperature } \\
\text { (Entire Day) }\end{array}$ & $\begin{array}{c}\text { Max. Humidity } \\
\text { (Entire Day) }\end{array}$ & $\begin{array}{c}\text { Min. Humidity } \\
\text { (Entire Day) }\end{array}$ \\
\hline $\mathbf{5 1 . 6}^{\circ} \mathbf{F}$ & $\mathbf{6 4}^{\circ} \mathbf{F}$ & $\mathbf{4 9}^{\circ} \mathbf{F}$ & $\mathbf{1 0 0 \%}$ & $\mathbf{7 2 \%}$ \\
\hline
\end{tabular}

\begin{tabular}{|ccc|}
\hline & KEY & \\
\hline & cold $\quad$ cool $\quad$ slightly cool & ○ neutral $\quad$ slightly warm $\quad$ warm $\quad$ hot \\
\hline
\end{tabular}

${ }^{1}$ Data taken from weatherunderground.com, where climate data is collected hourly; data range relates to 4:53pm to 5:53pm.

${ }^{2}$ Data taken from weatherunderground.com, where climate data is collected hourly; data relates to 9:53am to 10:53am. 
Figure 16.

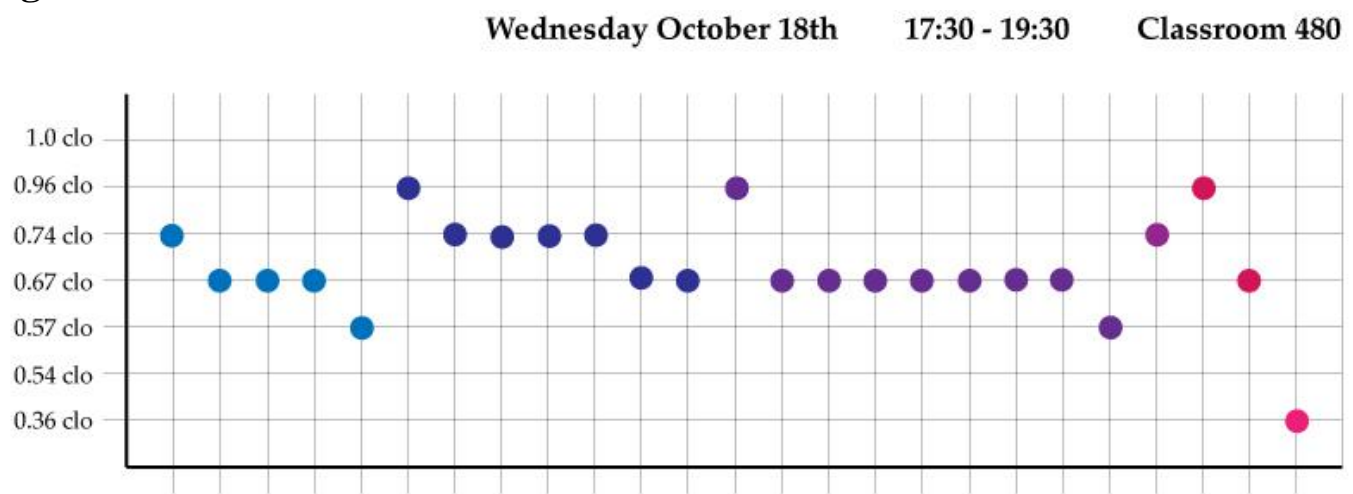

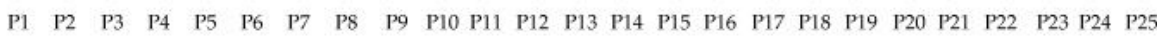

\section{Figure 17.}

Wednesday October 18th 17:40 - 21:10 Classroom 295

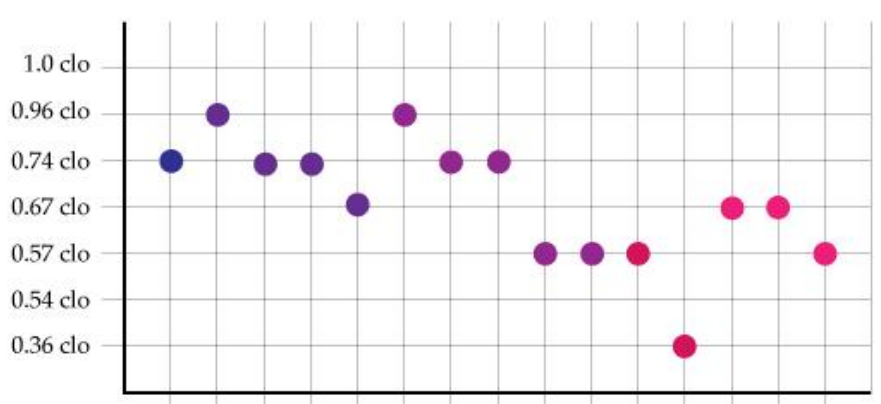

$\begin{array}{llllllllllllllllllllll}\text { P1 } & \text { P2 } & \text { P3 } & \text { P4 } & \text { P5 } & \text { P6 } & \text { P7 } & \text { P8 } & \text { P9 } & \text { P10 } & \text { P11 } & \text { P12 } & \text { P13 } & \text { P14 } & \text { P15 }\end{array}$

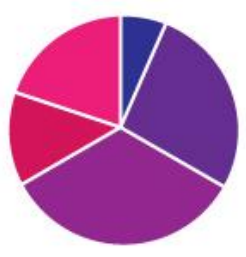

OUTDOOR CLIMATE DATA: WEDNESDAY OCTOBER $18^{\mathrm{TH}}, 2017$

\begin{tabular}{|c|c|c|c|c|}
\hline $\begin{array}{c}\text { Temp. at Time of } \\
\text { Survey Distribution }\end{array}$ & $\begin{array}{c}\text { Max. Temperature } \\
\text { (Entire Day) }\end{array}$ & $\begin{array}{c}\text { Min. Temperature } \\
\text { (Entire Day) }\end{array}$ & $\begin{array}{c}\text { Max. Humidity } \\
\text { (Entire Day) }\end{array}$ & $\begin{array}{c}\text { Min. Humidity } \\
\text { (Entire Day) }\end{array}$ \\
\hline $\mathbf{6 3 . 5}^{\circ} \mathbf{F}$ & $\mathbf{6 4}^{\circ} \mathbf{F}$ & $\mathbf{4 9}^{\circ} \mathbf{F}$ & $\mathbf{1 0 0 \%}$ & $\mathbf{7 2 \%}$ \\
\hline
\end{tabular}

\begin{tabular}{|c|c|c|c|c|c|c|}
\hline cold & cool & slightly cool & $\begin{array}{c}\text { KEY } \\
\text { neutral }\end{array}$ & slightly warm & warm & hot \\
\hline
\end{tabular}

${ }^{1}$ Data taken from weatherunderground.com, where climate data is collected hourly; data range relates to 4:53pm to 5:53pm. 
Figure 18.

Friday October 20th $\quad 12: 00-13: 50 \quad$ Classroom 380
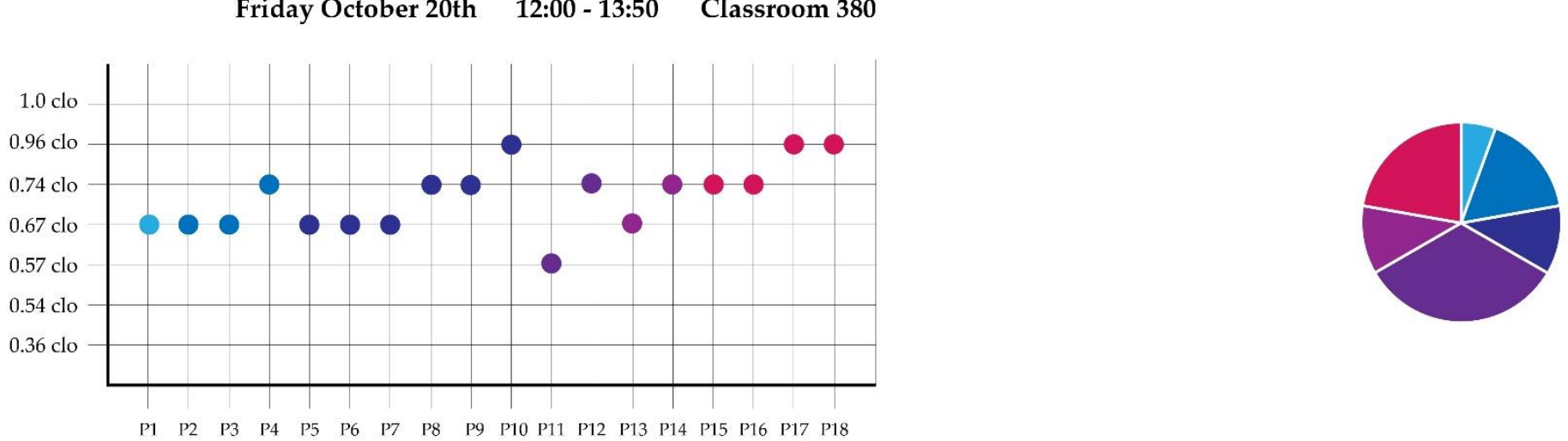

\section{OUTDOOR CLIMATE DATA: FRIDAY OCTOBER $20^{\mathrm{TH}}, 2017$}

\begin{tabular}{|c|c|c|c|c|}
\hline $\begin{array}{c}\text { Temp. at Time of } \\
\text { Survey Distribution }\end{array}$ & $\begin{array}{c}\text { Max. Temperature } \\
\text { (Entire Day) }\end{array}$ & $\begin{array}{c}\text { Min. Temperature } \\
\text { (Entire Day) }\end{array}$ & $\begin{array}{c}\text { Max. Humidity } \\
\text { (Entire Day) }\end{array}$ & $\begin{array}{c}\text { Min. Humidity } \\
\text { (Entire Day) }\end{array}$ \\
\hline $\mathbf{5 1 . 8}^{\circ} \mathbf{F}$ & $\mathbf{5 4}^{\circ} \mathbf{F}$ & $\mathbf{4 8}^{\circ} \mathbf{F}$ & $\mathbf{9 3 \%}$ & $\mathbf{8 0 \%}$ \\
\hline
\end{tabular}

Figure 19.

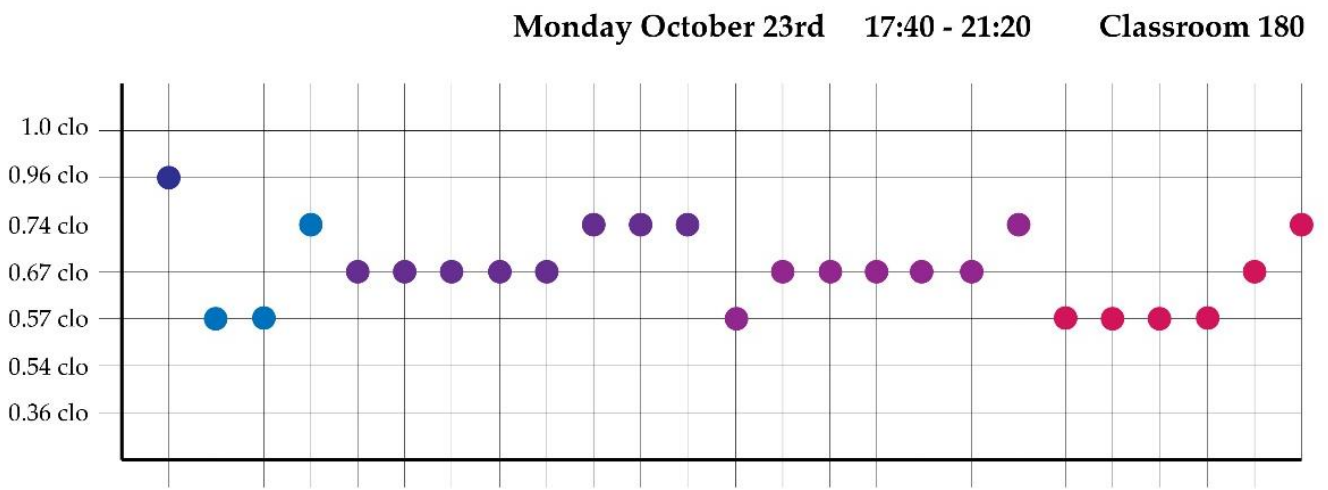

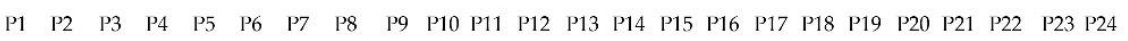

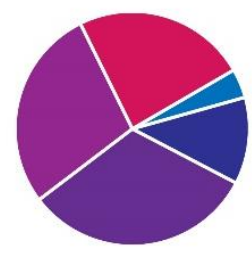

\section{OUTDOOR CLIMATE DATA: MONDAY OCTOBER 23 ${ }^{\mathrm{RD}}, 2017$}

\begin{tabular}{|c|c|c|c|c|}
\hline $\begin{array}{c}\text { Temp. at Time of } \\
\text { Survey Distribution }\end{array}$ & $\begin{array}{c}\text { Max. Temperature } \\
\text { (Entire Day) }\end{array}$ & $\begin{array}{c}\text { Min. Temperature } \\
\text { (Entire Day) }\end{array}$ & $\begin{array}{c}\text { Max. Humidity } \\
\text { (Entire Day) }\end{array}$ & $\begin{array}{c}\text { Min. Humidity } \\
\text { (Entire Day) }\end{array}$ \\
\hline $\mathbf{6 2 . 6}^{\circ} \mathbf{F}$ & $\mathbf{6 4}^{\circ} \mathbf{F}$ & $\mathbf{4 8}^{\circ} \mathbf{F}$ & $\mathbf{1 0 0 \%}$ & $\mathbf{6 3 \%}$ \\
\hline
\end{tabular}

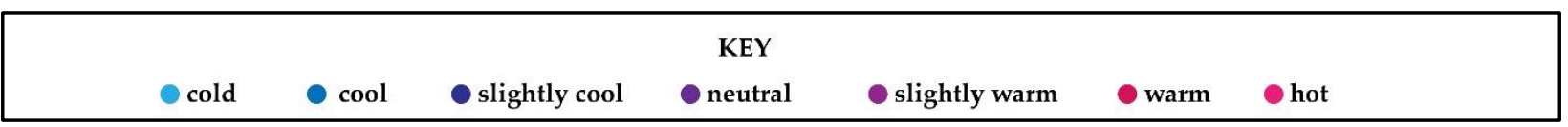

${ }^{1}$ Data taken from weatherunderground.com, where climate data is collected hourly; data range relates to 4:53pm to 5:53pm.

${ }^{2}$ Data taken from weatherunderground.com, where climate data is collected hourly; data range relates to 4:53pm to 5:53pm. 
Figure 20.
Monday October 30th
$17: 30-21: 10$
Classroom 385

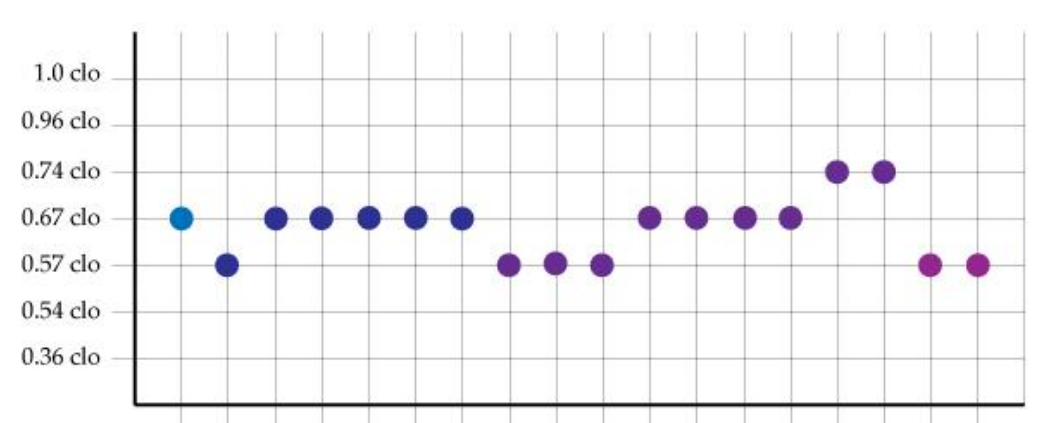

$\begin{array}{lllllllllllllllllllllllllllllllll}\text { P1 } & \text { P2 } & \text { P3 } & \text { P4 } & \text { P5 } & \text { P6 } & \text { P7 } & \text { P8 } & \text { P9 } & \text { P10 } & \text { P11 } & \text { P12 } & \text { P13 } & \text { P14 } & \text { P15 } & \text { P16 } & \text { P17 } & \text { P18 }\end{array}$

\section{Figure 21.}

\section{Monday October 30th 17:40 - 21:10 Classroom 180}

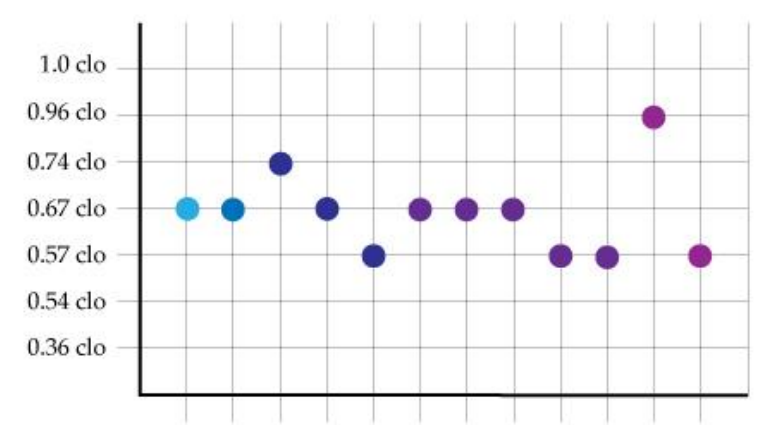

$\begin{array}{llllllllllllll}\text { P1 } & \text { P2 } & \text { P3 } & \text { P4 } & \text { P5 } & \text { P6 } & \text { P7 } & \text { P8 } & \text { P9 } & \text { P10 } & \text { P11 } & \text { P12 }\end{array}$

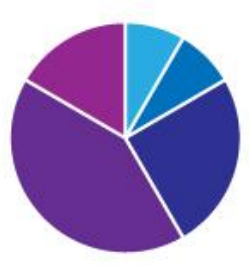

OUTDOOR CLIMATE DATA: MONDAY OCTOBER 30 ${ }^{\mathrm{TH}}, 2017$

\begin{tabular}{|c|c|c|c|c|}
\hline $\begin{array}{c}\text { Temp. at Time of } \\
\text { Survey Distribution }\end{array}$ & $\begin{array}{c}\text { Max. Temperature } \\
\text { (Entire Day) }\end{array}$ & $\begin{array}{c}\text { Min. Temperature } \\
\text { (Entire Day) }\end{array}$ & $\begin{array}{c}\text { Max. Humidity } \\
\text { (Entire Day) }\end{array}$ & $\begin{array}{c}\text { Min. Humidity } \\
\text { (Entire Day) }\end{array}$ \\
\hline $\mathbf{5 9 . 6}^{\circ} \mathbf{F}$ & $\mathbf{6 3}^{\circ} \mathbf{F}$ & $\mathbf{4 9}^{\circ} \mathbf{F}$ & $\mathbf{8 6 \%}$ & $\mathbf{2 3 \%}$ \\
\hline
\end{tabular}

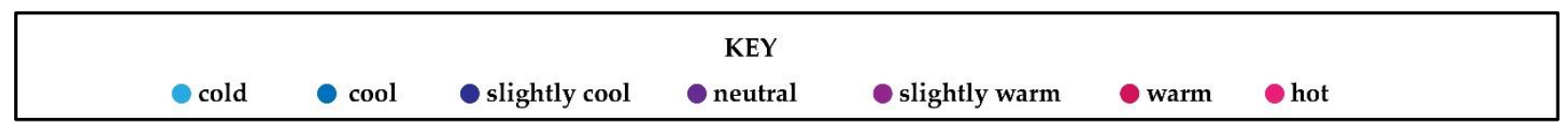

\footnotetext{
${ }^{1}$ Data taken from weatherunderground.com, where climate data is collected hourly; data range relates to 4:53pm to 5:53pm.
} 
Figure 22.

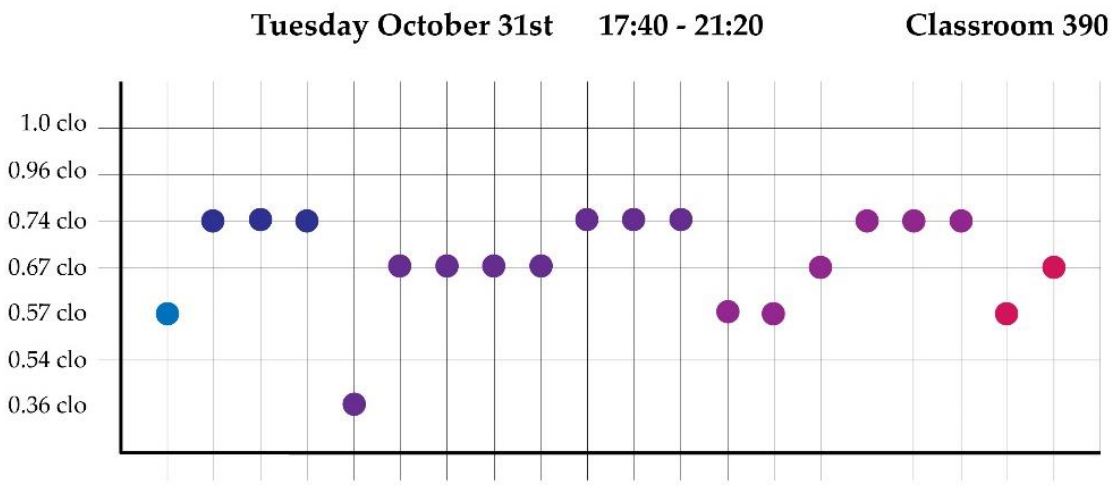

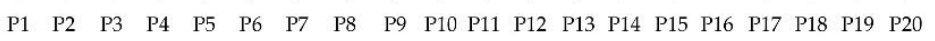

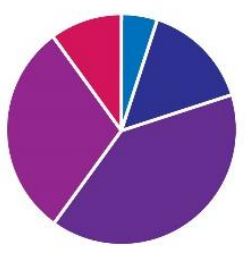

\section{OUTDOOR CLIMATE DATA: TUESDAY OCTOBER 31 ${ }^{\mathrm{ST}}, 2017$}

\begin{tabular}{|c|c|c|c|c|}
\hline $\begin{array}{c}\text { Temp. at Time of } \\
\text { Survey Distribution }\end{array}$ & $\begin{array}{c}\text { Max. Temperature } \\
\text { (Entire Day) }\end{array}$ & $\begin{array}{c}\text { Min. Temperature } \\
\text { (Entire Day) }\end{array}$ & $\begin{array}{c}\text { Max. Humidity } \\
\text { (Entire Day) }\end{array}$ & $\begin{array}{c}\text { Min. Humidity } \\
\text { (Entire Day) }\end{array}$ \\
\hline $\mathbf{6 0}^{\circ} \mathbf{F}$ & $\mathbf{6 2}^{\circ} \mathbf{F}$ & $\mathbf{3 5}^{\circ} \mathbf{F}$ & $\mathbf{9 2 \%}$ & $\mathbf{3 3 \%}$ \\
\hline
\end{tabular}

\section{Figure 23.}

Wednesday November 1st 10:15 - 11:20 Classroom 285
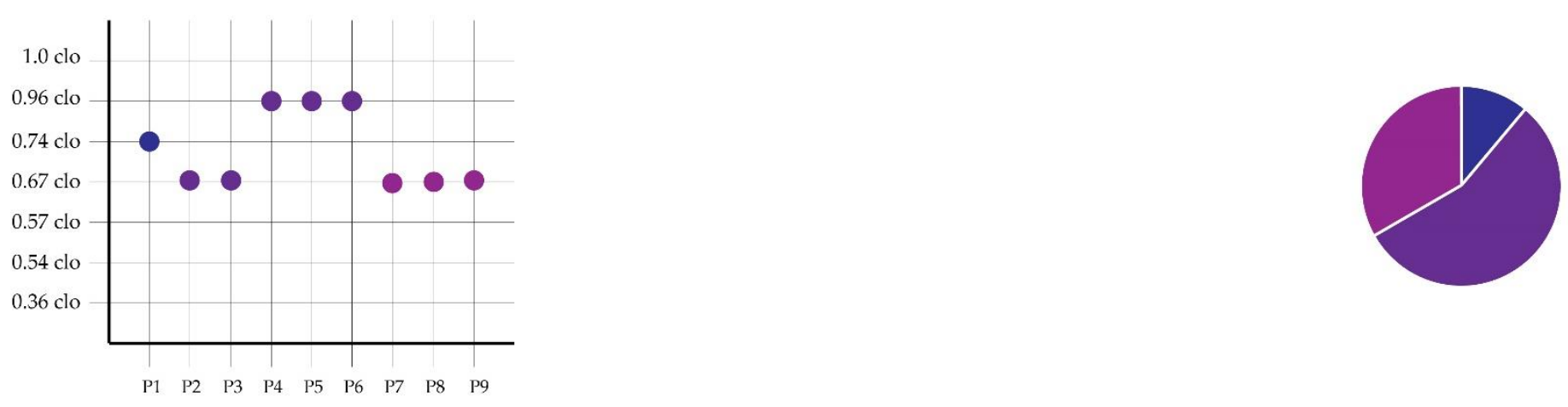

\section{OUTDOOR CLIMATE DATA: WEDNESDAY NOVEMBER 1 ${ }^{\text {ST }}, 2017$}

\begin{tabular}{|c|c|c|c|c|}
\hline $\begin{array}{c}\text { Temp. at Time of } \\
\text { Survey Distribution }\end{array}$ & $\begin{array}{c}\text { Max. Temperature } \\
\text { (Entire Day) }\end{array}$ & $\begin{array}{c}\text { Min. Temperature } \\
\text { (Entire Day) }\end{array}$ & $\begin{array}{c}\text { Max. Humidity } \\
\text { (Entire Day) }\end{array}$ & $\begin{array}{c}\text { Min. Humidity } \\
\text { (Entire Day) }\end{array}$ \\
\hline $\mathbf{5 3 . 5}^{\circ} \mathbf{F}$ & $\mathbf{5 8}^{\circ} \mathbf{F}$ & $\mathbf{4 7}^{\circ} \mathbf{F}$ & $\mathbf{8 6 \%}$ & $\mathbf{5 7 \%}$ \\
\hline
\end{tabular}

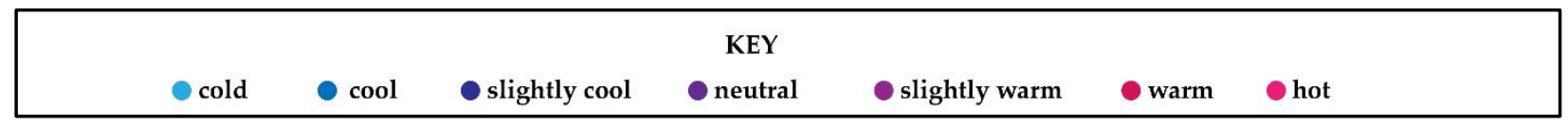

\footnotetext{
${ }^{1}$ Data taken from weatherunderground.com, where climate data is collected hourly; data range relates to 4:53pm to 5:53pm.

${ }^{2}$ Data taken from weatherunderground.com, where climate data is collected hourly; data relates to 9:53am to 10:53am.
} 
Figure 24.

Wednesday November 1st $\quad$ 17:30 - 19:30 Classroom 480

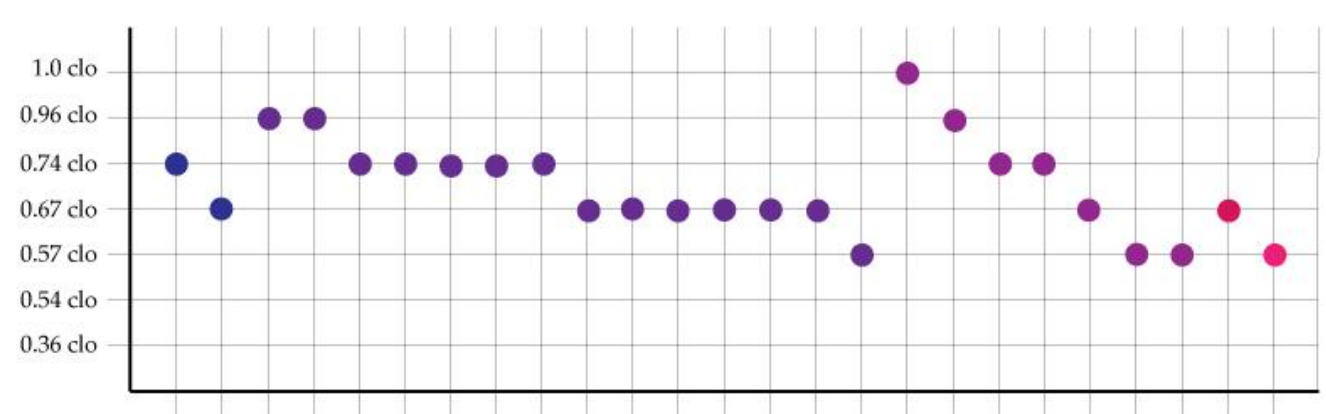

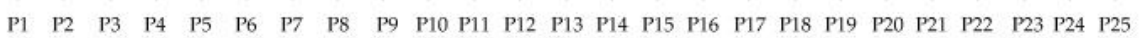

Figure 25.

Wednesday November 1st 17:30-21:20 Classroom 290

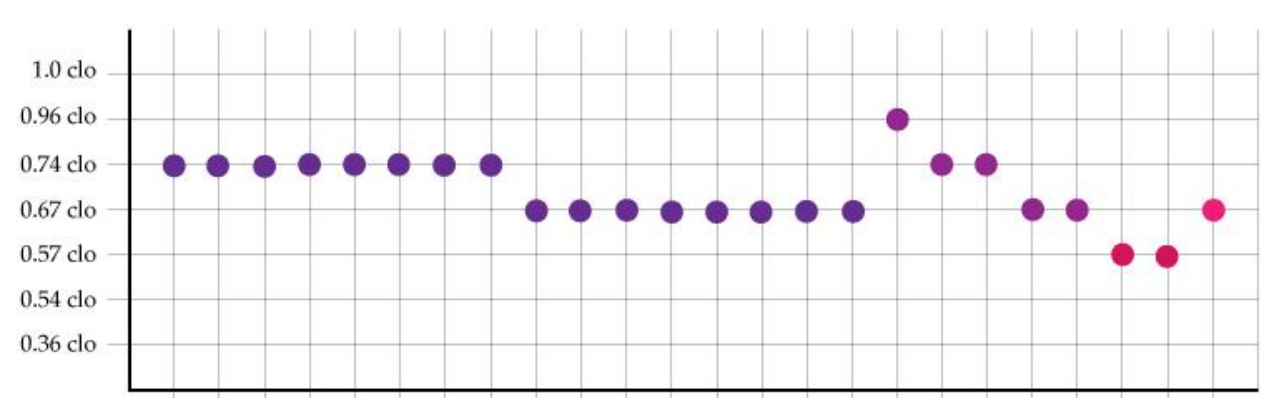

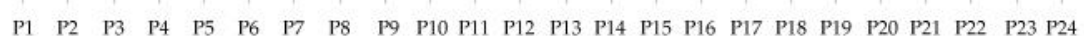

Figure 26.

Wednesday November 1st 17:40 - 21:10 Classroom 295
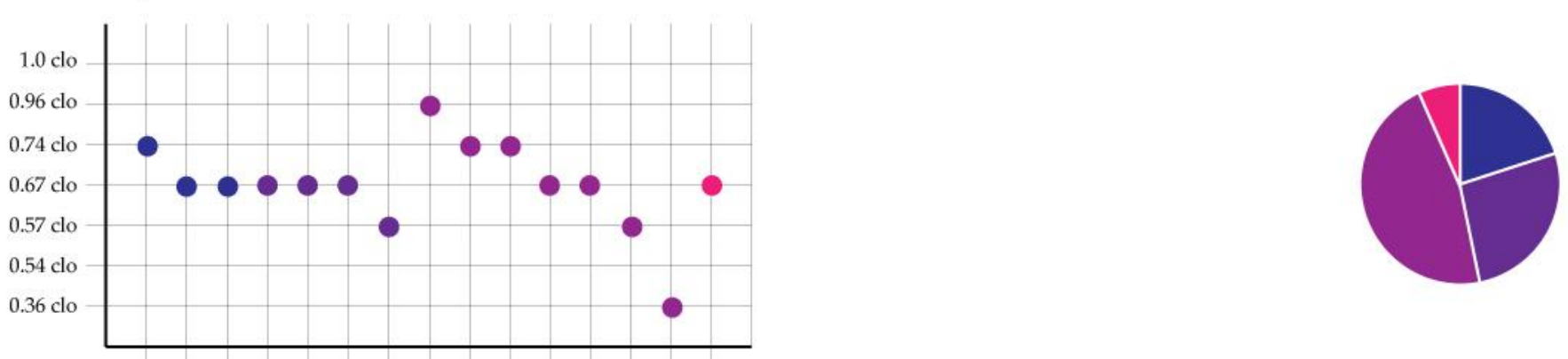

$\begin{array}{llllllllllllllll}\text { P1 } & \text { P2 } & \text { P3 } & \text { P4 } & \text { P5 } & \text { P6 } & \text { P7 } & \text { P8 } & \text { P9 } & \text { P10 } & \text { P11 } & \text { P12 } & \text { P13 } & \text { P14 } & \text { P15 }\end{array}$

OUTDOOR CLIMATE DATA: WEDNESDAY NOVEMBER $1^{\text {ST }}, 2017$

\begin{tabular}{|c|c|c|c|c|}
\hline $\begin{array}{c}\text { Temp. at Time of } \\
\text { Survey Distribution }\end{array}$ & $\begin{array}{c}\text { Max. Temperature } \\
\text { (Entire Day) }\end{array}$ & $\begin{array}{c}\text { Min. Temperature } \\
\text { (Entire Day) }\end{array}$ & $\begin{array}{c}\text { Max. Humidity } \\
\text { (Entire Day) }\end{array}$ & $\begin{array}{c}\text { Min. Humidity } \\
\text { (Entire Day) }\end{array}$ \\
\hline $\mathbf{5 4}^{\circ} \mathbf{F}$ & $\mathbf{5 8}^{\circ} \mathbf{F}$ & $\mathbf{4 7}^{\circ} \mathbf{F}$ & $\mathbf{8 6 \%}^{\circ}$ & $\mathbf{5 7 \%}$ \\
\hline
\end{tabular}

${ }^{1}$ Data taken from weatherunderground.com, where climate data is collected hourly; data range relates to 4:53pm to 5:53pm. 


\section{Figure 27.}

Friday November 3rd 12:00 - 13:50 Classroom 380
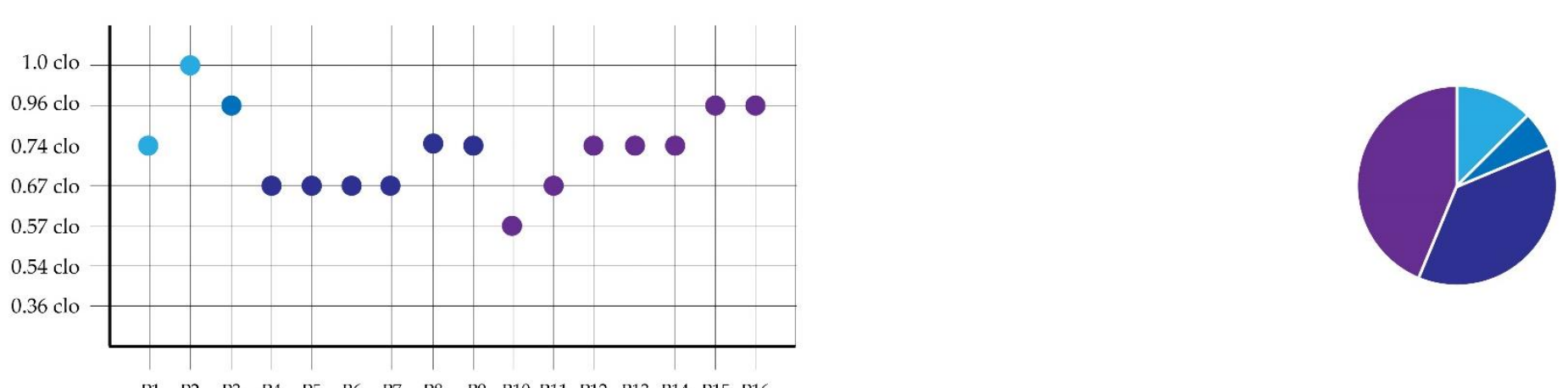

\section{OUTDOOR CLIMATE DATA: FRIDAY NOVEMBER $3^{\mathrm{RD}}, 2017$}

\begin{tabular}{|c|c|c|c|c|}
\hline $\begin{array}{c}\text { Temp. at Time of } \\
\text { Survey Distribution }\end{array}$ & $\begin{array}{c}\text { Max. Temperature } \\
\text { (Entire Day) }\end{array}$ & $\begin{array}{c}\text { Min. Temperature } \\
\text { (Entire Day) }\end{array}$ & $\begin{array}{c}\text { Max. Humidity } \\
\text { (Entire Day) }\end{array}$ & $\begin{array}{c}\text { Min. Humidity } \\
\text { (Entire Day) }\end{array}$ \\
\hline $\mathbf{4 6 . 5}^{\circ} \mathbf{F}$ & $\mathbf{5 0}^{\circ} \mathbf{F}$ & $\mathbf{4 3}^{\circ} \mathbf{F}$ & $\mathbf{8 9 \%}$ & $\mathbf{6 1 \%}$ \\
\hline
\end{tabular}

\footnotetext{
${ }^{1}$ Data taken from weatherunderground.com, where climate data is collected hourly; data range relates to 4:53pm to 5:53pm..
} 
Figure 28.

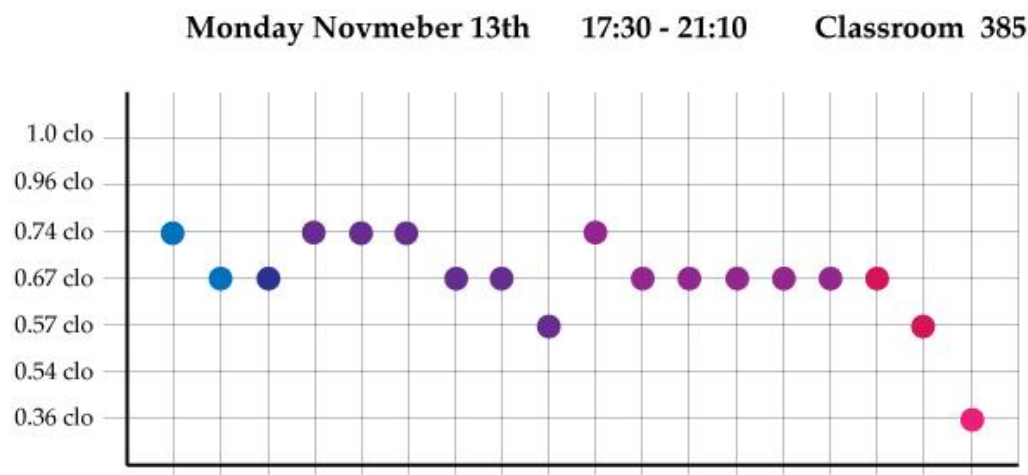

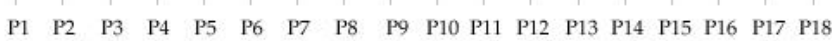

Figure 29.

Monday November 13th $\quad 17: 40-21: 10 \quad$ Classroom 180

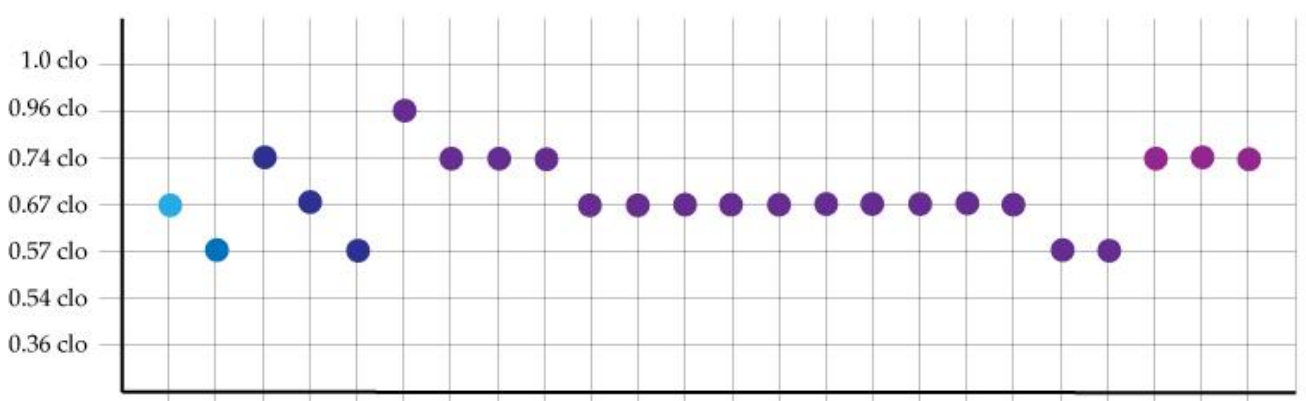

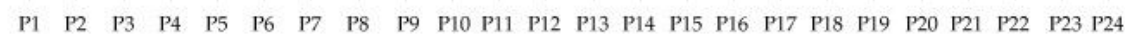

OUTDOOR CLIMATE DATA: MONDAY NOVEMBER $13^{\mathrm{TH}}, 2017$

\begin{tabular}{|c|c|c|c|c|}
\hline $\begin{array}{c}\text { Temp. at Time of } \\
\text { Survey Distribution }\end{array}$ & $\begin{array}{c}\text { Max. Temperature } \\
\text { (Entire Day) }\end{array}$ & $\begin{array}{c}\text { Min. Temperature } \\
\text { (Entire Day) }\end{array}$ & $\begin{array}{c}\text { Max. Humidity } \\
\text { (Entire Day) }\end{array}$ & $\begin{array}{c}\text { Min. Humidity } \\
\text { (Entire Day) }\end{array}$ \\
\hline $\mathbf{5 0 . 6}^{\circ} \mathbf{F}$ & $\mathbf{5 6}^{\circ} \mathbf{F}$ & $\mathbf{4 8}^{\circ} \mathbf{F}$ & $\mathbf{9 3 \%}$ & $\mathbf{6 6 \%}$ \\
\hline
\end{tabular}

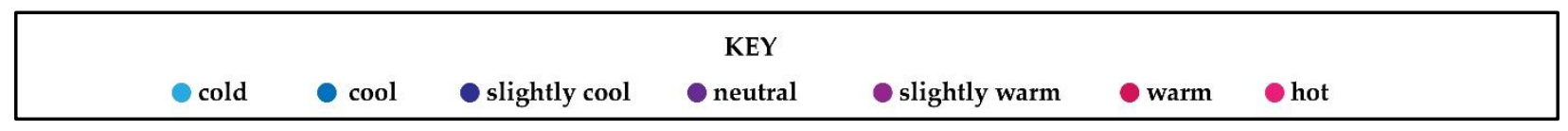

\footnotetext{
${ }^{1}$ Data taken from weatherunderground.com, where climate data is collected hourly; data range relates to 4:53pm to 5:53pm..
} 
Figure 30.

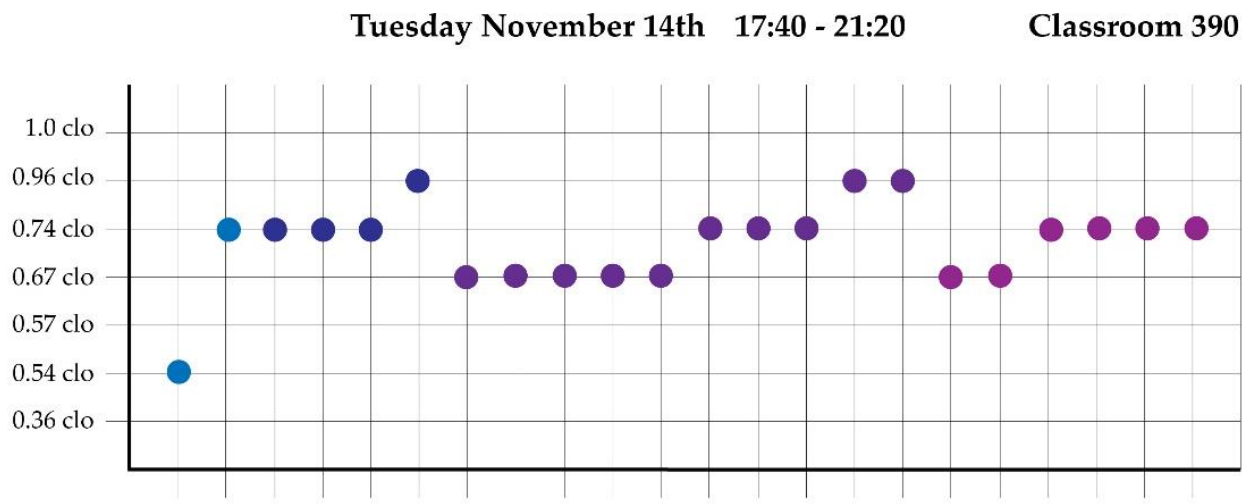

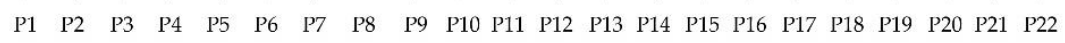

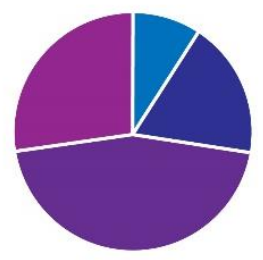

OUTDOOR CLIMATE DATA: WEDNESDAY NOVEMBER 14 ${ }^{\mathrm{TH}}, 2017$

\begin{tabular}{|c|c|c|c|c|}
\hline $\begin{array}{c}\text { Temp. at Time of } \\
\text { Survey Distribution }\end{array}$ & $\begin{array}{c}\text { Max. Temperature } \\
\text { (Entire Day) }\end{array}$ & $\begin{array}{c}\text { Min. Temperature } \\
\text { (Entire Day) }\end{array}$ & $\begin{array}{c}\text { Max. Humidity } \\
\text { (Entire Day) }\end{array}$ & $\begin{array}{c}\text { Min. Humidity } \\
\text { (Entire Day) }\end{array}$ \\
\hline $\mathbf{5 4 . 5}^{\circ} \mathbf{F}$ & $\mathbf{5 8}^{\circ} \mathbf{F}$ & $\mathbf{4 5}^{\circ} \mathbf{F}$ & $\mathbf{8 6 \%}$ & $\mathbf{4 3 \%}$ \\
\hline
\end{tabular}

\section{Figure 31.}

Wednesday November 15th 10:15 - 11:20 Classroom 285
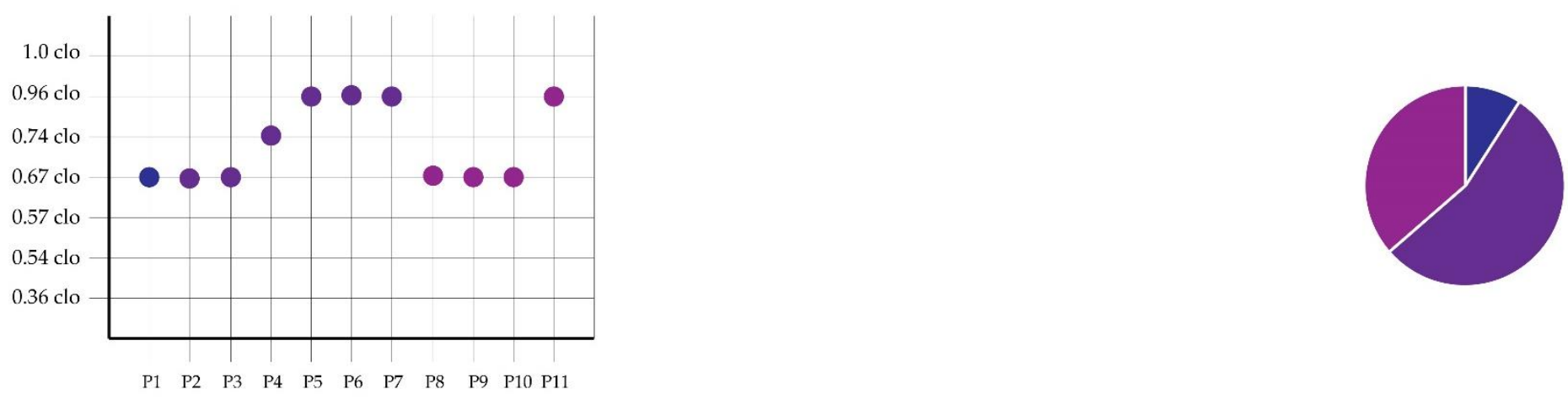

OUTDOOR CLIMATE DATA: WEDNESDAY NOVEMBER 15 ${ }^{\mathrm{TH}}, 2017$

\begin{tabular}{|c|c|c|c|c|}
\hline $\begin{array}{c}\text { Temp. at Time of } \\
\text { Survey Distribution }\end{array}$ & $\begin{array}{c}\text { Max. Temperature } \\
\text { (Entire Day) }\end{array}$ & $\begin{array}{c}\text { Min. Temperature } \\
\text { (Entire Day) }\end{array}$ & $\begin{array}{c}\text { Max. Humidity } \\
\text { (Entire Day) }\end{array}$ & $\begin{array}{c}\text { Min. Humidity } \\
\text { (Entire Day) }\end{array}$ \\
\hline $\mathbf{4 6 . 5}^{\circ} \mathbf{F}$ & $\mathbf{5 6}^{\circ} \mathbf{F}$ & $\mathbf{4 3}^{\circ} \mathbf{F}$ & $\mathbf{1 0 0 \%}$ & $\mathbf{4 7 \%}^{\circ}$ \\
\hline
\end{tabular}

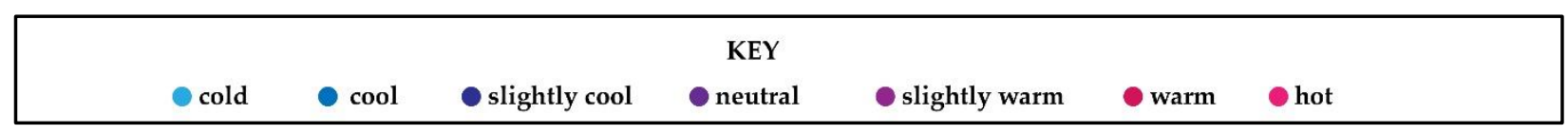

${ }^{1}$ Data taken from weatherunderground.com, where climate data is collected hourly; data relates to 9:53am to 10:53am.

${ }^{2}$ Data taken from weatherunderground.com, where climate data is collected hourly; data relates to 9:53am to 10:53am. 
Figure 32.

Wednesday November 15th

$17: 30-19: 30$

Classroom 480

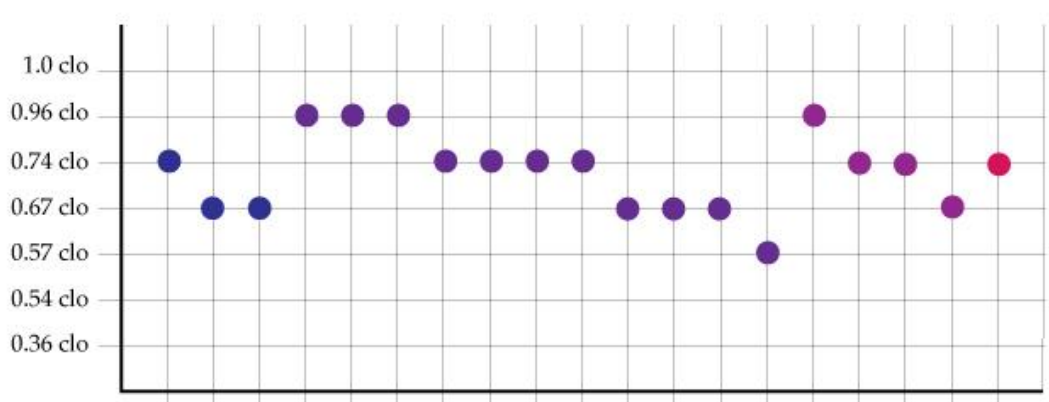

$\begin{array}{llllllllllllllllllllllllllll}\text { P1 } & \text { P2 } & \text { P3 } & \text { P4 } & \text { P5 } & \text { P6 } & \text { P7 } & \text { P8 } & \text { P9 } & \text { P10 } & \text { P11 } & \text { P12 } & \text { P13 } & \text { P14 } & \text { P15 } & \text { P16 } & \text { P17 } & \text { P18 } & \text { P19 }\end{array}$

Figure 33.
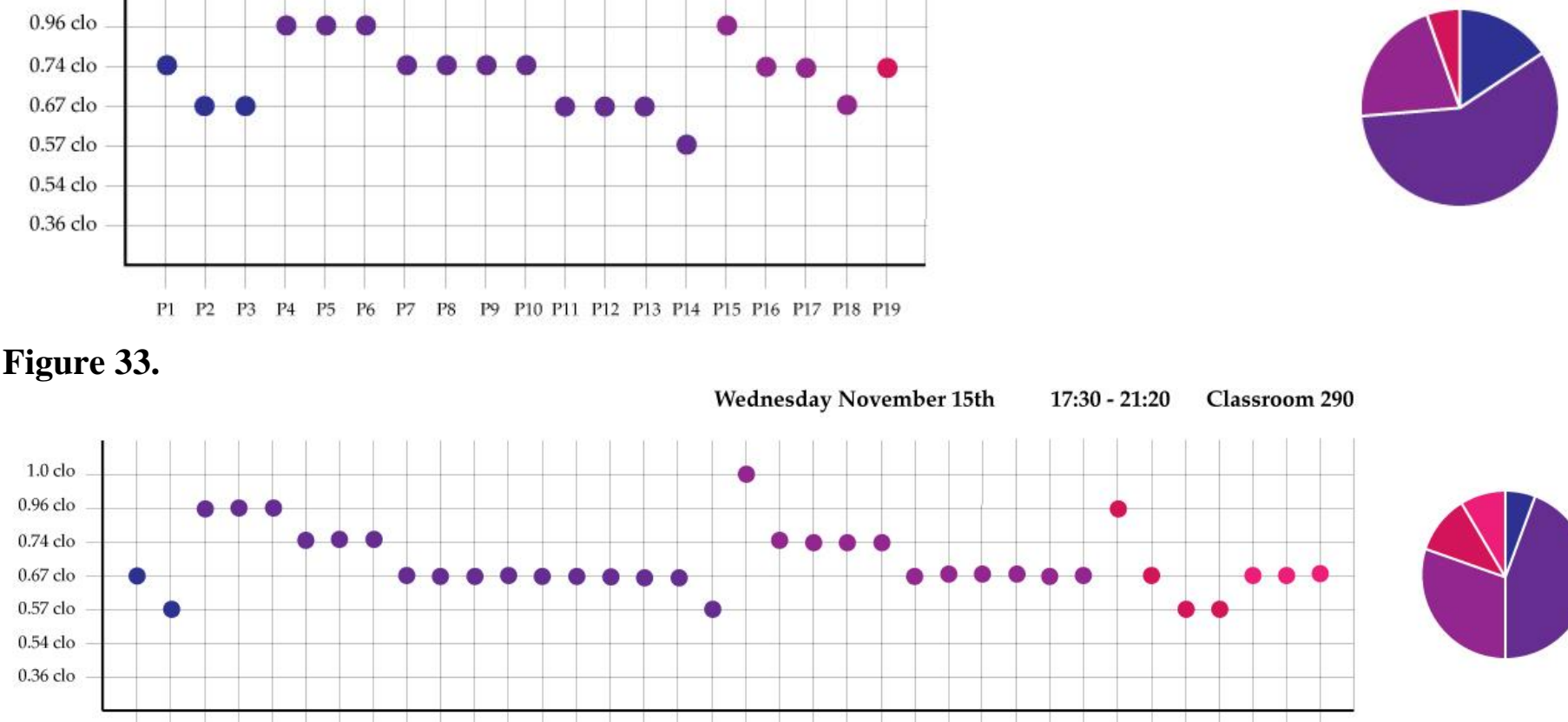

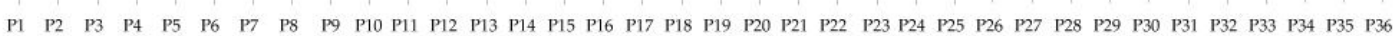

Figure 34.

Wednesday November 15th 17:40 - 21:10 Classroom 295

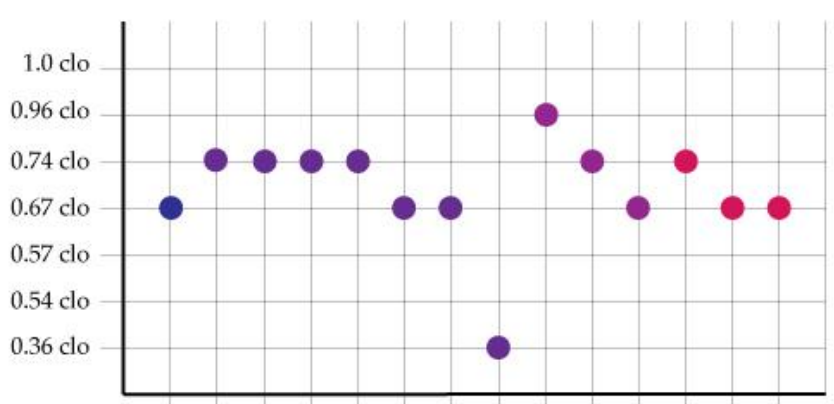

$\begin{array}{lllllllllllllll}\text { P1 } & \text { P2 } & \text { P3 } & \text { P4 } & \text { P5 } & \text { P6 } & \text { P7 } & \text { P8 } & \text { P9 } & \text { P10 } & \text { P11 } & \text { P12 } & \text { P13 } & \text { P14 }\end{array}$

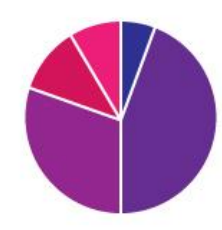

\section{OUTDOOR CLIMATE DATA: WEDNESDAY NOVEMBER 15 ${ }^{\mathrm{TH}}, 2017$}

\begin{tabular}{|c|c|c|c|c|}
\hline $\begin{array}{c}\text { Temp. at Time of } \\
\text { Survey Distribution }\end{array}$ & $\begin{array}{c}\text { Max. Temperature } \\
\text { (Entire Day) }\end{array}$ & $\begin{array}{c}\text { Min. Temperature } \\
\text { (Entire Day) }\end{array}$ & $\begin{array}{c}\text { Max. Humidity } \\
\text { (Entire Day) }\end{array}$ & $\begin{array}{c}\text { Min. Humidity } \\
\text { (Entire Day) }\end{array}$ \\
\hline $\mathbf{4 4}^{\circ} \mathbf{F}$ & $\mathbf{5 6}^{\circ} \mathbf{F}$ & $\mathbf{4 3}^{\circ} \mathbf{F}$ & $\mathbf{1 0 0 \%}$ & $\mathbf{4 7 \%}$ \\
\hline
\end{tabular}

\begin{tabular}{|cccc|}
\hline & KEY & \\
& & & \\
\hline & cold $\quad$ cool $\quad$ slightly cool & ○ neutral $\quad$ slightly warm $\quad$ warm $\quad$ hot \\
\hline
\end{tabular}

${ }^{1}$ Data taken from weatherunderground.com, where climate data is collected hourly; data range relates to 4:53pm to 5:53pm. 


\section{Figure 35.}

Monday November 20th 17:40 - 21:20 Classroom 180
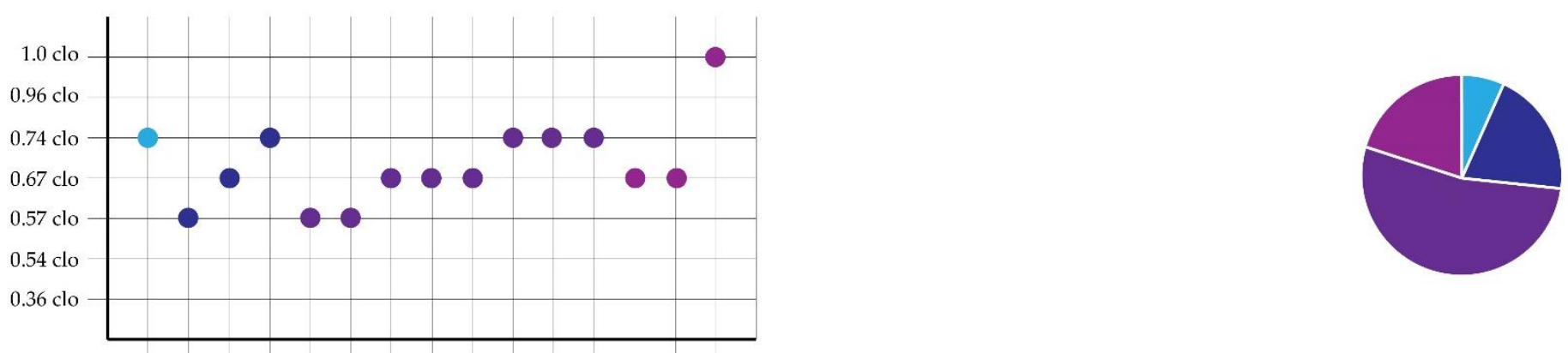

$\begin{array}{lllllllllllllll}\text { P1 } & \text { P2 } & \text { P3 } & \text { P4 } & \text { P5 } & \text { P6 } & \text { P7 } & \text { P8 } & \text { P9 } & \text { P10 } & \text { P11 } & \text { P12 } & \text { P13 } & \text { P14 } & \text { P15 }\end{array}$

OUTDOOR CLIMATE DATA: MONDAY NOVEMBER 20 ${ }^{\mathrm{TH}}, 2017$

\begin{tabular}{|c|c|c|c|c|}
\hline $\begin{array}{c}\text { Temp. at Time of } \\
\text { Survey Distribution }\end{array}$ & $\begin{array}{c}\text { Max. Temperature } \\
\text { (Entire Day) }\end{array}$ & $\begin{array}{c}\text { Min. Temperature } \\
\text { (Entire Day) }\end{array}$ & $\begin{array}{c}\text { Max. Humidity } \\
\text { (Entire Day) }\end{array}$ & $\begin{array}{c}\text { Min. Humidity } \\
\text { (Entire Day) }\end{array}$ \\
\hline $\mathbf{4 9 . 6}^{\circ} \mathbf{F}$ & $\mathbf{5 6}^{\circ} \mathbf{F}$ & $\mathbf{4 6}^{\circ} \mathbf{F}$ & $\mathbf{1 0 0 \%}$ & $\mathbf{7 2 \%}$ \\
\hline
\end{tabular}

Figure 36.
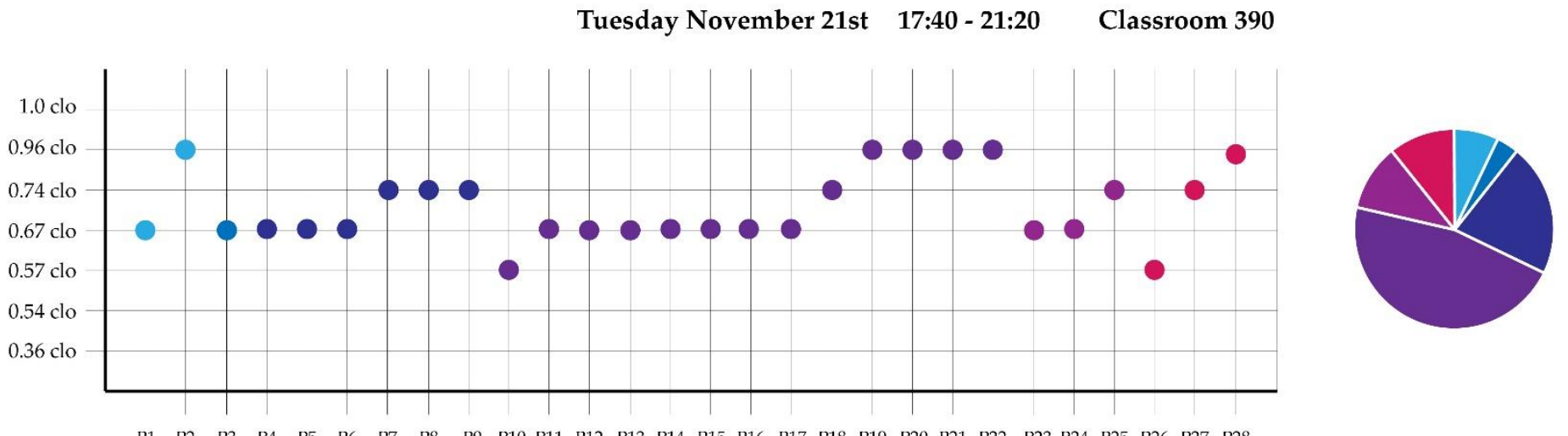

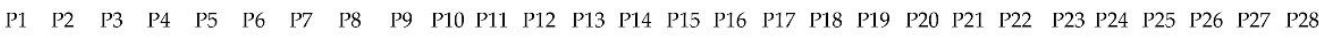

OUTDOOR CLIMATE DATA: TUESDAY NOVEMBER 21 ${ }^{\mathrm{ST}}, 2017$

\begin{tabular}{|c|c|c|c|c|}
\hline $\begin{array}{c}\text { Temp. at Time of } \\
\text { Survey Distribution }\end{array}$ & $\begin{array}{c}\text { Max. Temperature } \\
\text { (Entire Day) }\end{array}$ & $\begin{array}{c}\text { Min. Temperature } \\
\text { (Entire Day) }\end{array}$ & $\begin{array}{c}\text { Max. Humidity } \\
\text { (Entire Day) }\end{array}$ & $\begin{array}{c}\text { Min. Humidity } \\
\text { (Entire Day) }\end{array}$ \\
\hline $\mathbf{4 8 . 9}^{\circ} \mathbf{F}$ & $\mathbf{5 1}^{\circ} \mathbf{F}$ & $\mathbf{4 5}^{\circ} \mathbf{F}$ & $\mathbf{1 0 0 \%}$ & $\mathbf{8 3 \%}$ \\
\hline
\end{tabular}

\begin{tabular}{|c|c|c|c|c|c|c|}
\hline cold & cool & slightly cool & $\begin{array}{c}\text { KEY } \\
\text { neutral }\end{array}$ & slightly warm & warm & hot \\
\hline
\end{tabular}

${ }^{1}$ Data taken from weatherunderground.com, where climate data is collected hourly; data range relates to 4:53pm to 5:53pm.

${ }^{2}$ Data taken from weatherunderground.com, where climate data is collected hourly; data range relates to 4:53pm to 5:53pm. 


\section{Figure 37.}
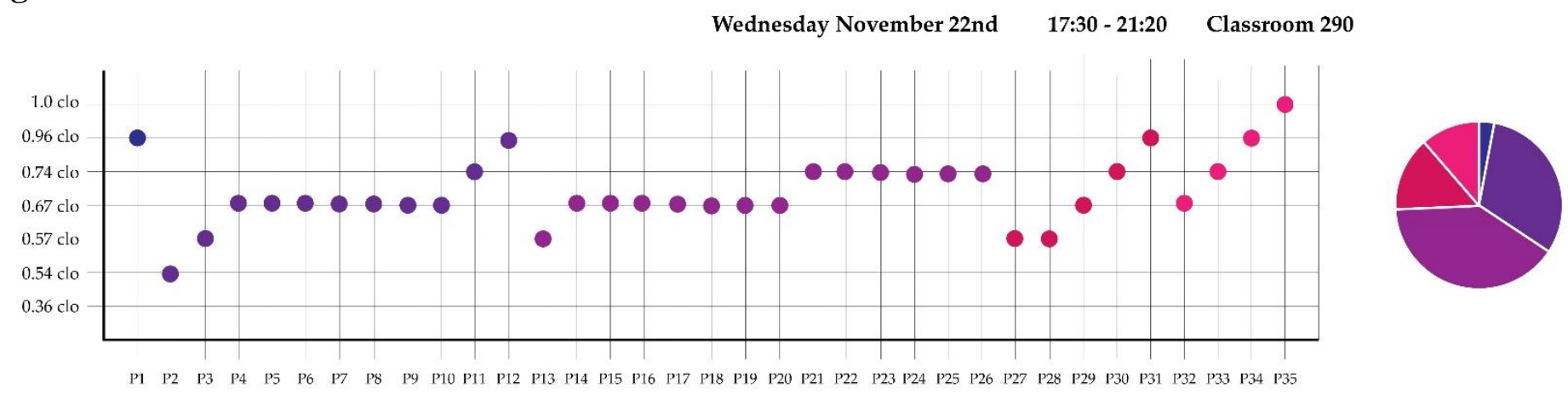

\section{OUTDOOR CLIMATE DATA: WEDNESDAY NOVEMBER 22 ${ }^{\mathrm{ND}}, 2017$}

\begin{tabular}{|c|c|c|c|c|}
\hline $\begin{array}{c}\text { Temp. at Time of } \\
\text { Survey Distribution }\end{array}$ & $\begin{array}{c}\text { Max. Temperature } \\
\text { (Entire Day) }\end{array}$ & $\begin{array}{c}\text { Min. Temperature } \\
\text { (Entire Day) }\end{array}$ & $\begin{array}{c}\text { Max. Humidity } \\
\text { (Entire Day) }\end{array}$ & $\begin{array}{c}\text { Min. Humidity } \\
\text { (Entire Day) }\end{array}$ \\
\hline $\mathbf{5 5}^{\circ} \mathbf{F}$ & $\mathbf{5 6}^{\circ} \mathbf{F}$ & $\mathbf{4 9}^{\circ} \mathbf{F}$ & $\mathbf{1 0 0 \%}$ & $\mathbf{8 6 \%}$ \\
\hline
\end{tabular}

\begin{tabular}{|cccc|}
\hline & KEY & \\
\hline & cold $\quad$ cool $\quad$ slightly cool & @ neutral $\quad$ slightly warm $\quad$ warm $\quad$ hot \\
\hline
\end{tabular}

\footnotetext{
${ }^{1}$ Data taken from weatherunderground.com, where climate data is collected hourly; data range relates to 4:53pm to 5:53pm.
} 


\section{APPENDIX B.}

See below for performance data correlating to perception data sets from 10/30-11/15 (interior temperature and $\mathrm{CO}_{2}$ data collected from specified classrooms)

\section{CHART 1.}

\begin{tabular}{|c|c|c|c|c|}
\hline ROOM \# & DATE & TIME & TEMPERATURE $\left(\mathrm{F}^{\circ}\right)$ & $\mathrm{CO}_{2}(\mathrm{PPM})$ \\
\hline 385 & $10 / 30 / 2017$ & $17: 15: 00$ & 74.8 & 456 \\
\hline 385 & $10 / 30 / 2017$ & $17: 30: 00$ & 75.2 & 638 \\
\hline 385 & $10 / 30 / 2017$ & $17: 45: 00$ & 76.4 & 845 \\
\hline 385 & $10 / 30 / 2017$ & 18:00:00 & 76.4 & 945 \\
\hline 385 & $10 / 30 / 2017$ & $18: 15: 00$ & 76.4 & 982 \\
\hline 385 & $10 / 30 / 2017$ & $18: 30: 00$ & 76.8 & 959 \\
\hline 385 & $10 / 30 / 2017$ & $18: 45: 00$ & 76.8 & 983 \\
\hline 385 & $10 / 30 / 2017$ & 19:00:00 & 76.7 & 883 \\
\hline 385 & $10 / 30 / 2017$ & $19: 15: 00$ & 76.7 & 936 \\
\hline 385 & $10 / 30 / 2017$ & $19: 30: 00$ & 76.7 & 1014 \\
\hline 385 & $10 / 30 / 2017$ & $19: 45: 00$ & 76.7 & 896 \\
\hline 385 & $10 / 30 / 2017$ & 20:00:00 & 76.4 & 795 \\
\hline 385 & $10 / 30 / 2017$ & $20: 15: 00$ & 76.6 & 973 \\
\hline 385 & $10 / 30 / 2017$ & $20: 30: 00$ & 76.9 & 988 \\
\hline 385 & $10 / 30 / 2017$ & $20: 45: 00$ & 76.9 & 1008 \\
\hline 385 & $10 / 30 / 2017$ & 21:00:00 & 76.9 & 1008 \\
\hline 385 & $10 / 30 / 2017$ & $21: 15: 00$ & 76.6 & 903 \\
\hline 385 & $10 / 30 / 2017$ & $21: 30: 00$ & 76.1 & 703 \\
\hline
\end{tabular}

*Note: Comfort data correlates to first to rows of data; 15 minutes before class as surveys were distributed up until the start of class. 
CHART 2.

\begin{tabular}{|c|c|c|c|c|}
\hline ROOM \# & DATE & TIME & TEMPERATURE $\left(\mathrm{F}^{\circ}\right)$ & $\mathrm{CO}_{2}(\mathrm{PPM})$ \\
\hline 180 & $10 / 30 / 2017$ & $17: 30: 00$ & 72.2 & 476 \\
\hline 180 & $10 / 30 / 2017$ & $17: 45: 00$ & 71.9 & 691 \\
\hline 180 & $10 / 30 / 2017$ & $18: 00: 00$ & 72.1 & 892992 \\
\hline 180 & $10 / 30 / 2017$ & $18: 15: 00$ & 72.6 & 1019 \\
\hline 180 & $10 / 30 / 2017$ & $18: 30: 00$ & 72.9 & 1003 \\
\hline 180 & $10 / 30 / 2017$ & $18: 45: 00$ & 73.1 & 991 \\
\hline 180 & $10 / 30 / 2017$ & 19:00:00 & 73.4 & 875 \\
\hline 180 & $10 / 30 / 2017$ & $19: 15: 00$ & 73.8 & 771 \\
\hline 180 & $10 / 30 / 2017$ & 19:30:00 & 74 & 671 \\
\hline 180 & $10 / 30 / 2017$ & $19: 45: 00$ & 74 & 661 \\
\hline 180 & $10 / 30 / 2017$ & 20:00:00 & 73.7 & 661 \\
\hline 180 & $10 / 30 / 2017$ & $20: 15: 00$ & 73.1 & 661 \\
\hline 180 & $10 / 30 / 2017$ & $20: 30: 00$ & 73 & 661 \\
\hline 180 & $10 / 30 / 2017$ & $20: 45: 00$ & 72.7 & 661 \\
\hline 180 & $10 / 30 / 2017$ & 21:00:00 & 72.5 & 661 \\
\hline 180 & $10 / 30 / 2017$ & $21: 15: 00$ & 72.5 & 661 \\
\hline 180 & $10 / 30 / 2017$ & 21:30:00 & 72 & 566 \\
\hline
\end{tabular}

*Note: Comfort data correlates to first to rows of data; 15 minutes before class as surveys were distributed up until the start of class. 
CHART 3.

\begin{tabular}{|c|c|c|c|c|}
\hline ROOM \# & DATE & TIME & TEMPERATURE $\left(\mathrm{F}^{\circ}\right)$ & $\mathrm{CO}_{2}(\mathrm{PPM})$ \\
\hline 480 & $11 / 1 / 2017$ & $17: 15: 00$ & 70.6 & 486 \\
\hline 480 & $11 / 1 / 2017$ & 17:30:00 & 71.6 & 539 \\
\hline 480 & $11 / 1 / 2017$ & $17: 45: 00$ & 72.5 & 847 \\
\hline 480 & $11 / 1 / 2017$ & 18:00:00 & 72.5 & 1049 \\
\hline 480 & $11 / 1 / 2017$ & $18: 15: 00$ & 72.5 & 1150 \\
\hline 480 & $11 / 1 / 2017$ & $18: 30: 00$ & 72.9 & 1204 \\
\hline 480 & $11 / 1 / 2017$ & $18: 45: 00$ & 73.1 & 1297 \\
\hline 480 & $11 / 1 / 2017$ & 19:00:00 & 73.1 & 1329 \\
\hline 480 & $11 / 1 / 2017$ & $19: 15: 00$ & 72.4 & 1029 \\
\hline 480 & $11 / 1 / 2017$ & 19:30:00 & 71.5 & 828 \\
\hline 480 & $11 / 1 / 2017$ & $19: 45: 00$ & 71.3 & 628 \\
\hline 480 & $11 / 1 / 2017$ & 20:00:00 & 70.7 & 539 \\
\hline 480 & $11 / 1 / 2017$ & $20: 15: 00$ & 70.1 & 486 \\
\hline 480 & $11 / 1 / 2017$ & $20: 30: 00$ & 70.3 & 456 \\
\hline 480 & $11 / 1 / 2017$ & $20: 45: 00$ & 71.3 & 771 \\
\hline 480 & $11 / 1 / 2017$ & 21:00:00 & 71.6 & 732 \\
\hline 480 & $11 / 1 / 2017$ & $21: 15: 00$ & 71.9 & 632 \\
\hline 480 & $11 / 1 / 2017$ & $21: 30: 00$ & 71.6 & 546 \\
\hline
\end{tabular}

*Note: Comfort data correlates to first to rows of data; 15 minutes before class as surveys were distributed up until the start of class. 
CHART 4.

\begin{tabular}{|c|c|c|c|c|}
\hline ROOM \# & DATE & TIME & TEMPERATURE $\left(\mathrm{F}^{\circ}\right)$ & $\mathrm{CO}_{2}(\mathrm{PPM})$ \\
\hline 290 & $11 / 1 / 2017$ & $17: 15: 00$ & 72.9 & 422 \\
\hline 290 & $11 / 1 / 2017$ & 17:30:00 & 72.9 & 455 \\
\hline 290 & $11 / 1 / 2017$ & $17: 45: 00$ & 73.6 & 755 \\
\hline 290 & $11 / 1 / 2017$ & 18:00:00 & 73.9 & 832 \\
\hline 290 & $11 / 1 / 2017$ & $18: 15: 00$ & 74.3 & 832 \\
\hline 290 & $11 / 1 / 2017$ & 18:30:00 & 74.3 & 856 \\
\hline 290 & $11 / 1 / 2017$ & $18: 45: 00$ & 74.6 & 873 \\
\hline 290 & $11 / 1 / 2017$ & 19:00:00 & 74.6 & 873 \\
\hline 290 & $11 / 1 / 2017$ & $19: 15: 00$ & 74.8 & 861 \\
\hline 290 & $11 / 1 / 2017$ & $19: 30: 00$ & 74.8 & 839 \\
\hline 290 & $11 / 1 / 2017$ & $19: 45: 00$ & 74.5 & 736 \\
\hline 290 & $11 / 1 / 2017$ & 20:00:00 & 74.5 & 665 \\
\hline 290 & $11 / 1 / 2017$ & $20: 15: 00$ & 74.5 & 765 \\
\hline 290 & $11 / 1 / 2017$ & $20: 30: 00$ & 74.5 & 805 \\
\hline 290 & $11 / 1 / 2017$ & $20: 45: 00$ & 74.5 & 805 \\
\hline 290 & $11 / 1 / 2017$ & 21:00:00 & 74.8 & 844 \\
\hline 290 & $11 / 1 / 2017$ & $21: 15: 00$ & 74.8 & 844 \\
\hline 290 & $11 / 1 / 2017$ & $21: 30: 00$ & 75 & 780 \\
\hline
\end{tabular}

*Note: Instance where comfort data correlates to the full class period; professor distributed survey approx. midway through class. 
CHART 5.

\begin{tabular}{|c|c|c|c|c|}
\hline ROOM \# & DATE & TIME & TEMPERATURE $\left(\mathrm{F}^{\circ}\right)$ & $\mathrm{CO}_{2}(\mathrm{PPM})$ \\
\hline 295 & $11 / 1 / 2017$ & $17: 30: 00$ & 74.3 & 723 \\
\hline 295 & $11 / 1 / 2017$ & $17: 45: 00$ & 73.7 & 522 \\
\hline 295 & $11 / 1 / 2017$ & 18:00:00 & 73.4 & 466 \\
\hline 295 & $11 / 1 / 2017$ & $18: 15: 00$ & 73.2 & 450 \\
\hline 295 & $11 / 1 / 2017$ & $18: 30: 00$ & 73.2 & 450 \\
\hline 295 & $11 / 1 / 2017$ & $18: 45: 00$ & 73.2 & 450 \\
\hline 295 & $11 / 1 / 2017$ & 19:00:00 & 73.2 & 450 \\
\hline 295 & $11 / 1 / 2017$ & $19: 15: 00$ & 73.2 & 450 \\
\hline 295 & $11 / 1 / 2017$ & 19:30:00 & 73.2 & 450 \\
\hline 295 & $11 / 1 / 2017$ & $19: 45: 00$ & 73.2 & 450 \\
\hline 295 & $11 / 1 / 2017$ & 20:00:00 & 73.2 & 450 \\
\hline 295 & $11 / 1 / 2017$ & $20: 15: 00$ & 73.2 & 450 \\
\hline 295 & $11 / 1 / 2017$ & 20:30:00 & 73.2 & 440 \\
\hline 295 & $11 / 1 / 2017$ & $20: 45: 00$ & 73.2 & 440 \\
\hline 295 & $11 / 1 / 2017$ & 21:00:00 & 73.2 & 440 \\
\hline 295 & $11 / 1 / 2017$ & $21: 15: 00$ & 72.9 & 440 \\
\hline 295 & $11 / 1 / 2017$ & $21: 30: 00$ & 72.9 & 440 \\
\hline
\end{tabular}

Note: Comfort data correlates to first to rows of data; 15 minutes before class as surveys were distributed up until the start of class. 
CHART 6.

\begin{tabular}{|c|c|c|c|c|}
\hline ROOM \# & DATE & TIME & TEMPERATURE $\left(\mathrm{F}^{\circ}\right)$ & $\mathrm{CO}_{2}(\mathrm{PPM})$ \\
\hline 385 & $11 / 13 / 2017$ & $17: 15: 00$ & 71.5 & 458 \\
\hline 385 & $11 / 13 / 2017$ & 17:30:00 & 71.5 & 558 \\
\hline 385 & $11 / 13 / 2017$ & $17: 45: 00$ & 72.2 & 832 \\
\hline 385 & $11 / 13 / 2017$ & 18:00:00 & 72.5 & 932 \\
\hline 385 & $11 / 13 / 2017$ & $18: 15: 00$ & 73 & 988 \\
\hline 385 & $11 / 13 / 2017$ & $18: 30: 00$ & 73 & 1034 \\
\hline 385 & $11 / 13 / 2017$ & $18: 45: 00$ & 73.3 & 1034 \\
\hline 385 & $11 / 13 / 2017$ & 19:00:00 & 73.7 & 1101 \\
\hline 385 & $11 / 13 / 2017$ & $19: 15: 00$ & 73.7 & 1018 \\
\hline 385 & $11 / 13 / 2017$ & 19:30:00 & 73.6 & 986 \\
\hline 385 & $11 / 13 / 2017$ & $19: 45: 00$ & 73.2 & 886 \\
\hline 385 & $11 / 13 / 2017$ & 20:00:00 & 73.2 & 864 \\
\hline 385 & $11 / 13 / 2017$ & $20: 15: 00$ & 73.2 & 925 \\
\hline 385 & $11 / 13 / 2017$ & $20: 30: 00$ & 73.2 & 939 \\
\hline 385 & $11 / 13 / 2017$ & $20: 45: 00$ & 73.5 & 928 \\
\hline 385 & $11 / 13 / 2017$ & 21:00:00 & 73.5 & 964 \\
\hline 385 & $11 / 13 / 2017$ & $21: 15: 00$ & 73.5 & 989 \\
\hline 385 & $11 / 13 / 2017$ & $21: 30: 00$ & 73.8 & 954 \\
\hline
\end{tabular}

*Note: Comfort data correlates to first to rows of data; 15 minutes before class as surveys were distributed up until the start of class. 
CHART 7.

\begin{tabular}{|c|c|c|c|c|}
\hline ROOM \# & DATE & TIME & TEMPERATURE $\left(\mathrm{F}^{\circ}\right)$ & $\mathrm{CO}_{2}(\mathrm{PPM})$ \\
\hline 180 & $11 / 13 / 2017$ & $17: 30: 00$ & 70.3 & 500 \\
\hline 180 & $11 / 13 / 2017$ & $17: 45: 00$ & 70.6 & 513 \\
\hline 180 & $11 / 13 / 2017$ & $18: 00: 00$ & 71 & 557 \\
\hline 180 & $11 / 13 / 2017$ & $18: 15: 00$ & 71.2 & 634 \\
\hline 180 & $11 / 13 / 2017$ & $18: 30: 00$ & 71.5 & 688 \\
\hline 180 & $11 / 13 / 2017$ & $18: 45: 00$ & 71.7 & 688 \\
\hline 180 & $11 / 13 / 2017$ & 19:00:00 & 71.9 & 700 \\
\hline 180 & $11 / 13 / 2017$ & $19: 15: 00$ & 71.9 & 700 \\
\hline 180 & $11 / 13 / 2017$ & 19:30:00 & 71.9 & 712 \\
\hline 180 & $11 / 13 / 2017$ & $19: 45: 00$ & 71.9 & 712 \\
\hline 180 & $11 / 13 / 2017$ & 20:00:00 & 71.9 & 684 \\
\hline 180 & $11 / 13 / 2017$ & $20: 15: 00$ & 71.5 & 669 \\
\hline 180 & $11 / 13 / 2017$ & $20: 30: 00$ & 71.2 & 642 \\
\hline 180 & $11 / 13 / 2017$ & $20: 45: 00$ & 1.2 & 607 \\
\hline 180 & $11 / 13 / 2017$ & 21:00:00 & 71 & 575 \\
\hline 180 & $11 / 13 / 2017$ & $21: 15: 00$ & 71 & 552 \\
\hline 180 & $11 / 13 / 2017$ & 21:30:00 & 70.7 & 513 \\
\hline
\end{tabular}

*Note: Comfort data correlates to first to rows of data; 15 minutes before class as surveys were distributed up until the start of class. 
CHART 8.

\begin{tabular}{|c|c|c|c|c|}
\hline ROOM \# & DATE & TIME & TEMPERATURE $\left(\mathrm{F}^{\circ}\right)$ & $\mathrm{CO}_{2}(\mathrm{PPM})$ \\
\hline 480 & $11 / 15 / 2017$ & $17: 15: 00$ & 70.7 & 439 \\
\hline 480 & $11 / 15 / 2017$ & $17: 30: 00$ & 70.7 & 460 \\
\hline 480 & $11 / 15 / 2017$ & $17: 45: 00$ & 70.7 & 486 \\
\hline 480 & $11 / 15 / 2017$ & 18:00:00 & 70.9 & 667 \\
\hline 480 & $11 / 15 / 2017$ & $18: 15: 00$ & 71.2 & 767 \\
\hline 480 & $11 / 15 / 2017$ & $18: 30: 00$ & 71.2 & 809 \\
\hline 480 & $11 / 15 / 2017$ & $18: 45: 00$ & 71.2 & 809 \\
\hline 480 & $11 / 15 / 2017$ & $19: 00: 00$ & 71.4 & 809 \\
\hline 480 & $11 / 15 / 2017$ & $19: 15: 00$ & 71.6 & 809 \\
\hline 480 & $11 / 15 / 2017$ & $19: 30: 00$ & 71.1 & 809 \\
\hline 480 & $11 / 15 / 2017$ & $19: 45: 00$ & 70.9 & 796 \\
\hline 480 & $11 / 15 / 2017$ & $20: 00: 00$ & 70.9 & 763 \\
\hline 480 & $11 / 15 / 2017$ & $20: 15: 00$ & 70.9 & 763 \\
\hline 480 & $11 / 15 / 2017$ & $20: 30: 00$ & 70.9 & 763 \\
\hline 480 & $11 / 15 / 2017$ & $20: 45: 00$ & 70.9 & 779 \\
\hline 480 & $11 / 15 / 2017$ & 21:00:00 & 70.9 & 879 \\
\hline 480 & $11 / 15 / 2017$ & $21: 15: 00$ & 70.9 & 939 \\
\hline 480 & $11 / 15 / 2017$ & $21: 30: 00$ & 70.9 & 936 \\
\hline
\end{tabular}

*Note: Comfort data correlates to first to rows of data; 15 minutes before class as surveys were distributed up until the start of class. 
CHART 9.

\begin{tabular}{|c|c|c|c|c|}
\hline ROOM \# & DATE & TIME & TEMPERATURE $\left(\mathrm{F}^{\circ}\right)$ & $\mathrm{CO}_{2}(\mathrm{PPM})$ \\
\hline 290 & $11 / 15 / 2017$ & $17: 15: 00$ & 71.7 & 1247 \\
\hline 290 & $11 / 15 / 2017$ & $17: 30: 00$ & 71.5 & 939 \\
\hline 290 & $11 / 15 / 2017$ & $17: 45: 00$ & 72.1 & 1245 \\
\hline 290 & $11 / 15 / 2017$ & 18:00:00 & 72.4 & 1042 \\
\hline 290 & $11 / 15 / 2017$ & $18: 15: 00$ & 72.8 & 742 \\
\hline 290 & $11 / 15 / 2017$ & $18: 30: 00$ & 72.8 & 642 \\
\hline 290 & $11 / 15 / 2017$ & $18: 45: 00$ & 73 & 551 \\
\hline 290 & $11 / 15 / 2017$ & 19:00:00 & 73 & 502 \\
\hline 290 & $11 / 15 / 2017$ & $19: 15: 00$ & 73 & 477 \\
\hline 290 & $11 / 15 / 2017$ & $19: 30: 00$ & 73 & 465 \\
\hline 290 & $11 / 15 / 2017$ & $19: 45: 00$ & 73 & 455 \\
\hline 290 & $11 / 15 / 2017$ & 20:00:00 & 73 & 455 \\
\hline 290 & $11 / 15 / 2017$ & $20: 15: 00$ & 72.5 & 756 \\
\hline 290 & $11 / 15 / 2017$ & $20: 30: 00$ & 7.4 & 754 \\
\hline 290 & $11 / 15 / 2017$ & $20: 45: 00$ & 72.7 & 748 \\
\hline 290 & $11 / 15 / 2017$ & 21:00:00 & 72.7 & 750 \\
\hline 290 & $11 / 15 / 2017$ & $21: 15: 00$ & 72.3 & 653 \\
\hline 290 & $11 / 15 / 2017$ & $21: 30: 00$ & 72 & 550 \\
\hline
\end{tabular}

*Note: Instance where comfort data correlates to the full class period; professor distributed survey approx. midway through class. 
CHART 10.

\begin{tabular}{|c|c|c|c|c|}
\hline ROOM \# & DATE & TIME & TEMPERATURE $\left(\mathrm{F}^{\circ}\right)$ & $\mathrm{CO}_{2}(\mathrm{PPM})$ \\
\hline 295 & $11 / 15 / 2017$ & $17: 30: 00$ & 72.7 & 847 \\
\hline 295 & $11 / 15 / 2017$ & $17: 45: 00$ & 73.1 & 745 \\
\hline 295 & $11 / 15 / 2017$ & $18: 00: 00$ & 72.3 & 771 \\
\hline 295 & $11 / 15 / 2017$ & $18: 15: 00$ & 72.3 & 815 \\
\hline 295 & $11 / 15 / 2017$ & $18: 30: 00$ & 72.5 & 815 \\
\hline 295 & $11 / 15 / 2017$ & $18: 45: 00$ & 72.5 & 828 \\
\hline 295 & $11 / 15 / 2017$ & 19:00:00 & 72.5 & 847 \\
\hline 295 & $11 / 15 / 2017$ & $19: 15: 00$ & 72.8 & 798 \\
\hline 295 & $11 / 15 / 2017$ & $19: 30: 00$ & 72.8 & 831 \\
\hline 295 & $11 / 15 / 2017$ & $19: 45: 00$ & 72.8 & 819 \\
\hline 295 & $11 / 15 / 2017$ & 20:00:00 & 72.6 & 819 \\
\hline 295 & $11 / 15 / 2017$ & $20: 15: 00$ & 72.2 & 742 \\
\hline 295 & $11 / 15 / 2017$ & $20: 30: 00$ & 72 & 723 \\
\hline 295 & $11 / 15 / 2017$ & $20: 45: 00$ & 71.6 & 691 \\
\hline 295 & $11 / 15 / 2017$ & 21:00:00 & 72 & 668 \\
\hline 295 & $11 / 15 / 2017$ & $21: 15: 00$ & 71.3 & 611 \\
\hline 295 & $11 / 15 / 2017$ & $21: 30: 00$ & 71 & 548 \\
\hline
\end{tabular}

Note: Comfort data correlates to first to rows of data; 15 minutes before class as surveys were distributed up until the start of class. 


\section{APPENDIX C.}

See below for example survey, relating to room 180. Figure 1 shows front of survey, and figure 2 shows the back of survey where consent information is stated. Question 4 is the only difference between surveys, where the plan shown relates to the specific classroom

\section{Figure 1.}

\section{KMC room \#180}

\section{$\underline{\text { Karl Miller Center Comfort Survey - Fall } 2017}$}

Check this box if you choose to be a participant in this survey. By checking the box, you give consent for your anonymous answers to be used in this study of the effectiveness the Karl Miller Center's sustainable design is in creating comfortable spaces to occupy. Please see consent information on back.

1. Please circle inside the square that corresponds to your current clothing level

\begin{tabular}{|c|c|c|c|c|c|c|}
\hline $\begin{array}{c}\text { short sleeve shirt } \\
+ \\
\text { shorts }\end{array}$ & $\begin{array}{c}\text { shart sleeve shirt } \\
+ \\
\text { capris }\end{array}$ & $\begin{array}{c}\text { shart sleeve shirt } \\
\text { pants }\end{array}$ & $\begin{array}{c}\text { lang sleeve shirt } \\
+ \\
\text { pants }\end{array}$ & $\begin{array}{c}\text { lang sleeve shirt } \\
+ \\
\text { sweater } \\
+ \\
\text { pants }\end{array}$ & $\begin{array}{c}\text { jacket } \\
+ \\
\text { sweater } \\
+ \\
\text { long sleeve shirt } \\
+ \\
\text { pants }\end{array}$ & $\begin{array}{c}\text { down feather } \\
\text { jacket } \\
+ \\
\text { sweater } \\
+ \\
\text { lang sleeve shirt } \\
+ \\
\text { Pants } \\
+ \\
\text { scarf and/or hat }\end{array}$ \\
\hline
\end{tabular}

2. Please circle inside the square that corresponds to your current comfort level

\begin{tabular}{|l|l|l|l|l|l|l|l|l|}
\hline Cold & Cool & Slightly cool & Neutral & Slightly warm & Warm & Hot \\
\hline
\end{tabular}

3. Please circle inside the square(s) that corresponds to the time you are currently occupying the building

\begin{tabular}{|l|l|l|l|l|l|l|l|}
\hline $8 \mathrm{am}-10 \mathrm{~m}$ & $10 \mathrm{~mm}-12 \mathrm{pm}$ & $12 \mathrm{pm}-2 \mathrm{pm}$ & $2 \mathrm{pm}-4 \mathrm{pm}$ & $4 \mathrm{pm}-6 \mathrm{pm}$ & $6 \mathrm{pm}-8 \mathrm{pm}$ & $8 \mathrm{pm}-10 \mathrm{pm}$ \\
\hline
\end{tabular}

4. Please make an $\mathbf{X}$ on the plan below to identify where you are currently located within classroom

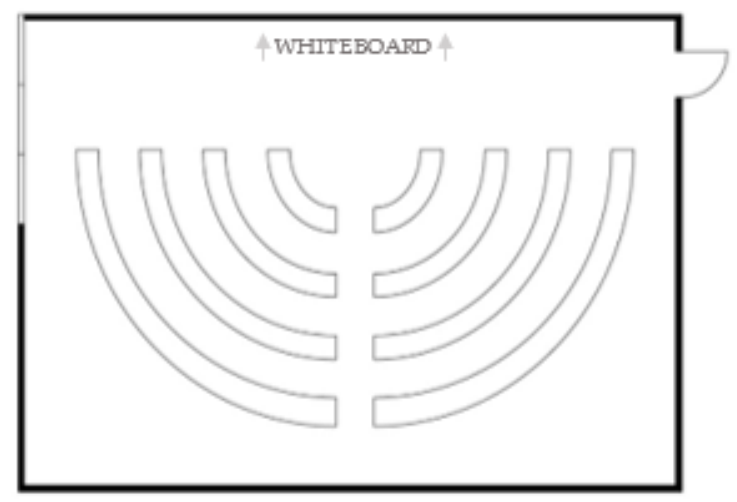

5. Comments: 


\section{Figure 2.}

Participant,

If you are willing to participate, you will be asked to over the duration of the fall term, September $25^{\text {th }}$ through to November 26 th ( 9 weeks), to complete a weekly five-question survey given to you as you enter your class. You will be asked to either retum the survey to me or your professor as instructed. The survey should take approximately 2 minutes. I want to make it clear that all survey answers are anonymous. Participation in this survey is completely voluntary. It is in your right to deny participation, and refusal of participation and/or discontinuation at any time will involve no penalty or loss of benefits.

This study includes research and data conducted on how the design of the Karl Miller Center's new addition effects the level of comfort as a partnership with Portland State University's Honors College and the SRG Partnership architecture firm. Over the course of the term comfort will be looked at in terms of both performance of the design and feeling of comfort by occupants. I am specifically looking at how passive architecture, a design mechanism that uses the climate, orientation, and location of a building to optimize the use of heat naturally given off by the sun and air available to flow a through a space, reduces the need of conventional HVAC systems.

If you have any questions, concerns, or complaints feel free to email me:

Kyhetica Lattin

klattin@pdx.edu

If you wish to contact someone independent of the research team for questions, concerns, or complaints about the research; questions about the subjects' rights; to obtain information' or to offer input, please contact:

The U.S. Department of Health \& Human Services

200 Independence Avenue, S.W.

Washington, D.C. 20201

Toll Free Call Center: 1-877-696-6775 